\title{
Examining Nursing Schools' Strategies for Recruitment and Retention of Nursing Faculty: An Exploratory Study
}

\author{
Naomi Elizabeth Himmelwright Lamm \\ West Virginia University
}

Follow this and additional works at: https://researchrepository.wvu.edu/etd

\footnotetext{
Recommended Citation

Lamm, Naomi Elizabeth Himmelwright, "Examining Nursing Schools' Strategies for Recruitment and Retention of Nursing Faculty: An Exploratory Study" (2011). Graduate Theses, Dissertations, and Problem Reports. 3556.

https://researchrepository.wvu.edu/etd/3556

This Dissertation is protected by copyright and/or related rights. It has been brought to you by the The Research Repository @ WVU with permission from the rights-holder(s). You are free to use this Dissertation in any way that is permitted by the copyright and related rights legislation that applies to your use. For other uses you must obtain permission from the rights-holder(s) directly, unless additional rights are indicated by a Creative Commons license in the record and/ or on the work itself. This Dissertation has been accepted for inclusion in WVU Graduate Theses, Dissertations, and Problem Reports collection by an authorized administrator of The Research Repository @ WVU. For more information, please contact researchrepository@mail.wvu.edu.
} 
Examining Nursing Schools' Strategies for Recruitment and Retention of Nursing Faculty: An Exploratory Study

Naomi Elizabeth Himmelwright Lamm

Dissertation submitted to the College of Human Resources and Education

at West Virginia University

in partial fulfillment of the requirements

for the degree of

Doctor of Education

in

Educational Leadership Studies

Elizabeth A. Jones, Ph.D., Chair

Ernest R. Goeres, Ph.D.

Patricia A. Obenauf, Ph.D.

Susan L. Aloi, Ed.D.

Nayna D. Philipsen, J.D., Ph.D., RN, CFE, FACCE

Department of Educational Leadership Studies

Morgantown, West Virginia

2011

Keywords: recruitment and retention of nursing faculty, nursing faculty shortage, strategies

Copyright 2011 


\begin{abstract}
Examining Nursing Schools' Strategies for Recruitment and Retention of Nursing Faculty: An Exploratory Study
\end{abstract}

\title{
Naomi Elizabeth Himmelwright Lamm
}

The purpose of this qualitative dissertation study was to examine the types of strategies that academic leaders utilized to address nursing faculty recruitment and retention in various universities. Four research questions were formulated, focusing on current strategies used to recruit and retain nursing faculty, the effectiveness of those strategies, external partnerships utilized, and reasons behind lack of recruitment and retention of nursing faculty. A pilot study and two case studies were conducted, in which nursing administrators and nursing faculty completed a demographic questionnaire and were interviewed using a nursing administrator interview protocol and a nursing faculty interview protocol. Participants at both case study institutions explained that low salary and high workload were the most significant factors in the lack of recruitment and retention of nursing faculty. Moreover, these individuals observed that if schools of nursing wish to increase recruitment and retention efforts, these factors should be modified. These findings were consistent with the literature. Recommendations for future practice and research were made. Further research should be conducted on the interrelationship of salary and workload with recruitment and retention of nursing faculty. 


\section{Acknowledgements}

I would like to thank Dr. Elizabeth Jones, chair of my dissertation and program director, for working with me, giving me encouragement, and guiding me through the program and the dissertation process. She has made so many efforts to help me understand the dissertation process and I greatly appreciate and thank her for her effort. Other faculty on the dissertation committee have been instrumental in guiding me and being supportive. Those faculty are Dr. Ernest Goeres, Dr. Pat Obenauf, Dr. Susan Aloi, and Dr. Nayna Philipsen. At any time I have needed assistance, guidance, or insight, each of these faculty have been there to support me. Thank you for the many hours you have spent reading my dissertation and giving me ideas that really made a difference in the process.

I would also like to recognize Dr. Rebecca F. Wiseman, my mentor at University of Maryland School of Nursing. Dr. Wiseman encouraged me to begin the doctoral program and has been instrumental in my success. Her kindness and friendship have made this process a little easier.

Additionally, I would like to thank Dr. Pat McMullen, Becky Minke, Ellen West, Dr. Susan Tasker, Tenna Taylor, Joyce Hedrick, Linda Stair, Elizabeth Ann Brooks, Sister Dolores Hudson, Sister Phyllis McNally, Martha Bird Middleton, and Laura Holland for their tireless support and friendship.

Finally, I would like to thank the administrators and faculty at the case study schools examined in this dissertation. Their willingness to participate and the openness of their comments will help future nursing faculty. 


\section{Dedication}

I would like to dedicate this dissertation to my daughter, Elizabeth Ellen Lamm, Esq., and my parents, Dr. George Overton Himmelwright and Mrs. Naomi Lashley Himmelwright. Beth has been so supportive, has helped me, and has given me guidance, but most of all has believed in me. My parents encouraged me since I was a small child to get an education and go on with the next degree. My father told me when I was about 10 years old that he wanted me to get a doctorate to be able to be a faculty member or hospital administrator. My father passed away in 2005, but he has been with me throughout my life and career. My mother has been supportive, encouraging, and very consistent. Nothing made my parents happier than one of their children or grandchildren receiving a new degree. My mother believed in consistency and perseverance and has remained constant throughout this dissertation.

Without Beth and my parents, I would not have made it through the eight-year process of my doctorate education. 


\section{Table of Contents}

Chapter One: Introduction and Problem Statement ………..................................................... 1

Factors Contributing to Recruitment and Retention Difficulties ........................................ 2

Implications of the Nursing Faculty Shortage …………................................................... 6

Strategies to Address the Nursing Faculty Shortage …………………………............ 7

Purpose of the Study and Research Questions ……………........................................ 8

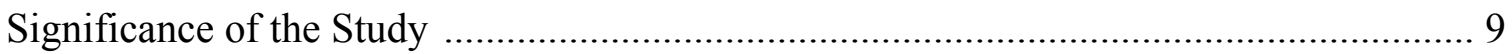

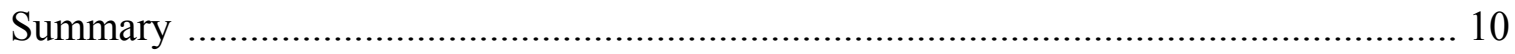

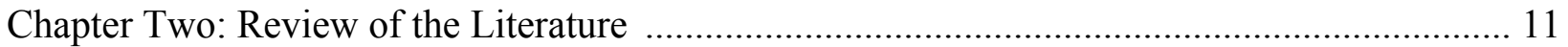

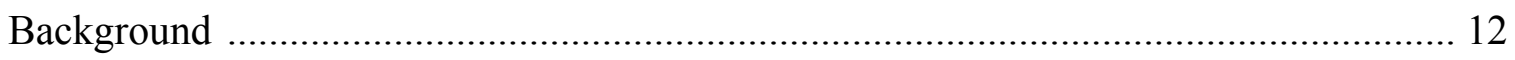

Faculty Shortages: Scope and Significance of the Issues ............................................ 12

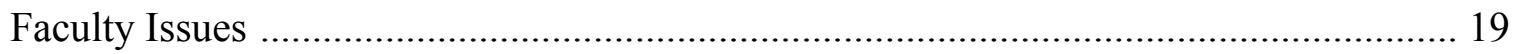

Student Issues for Faculty ................................................................................ 25

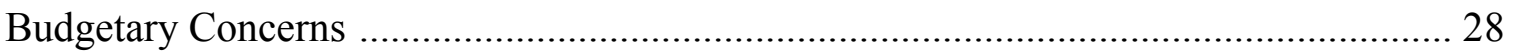

Impact of the Nursing Faculty Shortage ………………………................................... 30

Strategies to Increase the Number of Qualified Nursing Faculty .................................... 35

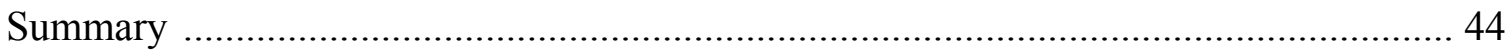

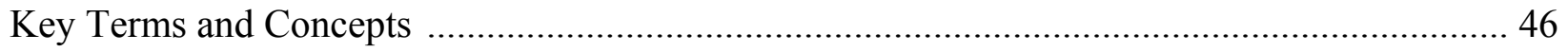

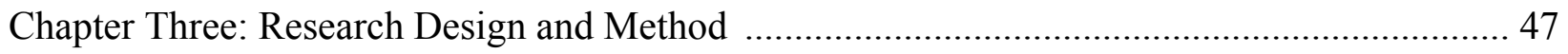

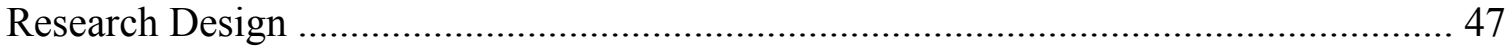

Qualitative Research Design ................................................................................... 47

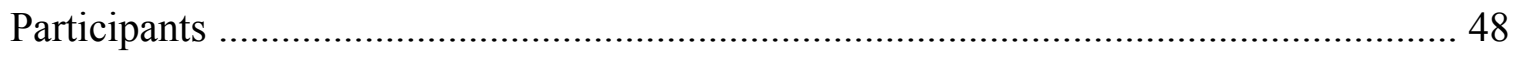

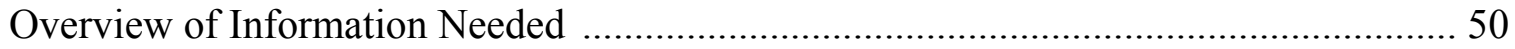




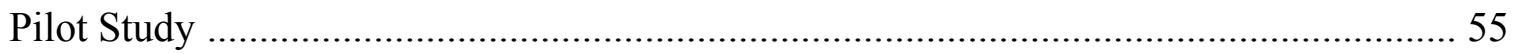

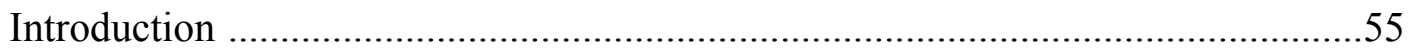

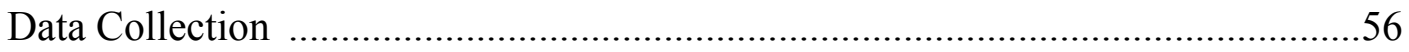

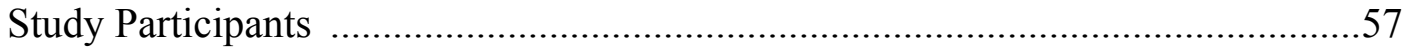

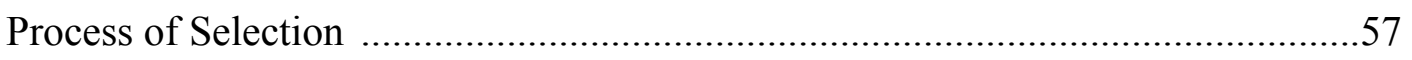

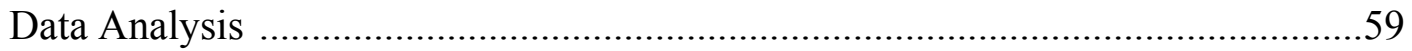

Results and Implications ………………....................................................5

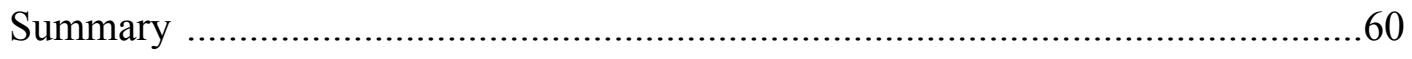

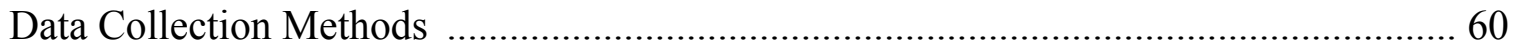

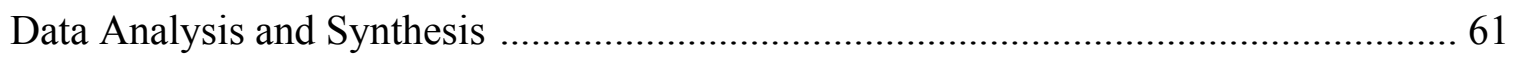

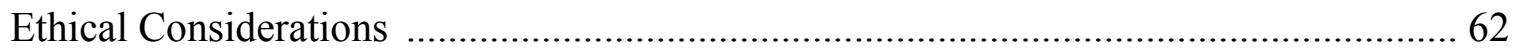

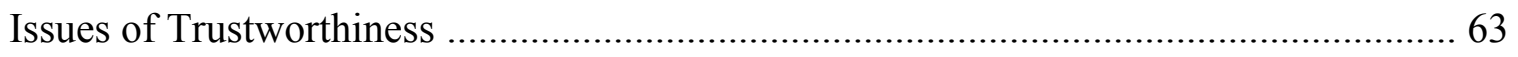

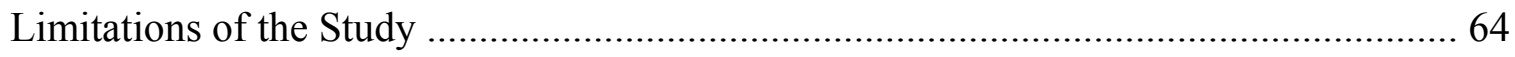

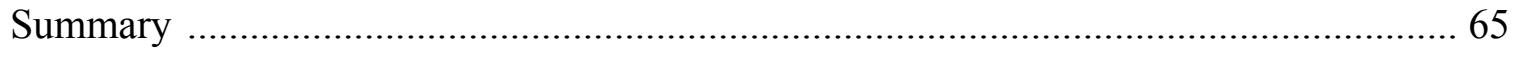

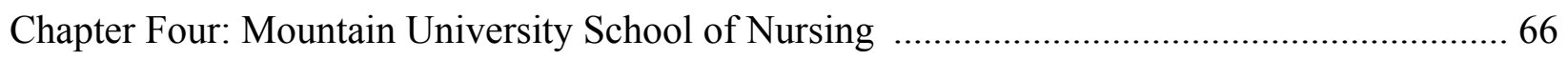

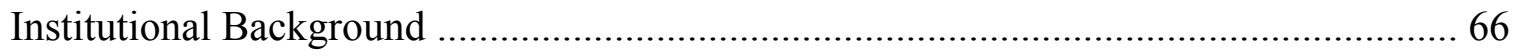

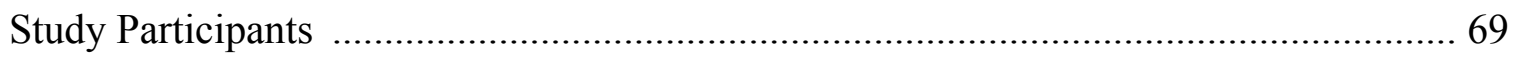

Responses to Interview Protocol ……………………............................................... 79

Setting the Context: Reasons to Teach Nursing -

Administrator and Faculty Responses ................................................................... 79

Research Question 1: Enrollment Management -

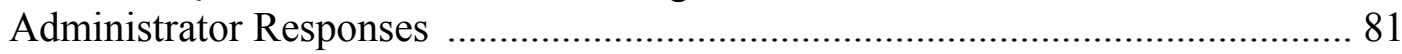

Research Question 1: Recruitment and Retention of

Nursing Faculty - Administrator Responses ......................................................... 84 
Research Question 2: Effective Strategies to Recruit and Retain

Nursing Faculty

Designing Courses: Faculty Perceptions ................................................... 86

Tenure Requirements: Administrator and

Faculty Perceptions

Research Question 3: Collaboration with External Stakeholders

Administrator Perceptions

Distance Education and Simulation Lab:

Administrator and Faculty Perceptions

Research Question 4: Lack of Recruitment and Retention .................................. 90

Working Conditions: Faculty Response …………………......................... 90

Lack of Recruitment and Retention of Nursing Faculty:

Administrator and Faculty Responses ....................................................... 91

Strategies to Increase Nursing Faculty in the Profession:

Administrator and Faculty Perceptions ......................................................... 93

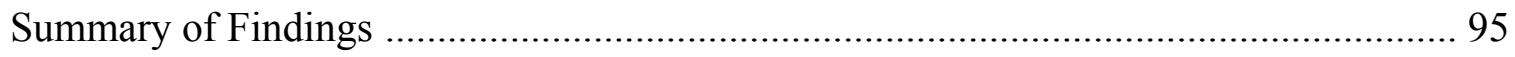

Chapter Five: Central University School of Nursing ................................................................. 97

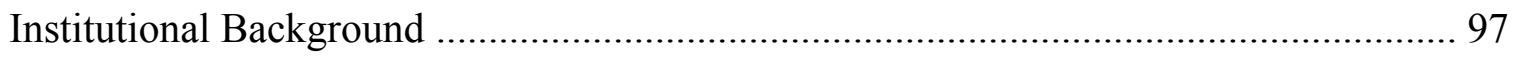

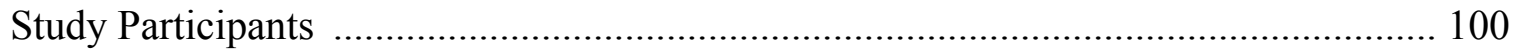

Responses to Interview Protocol ………………………...................................... 112

Setting the Context: Reasons to Teach Nursing -

Administrator and Faculty Responses

Research Question 1: Enrollment Management -

Administrator Responses

Research Question 1: Recruitment and Retention of

Nursing Faculty - Administrator Responses

Research Question 2: Effective Strategies to Recruit and Retain

Nursing Faculty 
Designing Courses: Faculty Perceptions

Tenure Requirements: Administrator and

Faculty Perceptions

Research Question 3: Collaboration with External Stakeholders

Administrator Perceptions

Distance Education and Simulation Lab:

Administrator and Faculty Perceptions

Research Question 4: Lack of Recruitment and Retention ................................. 123

Working Conditions: Faculty Response …………………………......... 123

Lack of Recruitment and Retention of Nursing Faculty:

Administrator and Faculty Responses

Strategies to Increase Nursing Faculty in the Profession:

Administrator and Faculty Perceptions

Summary of Findings

Chapter Six: Cross Site Analysis of Two Schools of Nursing .......

Introduction

Study Participants

Responses to Interview Protocol

Setting the Context: Reasons to Teach Nursing -

Combined Administrator and Faculty Responses

Research Question 1: Enrollment Management -

Combined Administrator Responses

Research Question 1: Recruitment and Retention of

Nursing Faculty - Combined Administrator Responses

Research Question 2: Effective Strategies to Recruit and Retain

Nursing Faculty

Designing Courses: Combined Faculty Perceptions 143 
Research Question 3: Collaboration with External Stakeholders

Combined Administrator Perceptions

Research Question 4: Lack of Recruitment and Retention .................................. 144

Working Conditions: Combined Faculty Response ................................... 144

Lack of Recruitment and Retention of Nursing Faculty:

Combined Administrator and Faculty Responses

Strategies to Increase Nursing Faculty in the Profession:

Combined Administrator and Faculty Perceptions

Summary

Chapter Seven: Summary, Conclusion, and Recommendations for Future

Research and Practice

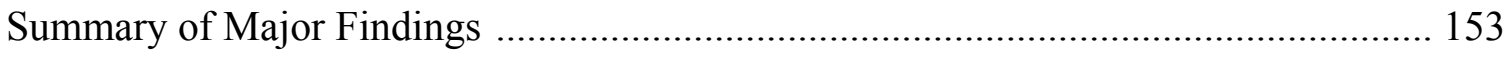

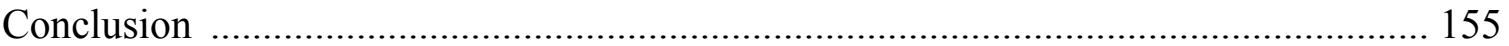

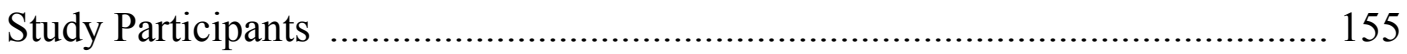

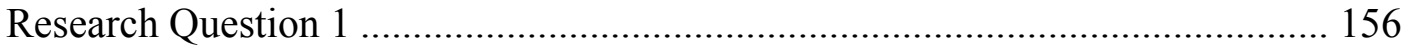

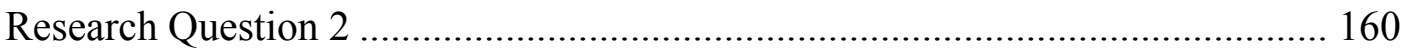

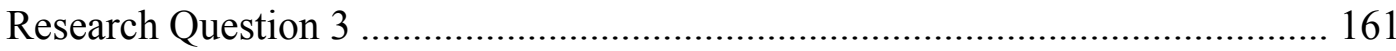

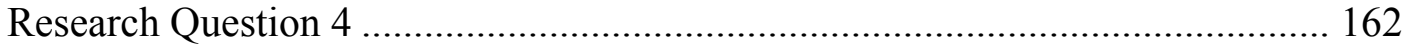

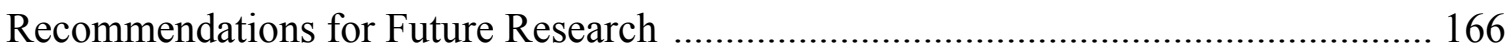

Recommendations for Future Practice …………….............................................. 167

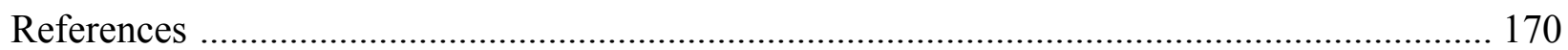

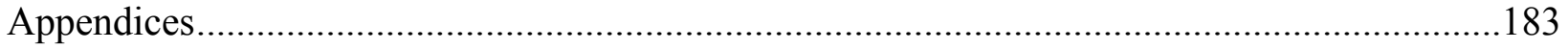




\section{List of Tables}

Table 1 Boyer Model of Scholarship ................................................................................ 24

Table 2 Alignment of Research Questions (RQ) with Interview Protocol Items ...................... 54

Table 3 Characteristics of MU SON Interview Respondents ............................................... 71

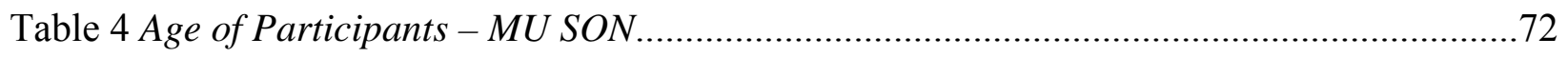

Table 5 Current Salary of Participants - MU SON …...................................................... 72

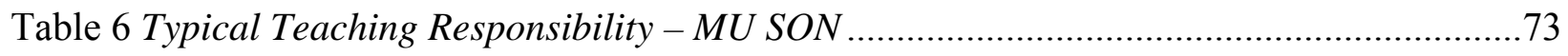

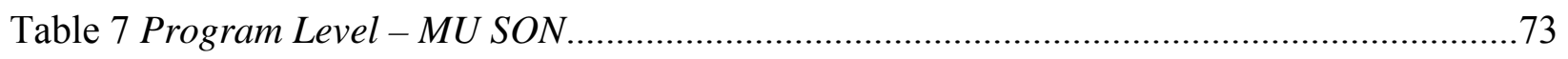

Table 8 Hours Per Week Spent in Instruction, Office Hours,

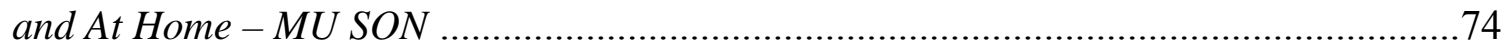

Table 9 Number of Courses, Clinicals, and Credits Per Semester - MU SON .........................75

Table 10 Clinicals, Advisees, and Committees Per Year - MU SON .......................................76

Table 11 Revising or Creating a Course Per Year - MU SON .............................................76

Table 12 Hours Per Week Spent Completing Duties - MU SON ...........................................77

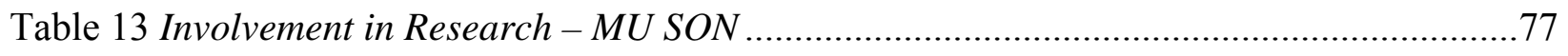

Table 14 Number of Publications in the Past Three Years - MU SON ....................................78

Table 15 Faculty Beliefs of Full Compensation for

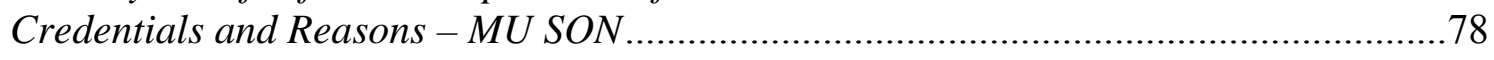

Table 16 Satisfaction in Current Role and Reasons - MU SON ...........................................79

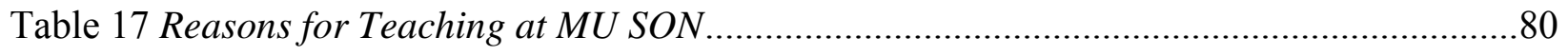

Table 18 Reasons for Remaining as Nursing Faculty - MU SON ...........................................81

Table 19 Limitations to Increasing Student Admissions - MU SON ........................................84

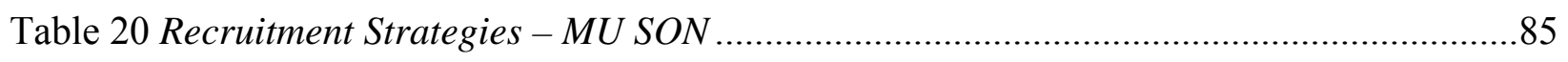

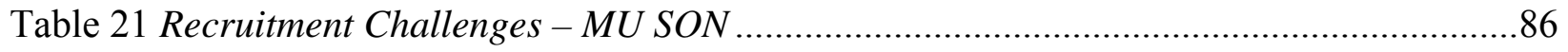

Table 22 Freedom in Designing and Conducting Courses - MU SON ...................................87 
Table 23 External Partnerships - MU SON

Table 24 Working Conditions at MU SON

Table 25 Reasons Impacting Recruitment and Retention - MU SON .....

Table 26 Reasons Nursing Faculty Leave MU SON.....

Table 27 Strategies to Recruit Nursing Faculty in the Profession - MU SON.

Table 28 Strategies to Retain Nursing Faculty in the Profession - MU SON. .95

Table 29 Characteristics of CU SON Interview Respondents 102

Table 30 Age of Participants - CU SON .103

Table 31 Current Salary of Participants - CU SON .104

Table 32 Typical Teaching Responsibility - CU SON.

Table 33 Program Level - CU SON

Table 34 Hours Per Week Spent in Instruction, Office Hours, and At Home - CU SON .106

Table 35 Number of Courses, Clinicals, and Credits Per Semester - CU SON 107

Table 36 Clinicals, Advisees, and Committees Per Year - CU SON.

Table 37 Revising or Creating a Course Per Year - CU SON. .108

Table 38 Hours Per Week Spent Completing Duties - CU SON

Table 39 Involvement in Research - CU SON.

Table 40 Number of Publications in the Past Three Years - CU SON.

Table 41 Anticipation of Remaining in Role as Nursing Faculty for Three Years - CU SON

Table 42 Faculty Beliefs of Full Compensation for

Credentials and Reasons - CU SON .....

Table 43 Satisfaction in Current Role and Reasons - CU SON.....

Table 44 Reasons for Teaching at CU SON .113 
Table 45 Reasons for Remaining as Nursing Faculty - CU SON

Table 46 Limitations to Increasing Student Admissions - CU SON..........................................116

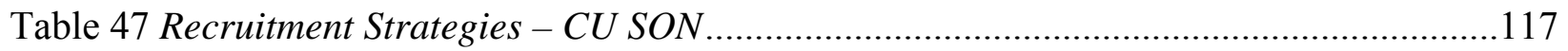

Table 48 Recruitment Challenges - CU SON ……................................................................118

Table 49 Freedom in Designing and Conducting Courses - CU SON.....................................119

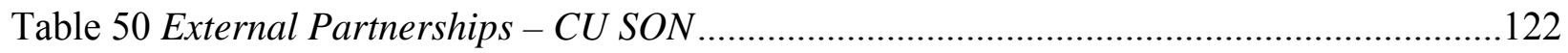

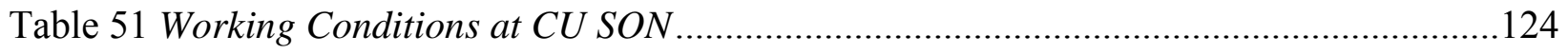

Table 52 Reasons Impacting Recruitment and Retention - CU SON ........................................125

Table 53 Reasons Nursing Faculty Leave CU SON ………...................................................126

Table 54 Strategies to Recruit Nursing Faculty in the Profession - CU SON ............................127

Table 55 Strategies to Retain Nursing Faculty in the Profession - CU SON.............................129

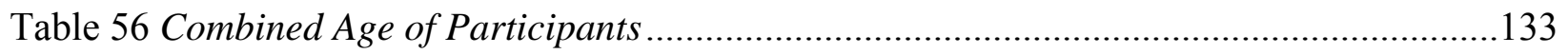

Table 57 Combined Current Salary of Participants ..................................................................134

Table 58 Combined Hours Per Week Spent in Instruction,

Office Hours, and At Home

Table 59 Combined Number of Courses, Clinicals, and Credits Per Semester ..........................136

Table 60 Combined Advisees and Committees Per Year ..............................................................136

Table 61 Combined Hours Per Week Spent Completing Duties...............................................137

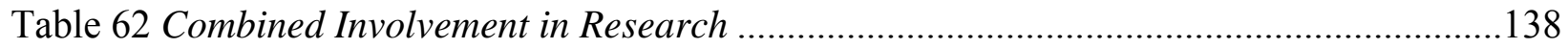

Table 63 Combined Number of Publications in the Past Three Years .......................................138

Table 64 Combined Reasons for Teaching at School of Nursing ...............................................140

Table 65 Combined Reasons for Remaining as Nursing Faculty ..............................................141

Table 66 Combined Limitations to Increasing Student Admissions ...........................................141

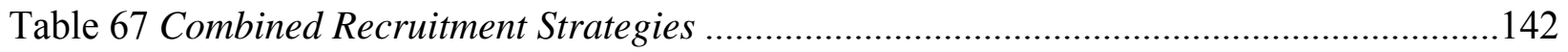


Table 68 Combined Recruitment Challenges

Table 69 Combined Freedom in Designing and Conducting Courses ...... .143

Table 70 Combined External Partnerships

Table 71 Combined Working Conditions at School of Nursing.......

Table 72 Combined Reasons Impacting Recruitment and Retention..........................................146

Table 73 Combined Reasons Nursing Faculty Leave Schools of Nursing.

Table 74 Combined Strategies to Recruit Nursing Faculty in the Profession

Table 75 Combined Strategies to Retain Nursing Faculty in the Profession 149 


\section{List of Appendices}

Appendix A: Faculty and Administrator Demographic Questionnaire ..................................183

Appendix B-1: Interview Protocol for Nursing Administrator Participants ............................189

Appendix B-2: Interview Protocol for Nursing Faculty Participants .....................................191

Appendix C: Letter to Request Institutional Approval for Pilot Study ............................... 193

Appendix D: Letter Template from Institution Granting Permission

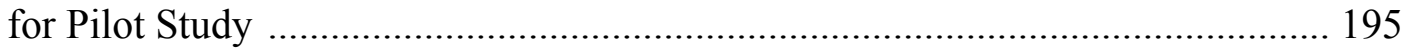

Appendix E: Pilot Participant Invitation Letter .......................................................... 196

Appendix F: Letter to Request Institutional Site Approval ............................................... 197

Appendix G: Letter Template from Institution Granting Permission

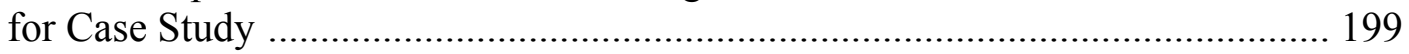

Appendix H: Case Study Participant Invitation Letter .................................................. 200 


\section{Chapter One: Introduction and Problem Statement}

Nursing education is in a crisis situation. There are multiple causes for the crisis, one of which is the lack of qualified nursing faculty. This factor is the most significant in continuing to increase the capacity of nurses to work in the nation's health care systems (American Association of Colleges of Nursing, 2008a). Without qualified faculty to fill positions and to meet the needs of schools of nursing, there can only be a limited number of undergraduate applicants admitted per year to these schools.

Recent statistics released in February 2009 (AACN, 2009c), paint a telling portrait of the current state of the nursing faculty shortage. The statistics show that "[i]n the 2007-2008 academic year, 190,483 completed applications were received for entry-level baccalaureate nursing programs with 122,001 meeting admission criteria and 80,616 applications accepted" (AACN, 2009c, p. 2). What these numbers do not reflect, however, is the number of students turned away from Associate Degree and Diploma Nursing programs. Extrapolating data provided by the National League for Nursing (2006b), during the 2004-2005 academic year, over 99,673 qualified Associate Degree candidates and over 5,177 qualified Diploma Nursing candidates were denied enrollment into their respective nursing programs. The resounding reason for this denial is the lack of qualified faculty to educate these students (NLN, 2006b)

When students are denied enrollment, the applicants do not always reapply so they are lost to other professions or careers. Therefore, a large body of persons to help meet the shortage is eliminated. Reasons for turning away qualified nursing applicants include the lack of qualified faculty, insufficient clinical sites, inadequate classroom space, deficient number of clinical preceptors, and budget constraints (AACN, 2005). Conversely, nursing faculty vacancies have 
risen to $7.6 \%$ between 2008 and 2009 - a record high (AACN, 2008c; AACN, 2008d). Over $88.1 \%$ of these vacancies required a doctoral degree (AACN, 2008c; AACN, 2008d).

This national trend is observable in the different regions of the United States as well. In the Southern Region alone, the percentage of vacant positions increased to $10.1 \%$ in a 2008 survey (AACN, 2008c). The nursing educator vacancies are only accounted for as budgeted positions and not additional positions needed to increase the number of students that can be admitted. The national shortage of nursing faculty vacancies will, if not addressed, prevent the progress of answering the call of increasing the number of nurses educated at the colleges and universities in the United States.

\section{Factors Contributing to Recruitment and Retention Difficulties}

A recent study conducted for the Robert Wood Johnson Foundation (Yordy, 2006) identified initial factors to examine when looking at the nursing faculty shortage. The first factor is lack of interest in nursing faculty careers. Yordy identifies the second factor as "long periods of clinical practice delay entry into faculty profession" (p. 4). Third, fluctuating enrollment in nursing programs is shown to be an important consideration. Fourth, Yordy also points to academic salaries, and fifth, the high costs involved in faculty training. The last two factors identified are dissatisfaction with a faculty career and "inadequate institutional funding for additional faculty positions" (p. 5). To meet the need for increasing the nursing workforce, nursing educators need to be in the pipeline to educate nursing students. Yordy highlights inadequate funding for additional faculty positions that place nursing education at a disadvantage because shortages in other health professions are in competition with them. A disparity between clinical and faculty funding may become a factor as hospitals raise salaries for clinical nurses due to the overall nursing shortage. 
Moskowitz (2007) of the Association of Academic Health Centers presented findings from a survey sent to Chief Executive Officers (CEOs) of academic health centers. According to those who responded, $81 \%$ of CEOs "declared nursing faculty shortages to be a problem at their institutions" and $45 \%$ of respondents "rated nursing faculty shortages most severely" (Moskowitz, 2007, pp. 1-2). In addition, Hinshaw (2008) explains that the interplay between the "baby boomer" generation and the current increase of health care services is a growing concern. She posits that nursing is currently experiencing a "perfect storm," in which multiple factors the rising age of nurses and nursing faculty, the educational enrollment of nurses, the inability of schools of nursing to expand enrollment limits, and work environment difficulties - give rise to an unprecedented catastrophe (Hinshaw, 2008, pp. 54-56).

Moreover, in Moskowitz's study, several different contributory factors to the nursing faculty shortage were examined, such as:

1. Little interest in becoming a faculty in academia.

2. Large faculty workloads. Faculty positions require scholarship, teaching, service to the community, and continuing education.

3. Huge financial disparities between academe and private practice or institutions.

4. Late point of entry for nursing faculty careers after spending long time in clinical practice.

5. Educational costs and higher incidence of debt for nursing graduates.

A groundbreaking and innovative study by Joynt and Kimball (2008) also elucidates additional factors giving rise to the nursing faculty shortage. The increased popularity and demand for the advanced practice role of the nurse practitioner, certified nurse midwife, and nurse anesthetist led schools of nursing to devote their master's degree programs to these roles, 
thereby reducing or closing programs in clinical specialties and education that were common prior to the boom of the advanced practice role. With nurses gaining prescriptive authority, they flocked from the hospitals, clinics, and work places to gain these new skills so that they could become independent or interdependent practitioners (Joynt \& Kimball, 2008).

Nurse managed health care is at the forefront of caring for the uninsured and underinsured in underserved areas of the United States. Due to the lack of primary care providers such as physicians, nurses are filling these roles. Primary care in medical schools has become antiquated and medical students are seeking "controlled lifestyle" specialties that limit the time involved in being available to care for patients. Coincidentally, these specialties also pay much higher than the average primary care physician (U.S. Bureau of Labor Statistics, 2008).

Furthermore, in the past fifteen to twenty years, women who might have applied to schools of nursing are applying to and being admitted to historically male-dominated fields, such as medicine, law, accounting, and engineering. Until 2001, schools of nursing applications were decreasing, programs were reduced in size, and budgeted positions used for other professions at the universities (AACN, 2008c; Harper and Johnson, 1998).

The educational infrastructure has not kept pace with the need for nurses and nursing faculty. Faculty shortages are a barrier to accepting nursing school applicants. Joynt and Kimball (2008) suggest that the primary bottleneck in education infrastructure is the lack of faculty. Aging faculty add to the problem since half of nursing school faculty will retire in the next ten years (Kaufman, 2007). There are very few nurse educators in the pipeline to fill these positions. Nurses who are interested in becoming nursing faculty begin this career shift at a later stage of life and are older. The normal route to becoming a nursing faculty member is to obtain a 
Bachelor of Science Degree in Nursing (BSN), then a Master of Science (MS) or a Master of Science in Nursing (MSN), and then a doctorate in Nursing, Nursing Administration, or Education.

Doctoral programs do not provide teacher preparation because of the focus on nursing research and the increased emphasis on school rankings. Those nurses receiving a Doctor of Philosophy in Nursing $(\mathrm{PhD})$ are expected to conduct nursing research, secure funding, and are placed in the role of a nurse researcher, not a nurse educator (Joynt \& Kimball, 2008). Some nurses do not want to pursue a research doctorate and are pursuing doctorates in education or are entering a new program called the Doctor of Nursing Practice (DNP). It takes years to complete these levels. More importantly, many sacrifices - monetary and otherwise - are required in order for nurses to return to school to further their education. These are mostly women who have families and must work full-time while working on their advanced degrees.

The length of time it takes for individuals to complete the doctoral program affects their ability to enter the faculty ranks and their access to full-time teaching positions. For example, nursing doctoral students spend an average of 8.8 years in a doctoral program. The time from entry into a master's program to the completion of a nursing doctorate is 10.5 years (Joynt \& Kimball, 2008). In addition, one must consider that required clinical experience is needed to teach nursing students. Thus, the length of time needed to be able to become nursing faculty is further increased.

Nursing is different than other health professions as nursing tends to "produce educators in a sequential rather than simultaneous manner" (Joynt \& Kimball, 2008; Yordy, 2006). The combined need for highly qualified faculty, plus the demands of doctoral level education requirements, in addition to the need for a competent clinical background, is a barrier for nurses 
who wish to achieve nursing educator status. It is a recurring trend that young nurses with families do not want to place their families under any additional burdens to further their education in order to teach nursing. Also, the salaries for clinical positions are, in many locations, \$20,000 more than what could be expected as a nurse educator (Joynt \& Kimball, 2008).

It is estimated that approximately 500,000 new nurses will be needed by 2025 unless steps are taken to improve this projected outcome (Buerhaus, Staiger \& Auerbach, 2000). Nursing programs lack nursing faculty and they lack the funds to create new teaching lines and to expand lab facilities. In this era of economic uncertainty, universities and colleges continue to cut funding and decrease the number of faculty (AACN, 2008d). With the rising costs of healthcare, the extensive involvement of insurance companies, and increased stresses placed upon employers of nurses, there is a real urgency to decrease the number of nurses in order to minimize costs. Nurses are second guessed, pressured to care for more patients, worked in a daily crisis situation - and they are expected to do this each and every day. This crisis situation with the lack of caretakers causes much worry, anxiety, and mistakes, thereby influencing nurses to leave the profession if they are able to do so (Maryland Statewide Commission on the Crisis in Nursing, 2005; Aiken, Clarke, Cheung, Sloane, \& Silber, 2003). With this additional loss of nurses, the crisis situation becomes even more critical.

\section{Implications of the Nursing Faculty Shortage}

The nursing faculty shortage has multiple implications for colleges and universities. New applications are declining in all types of nursing education programs. Students applying to the baccalaureate programs have a 20 percent rejection rate and associate degrees have a 32.7 percent rejection rate of qualified applicants (NLN, 2008). In 2006, over 1,390 faculty positions 
were vacant, according to an estimate prepared by the National League of Nursing (NLN, 2006a). It is more telling that of these vacant positions, 869 positions were at the baccalaureate level with another 564 vacant positions in associate degree programs (NLN, 2006a).

A special survey was conducted that analyzed membership of the American Association of Colleges of Nursing (AACN) for vacant faculty positions for the 2008-2009 academic year (AACN, 2008c). The survey showed lack of sufficient funding as a major barrier to the increased need of nursing faculty positions throughout the United States. Moreover, the survey highlights additional results of the nursing faculty shortage, such as the unwillingness and inability of schools of nursing to add new faculty lines, losing competition between nursing and other health care areas for the same personnel pool, and an overall lack of qualified faculty (AACN, 2008c).

With the nurse faculty shortage comes a general nurse shortage. Coupled with this dire prediction is the fact that nurses are not only leaving the profession, but are older and retiring soon (Buerhaus, Donelan, Ulrich, Norman \& Dittus, 2005). Today's nurses are faced with mandatory overtime, a high patient-to-nurse ratio, sicker patients in higher numbers, new and complicated technologies, and the ever present regulatory bodies (Buerhaus et al., 2007). All of these barriers are escalating and contributing to the nursing faculty shortage.

\section{Strategies to Address the Nursing Faculty Shortage}

A variety of strategies may address the current nursing faculty shortage. Studies conducted in the past ten years have focused on developing partnerships with hospitals, health systems, and other schools of nursing (Allan \& Aldebron, 2008); lobbying state and federal legislators for increased funding for more nurse faculty positions and tuition support for undergraduate and graduate level programs (Reinecke, 2008); creating new academic pathways 
for nurses to obtain the doctoral level degree (i.e., CNL and DNP degrees) (AACN, 2009a);

closing the gap on salaries between the clinical area and the nurse educator (Yordy, 2006);

recruiting younger nurses into academia; engaging in large scale advertising campaigns; and

increasing collaboration within and without the community (AACN, 2005).

\section{Purpose of the Study and Research Questions}

The purpose of this research study was to examine the types of strategies that academic leaders utilized to address recruitment and retention of nursing faculty in various universities. While the causes and the results of the nursing faculty shortage have been examined in depth, current studies proposing various solutions to the nursing faculty shortage have not been given detailed attention. What has not been examined is how schools of nursing are implementing these strategies for practical use within each school. Moreover, some strategies proposed by researchers may not be practical or effective. In addition, strategies previously disregarded or not formed may be applicable to help schools of nursing in this time of need. This study is highly significant as it presents a current portrait of the ways in which schools of nursing help alleviate this shortage. As the literature review demonstrates, scholars have only focused on a limited number of strategies and have not fully developed alternative strategies for use in this current nursing environment. Within this study, the following research questions are presented:

1. What recent strategies have individual schools of nursing implemented to address recruitment and retention of nursing faculty at their own institution?

2. Which of these strategies do nursing school educators/administrators believe have been effective for them?

3. What external stakeholders collaborate with nursing faculty? 
4. What are the reasons behind the lack of recruitment and retention of faculty within schools of nursing, as perceived by nursing school faculty and administrators?

The researcher interviewed nursing school administrators and nursing faculty at two schools of nursing that provide baccalaureate- to doctoral-level education. In addition, documents such as self-study reports, press releases, internal communications, and strategic plans were reviewed. The researcher analyzed this data to address the four research questions investigated in this study.

\section{Significance of the Study}

There is a shortage of nurses to care for persons in the United States and the "showstopper" to the shortage is the lack of qualified nursing faculty to teach nursing students. Researchers have suggested multiple causes and strategies for this deficit of nursing faculty. Schools of nursing are turning away thousands of qualified nursing students each year to become nurses. With the recent passage of the Patient Protection and Affordability Care Act (PPACA) that will provide health insurance for all citizens of the United States, an increased need of nurses is necessary to care for the additional people to be covered by this insurance. Qualified nursing faculty are essential to meet the need to teach students who have applied to nursing baccalaureate programs.

This study examined a sample of two schools of nursing and performed in-depth case studies to identify short and long term strategies that the schools used to improve the numbers of nursing faculty available to teach qualified students. Also, many nursing faculty left schools of

nursing for clinical areas. Recruitment, retention, and promotion were studied at these schools of nursing. 
Without qualified nursing faculty to teach nursing students, there will be a continued nursing shortage. To become a nursing faculty, one must undergo additional training at extra expense and accept a less lucrative position for more work, as compared with a clinical position. Nursing schools have eschewed the nurse educator track in master's programs in favor of the nurse practitioner role and the new Doctor of Nursing Practice degree. As there are fewer students becoming nurse educators, there are less nursing faculty in the pipeline and therefore, fewer qualified faculty to teach students.

The intent is that this study will make a contribution to the understanding of the strategies needed to increase nursing schools' recruitment and retention of nursing faculty. Also, it is hoped that this study will be of value to educators who are responsible for teaching the nurses of tomorrow.

\section{Summary}

Chapter One focused on an overarching view of the nursing faculty shortage. The causes of, results of, and strategies to alleviate the shortage were elucidated. In Chapter Two, a literature review provides an in-depth examination of past studies, solutions, and frameworks. Furthermore, Chapter Two also provides a lens through which to view the nursing faculty shortage in its current incarnation. In Chapter Three, the methods used in the collection of the data for this qualitative study will be explained and highlighted. Thus, these first three chapters provide the reader with a foundation in which to approach the all encompassing issue of the nursing faculty shortage. 


\section{Chapter Two: Review of the Literature}

Nurses provide extraordinary care. . . [T] hey are on the frontlines of the health care system. And they don't get paid very well. Their working conditions aren't as good as they should be. And when it comes to nursing faculty, they get paid even worse than active nurses. So. . it is very difficult for a nurse practitioner to go to teaching, because they're losing money.

The notion that we would have to import nurses makes absolutely no sense. And for people who get fired up about the immigration debate and yet don't notice that we could be training nurses right here in the United States -- and there are a lot of people who would love to be in that helping profession and yet we just aren't providing the resources to get them trained -- that's something we've got to fix. That should be a nobrainer. That should be a bipartisan no-brainer to make sure that we've got the best possible nursing staffs in the country." (Obama, 2009)

The above quote by President Barack Obama is evidence that the nursing shortage and the nursing faculty shortage are high priority issues, not only for those in academia, but for those in government as well. This review of literature focuses on the factors contributing to the nursing faculty shortage, the implications of the nursing faculty shortage, and proposed strategies to alleviate the nursing faculty shortage. No single proposed strategy will be able to solve the current crisis and, in fact, many dominant strategies must be intertwined to provide needed relief. Juxtaposed upon this review of literature will be proposed frameworks through which to view the nursing faculty shortage and proposed solutions. The review concludes with an examination of existing and potential strategies utilized by schools of nursing. 


\section{Background}

Multiple factors have led to the current nursing and nursing faculty shortage. In the 1990s, managed care organizations swept the nation and it was predicted by the insurance industry and hospital executives that hospitals would be downsizing and nursing positions thereby cut. The notion that patients would have decreased lengths of stays in hospital and more ambulatory procedures would preclude the need for nurses. In fact, hospitals would be closing beds, merging with other hospitals and health systems, and costs would be decreased (Nevidjon \& Erickson, 2001). Adding non-nursing staff was thought to be a solution so as to decrease the number of nurses - and, therefore, the cost of nurses' salaries and benefits - to work in institutions. Concurrently during this era, women were breaking the glass ceiling and entering traditionally male-dominated fields: medicine, law, finance, and business (AACN, 2005).

Women were not joining nursing at the same rate as they had previously due to the opening up of the traditional male occupations. Nursing schools during this time saw a decreased enrollment and, therefore, lines of faculty and programs were cut (Joynt \& Kimball, 2008). Thus, nurses have not been in the pipeline to replace aging clinical nurses and nursing faculty.

As sick patients are kept in the community for longer periods of time before a hospital admission, the level of acuity for hospital admissions has increased. This has resulted in an expanded need for competent, well-trained nurses to care for these patients. More recently, nurses are needed even more to provide care for those who are uninsured and underserved in this country.

\section{Faculty Shortages: Scope and Significance of the Issues}

An important early study conducted by Buerhaus, Staiger, \& Auerbach (2000) identified that the United States was in a major nursing shortage crisis due to a lack of interest in the 
nursing profession, the increasing age of baby boomers and their subsequent need for more care, and the rising age of current nurses. Also, nurses left the profession for other careers or they retired. Working conditions at hospitals, health centers, and nursing homes were arduous, demanding, and fraught with staffing issues, a lack of advanced knowledge in acute care situations, and interruptions in flow (i.e., waiting to take a patient to laboratory or x-ray testing). Mandatory overtime was an every day problem.

A nursing faculty shortage paralleled the nursing shortage due to the lack of qualified nursing faculty in the pipeline to replace aging and retiring faculty and those who were leaving teaching (Hinshaw, 2001; Yordy, 2006; Joynt \& Kimball 2008). The American Association of Colleges of Nursing (AACN) collected information from schools of nursing concerning faculty positions in a "Special Survey on Vacant Faculty Positions" released in July 2008. Data show that for the 2008-2009 academic year, there were a total of 814 faculty position vacancies at 449 nursing schools with baccalaureate and/or graduate programs in the United States. This translates into approximately 1.8 faculty vacancies per school (AACN, 2008c). Moreover, the Association of Academic Centers reported in its 2007 survey that the nursing faculty shortage is the most severe shortage of all health professions (Moskowitz, 2007).

Aging faculty is a major issue in the nursing faculty shortage. In a 2008-2009 AACN report (AACN, 2009a), the age of master's prepared faculty are: professors, 58.9 years; associate professors, 55.2 years; and assistant professors, 50.1 years. For faculty with a doctoral degree, the ages increase: 59.1 years for those holding the rank of professor; 56.1 years for associate professor; and 51.7 years for assistant professor. Nursing faculty begin their entry into master's programs at a later stage after completing several years in a clinical position (Joynt \& Kimball, 2008). It is essential for nursing faculty to be both academically and clinically competent to 
educate nurses. Also, the cost to further the education in a master's program is extremely high. In addition, nurses are primarily educated at the associate degree level and a baccalaureate degree in nursing is required to apply and to enroll in a master's degree program in nursing. This adds more years for those who wish to enter the master's program.

In addition, there is a huge salary disparity between clinical positions and nursing faculty positions. In many locations, there may be up to a $\$ 20,000$ difference between master's prepared faculty positions and clinical positions. It is cost prohibitive to many to become a nurse faculty member due to this wide disparity in salaries.

To become a nurse faculty member in a baccalaureate program, a doctoral degree or the completion of substantial course work in a doctoral program is usually required. Few nurses want to become a doctoral prepared nurse because of the high costs associated with education, the vast opportunities in clinical settings to advance, higher salaries in clinical positions, and the time it takes to become a nurse with a doctorate (Hinshaw, 2001; AACN, 2005; Joynt \& Kimball, 2008; National Council of States Boards of Nursing, 2008). The number of years it takes to become a doctorally prepared nurse is 7.8 years (AACN, 2008c). This length of time is a very big investment for the master's prepared nurse to devote to becoming a nurse faculty who is fully qualified to teach in schools of nursing.

Furthermore, it is also essential to have preparatory programs to develop the nurse educator in master's programs. Beginning in the undergraduate nursing programs, it is important to encourage students to advance their education in master's programs and to develop the role of the nurse educator. For the past fifteen years, schools of nursing have developed the role of the nurse practitioner in their master's programs instead of the nurse educator (Joynt \& Kimball, 2008). In 1992, during the Clinton Administration, a summit for nurse practitioners was held in 
Washington, D.C. The nurse practitioner summit developed a National Nurse Practitioner Coalition which became a political "arm" in Washington and the American Association of Nurse Practitioners (AANP) was formed (Edmunds, 2000). The development of the advanced nurse practitioner has garnered great support in nursing programs and nurses have flocked to become nurse practitioners for a myriad of reasons. Nurse practitioners can practice independently and also have prescriptive authority which gives autonomy to these nurses to practice and care for their patients. Salaries are much higher for nurse practitioners than nurse educators and there can be a $\$ 40,000$ or more difference between the two fields. The advent of the nurse practitioner and the continuing emphasis placed upon that field by schools of nursing remains a current trend in nursing education, while master's level nurse educators are given little attention or focus.

The most recent change is the addition of a new degree: the Doctor of Nursing Practice (DNP). The DNP is a clinical-based or "practice-based" terminal degree "designed specifically to prepare individuals for specialized nursing practice" (AACN, 2006, p. 7). Moreover, the DNP is not a research-based degree as is the Doctor of Philosophy (PhD) (AACN, 2006). The AACN explains that the "practice focused doctoral programs are designed to prepare experts in specialized advanced nursing practice. They focus heavily on practice that is innovative and evidence-based, reflecting the application of credible research findings" (AACN, 2006, p. 3).

The National Organization of Nurse Practitioner Faculties (NONPF) states that the DNP is an evolutionary - and, as some scholars believe, revolutionary - step for the nurse practitioner and will be the standard of entry for them (NONPF, 2006). However, the organization states that they do not want any timeline for this degree to become the required standard. They claim that it took many years and much planning for nurse practitioners to obtain a master's degree when 
they articulated from a post-basic certificate (NONPF, 2006). Nurse practitioners who obtain a DNP can teach in a school of nursing, but their primary qualification is in the role of the Advanced Practice Nurse in clinical practice - caring for patients in all types of settings such as clinics, ambulatory centers, offices, hospitals, emergency rooms, and emergent care centers. The role of the nurse educator is not within the curriculum of a nurse practitioner. Therefore, there is discontinuity between nurse practitioner-to-DNP prepared faculty and master's prepared-toresearch-based doctorate prepared faculty within schools of nursing. While the DNP may make strides in advancing the role of the nurse practitioner and provide more outlets for Advanced Practice Nurses, they are not research-based faculty or nurses and therefore cannot properly identify with the role of the nurse educator needed in nursing schools (Robetoy, 2006).

Recent trends evidence the demise of the nurse educator. In 1988, according to the National League for Nursing, $24.7 \%$ of nurses graduating from a master's degree nursing program focused on education (Berlin, Wilsey, \& Bednash, 2005). Between 1994 and 2002, the percentage of master's degree students emphasizing education dropped from $11.3 \%$ to $3.5 \%$ (Berlin, Wilsey, \& Bednash, 2005). The nurse educator has also suffered from the popularity implosion of the nurse practitioner and the profession's focus on clinical practice. Subsequently, there are not as many nurses moving on to become a doctorally prepared nurse (Joynt \& Kimball, 2008). Multiple opportunities abound for the nurse practitioner in clinics, ambulatory centers, and hospitals to work in an independent or quasi-independent role and make more money than nurse educators (Harper \& Johnson, 1998).

As a result, once students become nurses, there is a lack of desire for those nurses to become nurse educators. This translates into having few nurses in the pipeline to become nurse educators (AACN, 2005; Anderson, 1998). Therefore, with so few nurses pursuing the role of a 
nurse educator, the nursing faculty shortage is further intensified. Currently, there is a deficit in master's and doctoral programs. In 2008, over 5,900 nurses were turned away from master's programs and more than 1,000 were not given entry into doctoral programs due to the lack of nursing faculty (AACN, 2009d).

DNP programs show the largest growth in doctoral programs offered at schools of nursing, with a student population increase from 1,874 to 3,415 students (AACN, 2008a). By 2015, the AANP recommends that all nurse practitioners obtain a doctorate to be able to practice and to see patients (Harper \& Johnson, 1998). DNP programs answer the need for nurse practitioners to become doctorally prepared.

Enrollments in the research-focused doctoral programs saw only a $0.1 \%$ growth in the 2007-2008 academic year, which translated into only an additional three students (AACN, 2009d). These programs prepare students for a lifetime of intellectual inquiry and independent research to add to the body of nursing knowledge. Nurses who earn a research focused doctorate are prepared to teach in schools of nursing and can become administrators, have careers in government or the private sector, or focus on research and scholarly activities.

If a nurse wishes to pursue either the practice-based doctorate or a research-based doctorate, he or she must engage in many additional years of education in order to earn that degree. The DNP can take an additional two years of time whereas the research doctorate may take longer - up to seven years to obtain the $\mathrm{PhD}$ (Joynt \& Kimball, 2008). This is a tremendous amount of time, energy, and cost to nurses. Also, the nurse needs to have a master's degree in nursing to be able to apply to either the DNP program or research-based program. Another direction for nurses who want to pursue a doctoral degree is for the nurse to obtain a degree outside of nursing in the field of education, curriculum development, human development, public 
health, management, or health care administration. These degrees require lengthy coursework and also require a dissertation for completion.

No matter what route the master's nurse takes to obtain a doctorate either in nursing or other areas, it is very timely and the costs - financial and emotional - are excessive. Nurses take on additional debt at times when they are focusing on their families and, for many nurses, pursuit of a doctorate is not feasible. So, many times nurses wait until their children are grown, which delays entry into doctoral programs until they are much older (Joynt \& Kimball, 2008). There are sources of grants and loans that may be available to nurses who enter doctoral programs in nursing (AACN, 2009b). To those who enter from outside the field of nursing (e.g., those with backgrounds in health care administration, public health, or management), there are few programs other than government loans to assist them in paying for their higher education. Nursing faculty are highly recommended to have their doctoral degrees to teach in schools of nursing. A doctorate is also essential for retention, considerations of tenure, advancement, and for academic mobility purposes (e.g., lateral moves between schools of nursing). Currently, $53.7 \%$ of all nursing faculty vacancies require a doctoral degree (Webber, 2008).

The cost of obtaining a doctoral degree is extremely expensive and there is a considerable loan burden that many nurses must carry to pursue this degree (Hinshaw, 2001; Yordy, 2006; Joynt \& Kimball, 2008). There are some programs that help off-set tuition at schools of nursing but these are limited to what the particular institution has to offer. In addition, there are some federal grants and loan programs to which nurses can apply, but many of them are for narrow specialties and set forth rigorous requirements - such as a nurse must major in informatics or geriatrics (American Nurses Association, 2009). 
The American Nurses Association (ANA) is urging Congress to increase funding for the Nursing Workforce Development Programs contained in Title VIII of the Public Health Service Act. The ANA is requesting $\$ 215$ million in funds for fiscal year 2010 - a $\$ 44$ million increase from the previous fiscal year. Although the Health Resources and Services Administration (HRSA) projects that there will be a $36 \%$ shortage of nurses by the year 2020, in fiscal year 2008, HRSA turned away $92 \%$ of applicants for the Nurse Education Loan Repayment Program due to lack of funding (ANA, 2009).

Nursing faculty are vital in the training of more nurses. Without monies to educate both students in nursing programs and for nurses to obtain master's and doctoral degrees, the care and safety of the people in the nation will be hindered (ANA, 2009). This will result in additional shortages of nursing faculty on an already strained nursing system (National Advisory Council on Nurse Education and Practice, 2008).

\section{Faculty Issues}

Multiple nursing faculty issues are present in today's schools of nursing. Some of these issues are: increase in faculty workload, job dissatisfaction, salaries not commensurate with educational level, and concomitant demands placed on faculty to increase number of courses taught, perform research, and participate in nursing scholarship (Kaufman, 2007; NLN, 2007; Christmas, 2008) Also, faculty are expected to participate on committees, volunteer in their communities, and perform service for the academic community (Yordy, 2006; Bartels, 2007; Joynt \& Kimball, 2008).

Moreover, the work of nursing faculty is not always completed while on the job. Nursing faculty must grade and check students' assignments, develop new courses, and update courses. Many times these tasks cannot be completed "at the office" and must be finished at home due to 
committee meetings, faculty meetings, time spent in clinical and simulation labs with students, and teaching courses. A huge burden is thus placed on nursing faculty whereby their time and energy are constantly demanded by administration, students, other faculty, scholarly and research pursuits, and clinical or practice needs. The work carryover also places stress on the nursing faculty's family at home which interferes with the work-life balance. There is huge burden of workload that nursing faculty experience in their jobs in academia.

Shirey (2006) warned that dedicated nursing faculty who do too much and are "on fire" will lose their flame and "burn out." Many demands are placed on faculty who are subject to very few resources. Failure to properly address this problem may result in illness and disability. Burnout, according to Shirey (2006), has three dimensions: 1) exhaustion, 2) cynicism, and 3) inefficiency. Exhaustion is the most common denominator of burnout. Exhaustion manifests itself in physical, emotional, and mental symptoms. There may be lack of energy, sleeplessness, feelings of helplessness, and impatience. The second stage, cynicism, occurs as a result of exhaustion and the nurse disengages from other faculty, thereby further straining relationships. The third and final stage, inefficiency occurs when faculty feel a loss of accomplishment. Once these three phases are complete, faculty subsequently develop burnout (Shirey, 2006; Oermann, 1988).

Individuals who have higher levels of educational preparation are prone to burnout (Maslach, Schaufeli, \& Leiter, 2001). Also, those individuals with high job expectations and who are idealistic appear more prone to burnout. All of these attributes are characteristic of nursing faculty. Consequently, stress and burnout of nursing faculty is one of the major causes of the nursing faculty shortage. Nursing faculty leave academia to pursue other opportunities because of the stress and burnout they experience in this role. Other job situations exist for those 
who have a master's or doctoral degree such as hospital administration, nursing research, roles in non-profit agencies, and positions within community health organizations.

Interestingly, the National League for Nurses (NLN) examined faculty role satisfaction. It found that the main reason faculty stay in their role as nurse educators was because of devotion to their students (NLN, 2005). Other reasons that added to longevity as a nurse faculty member included contributing to the profession, working in an intellectually stimulating environment, and having autonomy and flexibility (NLN, 2005). In addition, leadership factors influenced satisfaction of nursing faculty. Nursing faculty were more satisfied if the school had a common vision and direction. The NLN study related that the causes of faculty leaving the profession were faculty salaries, promotion and tenure, faculty workload, and faculty hours.

Today, many changes affect institutions of higher education, such as fiscal constraints, accountability, increased enrollments, a more diverse student population, and expanding technologies (Gappa, Austin, \& Trice, 2007). For nursing faculty, not only is there a shortage, but many constraints are placed upon them which are not connected with teaching but heavily impact their role as an educator. Fink (2002, p. 47) defines teaching as "being effective in the process of helping someone else learn something significant." Using this definition, then, the teacher is an indirect factor in a student's education because it is the student, not the professor, who ultimately must learn and comprehend the material presented. But in nursing, so much of the teaching is hands-on training with specific instructions and guidelines. Teachers are more than role models and need to be experts in their respective fields to be able to draw on experiences and prior knowledge. Nursing proficiencies are of utmost importance in the safety and care of the general populace. 
In addition, schools of nursing must meet accreditation and mandatory minimal standards of learning. To ensure that these guidelines are met, courses are set up and implemented in an extremely regimented fashion. Moreover, schools of nursing require all nursing students to obtain the exact same information, as much as possible, so these courses are set up in a highly controlled and generic manner. Theory courses are set up to be exactly the same from course-tocourse and curriculum is unchanging. The result of this mandated and characterless, yet highly structured, system is a repression of academic individualism and growing nurse faculty dissatisfaction.

A concern about academic freedom arises when each course is designed, organized, and implemented like its counterparts (e.g., Nursing 200, Section 01 is exactly the same as Nursing 200 , Section 02 , etc.) and nursing faculty who are teaching the course have very little input. Online courses have these attributes of sameness. There is little variability in the courses. Outside forces have influenced the design of the curriculum and the format that it is to be taught. Gappa, Austin, \& Trice (2007) discuss declining faculty autonomy and control. They explain that administrators are taking more control because of fiscal constraints. Because of these fiscal issues, in some programs, faculty are suppressed and have little to no input or direction in the school's governance and curriculum.

Technology also hinders the role of the faculty in regards to curriculum development. It condenses the faculty role in preparing, delivering, and evaluating courses. Now, a curriculum designer prepares the course, a technology specialist develops the software to teach the course, a public relations specialist markets the course and the teacher is there to help the students to learn. Therefore, academic freedom and autonomy are being taken away slowly, but surely. 
Ultimately, it is apparent that faculty have lost a sense of control and autonomy (Gappa, Austin, $\&$ Trice, 2007).

Not only are nursing faculty constantly faced with the loss of academic freedom and autonomy, but they must balance increasing course loads and other competing restrictions on their time. Gappa, Austin, \& Trice (2007, p. 18) state there is no "limit or boundary on the amount of work for faculty to do." Faculty are concerned about balancing both work and life. Nursing faculty are required to teach, publish papers, keep up to date in clinical practice, perform research, apply for grants, and give service to their institutions and the general community. In many institutions, policies are in place to help with the work-life balance, such as having provisions for child care, elder care, compressed work weeks, telecommuting, on site-support programs, job-sharing, part-time work policies and family leave to name a few (Gappa, Austin, $\&$ Trice, 2007). These benefits are very helpful to faculty but also highly depend on the administration of the institution or that particular dean of the school of nursing. Many faculty are concerned about using these benefits due there are normative cultural biases that if one uses some of these work-life balancing provisions, they are looked down upon within the school (Gappa, Austin, \& Trice, 2007).

Boyer (1997) proposes an expanded way of viewing the professoriate. He explains that all the types of scholarship - discovery, integration, application, and teaching - should be supported (See Table 1). Many schools of nursing are now using the Boyer Model to evaluate their faculty. However, schools which do not subscribe to Boyer's Model of Scholarship want their faculty to be "superstars" in every facet of their careers and lives - prolific scholars and writers; intense researches and grant recipients; classroom and clinical educators; and highly involved in the university community. Boyer's Model dispels this standard as impractical and 
which, in actuality, leads to faculty burnout (Shirey, 2006). Instead, the theory focuses on the evaluation of faculty based upon the type(s) of scholarship in which they engage, thereby supporting and encouraging faculty who might be stronger in scholarship than research or in administration than in clinical education, for example. The underlying theory of the Boyer Model is the refusal to emphasize one role above another - faculty roles are diversified, but intertwine to be valuable to academia. Those faculty who are interested in teaching should be supported, just like other faculty (e.g., clinical-based faculty), according to Boyer.

Table 1

Boyer Model of Scholarship, Pacific Crest (2011)

\begin{tabular}{|c|c|c|}
\hline $\begin{array}{c}\text { Type of } \\
\text { scholarship }\end{array}$ & Purpose & Measures of performance \\
\hline Discovery & $\begin{array}{l}\text { Build new knowledge } \\
\text { through traditional research }\end{array}$ & $\begin{array}{l}\text { - Publishing in peer-reviewed forums } \\
\text { - Producing and/or performing creative } \\
\text { work within established field } \\
\text { - Creating infrastructure for future studies }\end{array}$ \\
\hline Integration & $\begin{array}{l}\text { Interpret the use of } \\
\text { knowledge across } \\
\text { disciplines }\end{array}$ & $\begin{array}{l}\text { Preparing a comprehensive literature } \\
\text { review } \\
\text { Writing a textbook for use in multiple } \\
\text { disciplines } \\
\text { Collaborating with colleagues to design } \\
\text { and deliver a core course }\end{array}$ \\
\hline Application & $\begin{array}{l}\text { Aid society and professions } \\
\text { in addressing problems }\end{array}$ & $\begin{array}{l}\text { - Serving industry or government as an } \\
\text { external consultant } \\
\text { - Assuming leadership roles in professional } \\
\text { organizations } \\
\text { - Advising student leaders, thereby } \\
\text { fostering their professional growth }\end{array}$ \\
\hline Teaching & $\begin{array}{l}\text { Study teaching models and } \\
\text { practices to achieve } \\
\text { optimal learning }\end{array}$ & $\begin{array}{l}\text { - Advancing learning theory through } \\
\text { classroom research } \\
\text { - Developing and testing instructional } \\
\text { materials } \\
\text { - Mentoring graduate students } \\
\text { - Developing and implementing a program- } \\
\text { level assessment system }\end{array}$ \\
\hline
\end{tabular}




\section{Student Issues for Faculty}

Students now enter nursing school later in their lives than was common in prior years. The National League for Nursing (NLN) surveys schools of nursing and collects and analyzes data about types of entering students, types of programs, and the number of faculty vacancies. A 2008 study by NLN revealed that during the 2006-2007 academic year, there were 181,862 students admitted to all schools of nursing. Of that number, 63,390 students enrolled in baccalaureate degree programs, 112,332 entered associate degree programs, and 6,140 students matriculated in diploma nursing programs (NLN, 2008). In baccalaureate programs, $16 \%$ of those admitted were over 40 years of age while $16 \%$ entered between the ages of $31-40$ (32\% of the total number of admitted students). Diploma schools admitted $14 \%$ of nursing students who were 40 years of age and $27 \%$ of nursing students between the ages of 31 to 40 ( $41 \%$ of the total number of admitted students). By far the greatest number of older students enrolled in associate degree nursing programs $-17 \%$ of students were over 40 years of age and $32 \%$ were between the ages of 31 to 40 (49\% of the total number of admitted students) (NLN, 2008).

These statistics reflect an older, non-traditional student who is entering nursing school. Some of these students are second degree students, others need jobs because of the economic condition of the United States, and there are now many ways that students can gain access to low cost loans or scholarships from the schools. Nursing is considered a stable profession and the news is filled constantly with reporters talking about nursing and healthcare shortages. Hospital advertisements are in newspapers and journals offering sign-on bonuses and advancement for nurses.

A broad range of individuals who enter nursing are challenging the nursing faculty. The students are older and they have more outside experiences. Also, most faculty are from the Baby 
Boomer era as they were born between 1945 and 1964. They are children born after World War II and make up about two-thirds of the workforce present in today's society (Leighty, 2007). These individuals learned the value of family and work - the Protestant work ethic was prized above all.

Nursing faculty also experience students who are the Generation X (born from 1964 to1979) and Generation Y or Millenials (born from 1980 to 2000). Each of these age groups have characteristics that demand different teaching approaches by faculty. Generation X students were the first latch-key children and are very independent. They grew up in households where both parents worked. The world of the Generation X student was borne in the rice paddies of Vietnam, marched through the streets in Alabama, demonstrated for women's rights, and came of age in the 1980s - a decade characterized by excess, corporate greed, and a focus on instant gratification. Generation X students are accustomed to independence, have faith in themselves to succeed, and became responsible for themselves at an earlier age. They want meaningful careers (Tulgan, 2000; Widger, Pye, Wilson-Keates, Squires, \& Tourangeau, 2007).

Generation Y or Millenial students have had a digitalized upbringing. They are upbeat, confident, and nurtured (Olson, 2009). They were born in the post-Vietnam economic boom time. These students were raised in sheltered environments where their families recognized their worth with such devices as car seats and safety locks. Families were busy but involved in their children's lives - the parents of Generation Y students are "soccer moms" and children grew up having "play dates." Generation Y students are deeply involved in activities inside and outside of school. They grew up in technologically advanced homes. There was a return in values for this generation with good manners and truth telling (Olson, 2009). This generation has been the most schooled. Those in Generation Y are the most globally aware and racially diverse 
generation in history (Lower, 2007). The internet has also been a primary source of attention for Generation Y students and their main outlet. Generation Y students want to work for creative organizations or non-profit agencies and a career such as nursing suits them well due to flexibility in scheduling, creativity, the opportunity to work in different environments, and changing technologies. They feel also they are entitled to a share in the revenues they helped to make. This generation thinks more like Baby Boomers than Generation X. They are innovative thinkers and will challenge the nursing work unit (Lower, 2007). Also, one of their biggest strengths is that they are experts at multi-tasking - this skill is extremely needed today in the nursing field. Thus, they are very well suited for this profession (Parker \& Kupperschmidt, 2002).

Nursing faculty are challenged when teaching Generation Y students. These students need to be entertained and stimulated. Because they are extremely fast multitaskers, they get bored very easily. They can process information quickly and they are the generation that may pose challenges to the Baby Boomer generation. They question work schedules, learning styles, professional image, and evaluations. They object and challenge as a way of life (Lower, 2007). These students are used to having flexible schedules and object to conformity. They like for faculty to "do something" to entertain them rather than to have to read, sit, and listen to a lecture. They question nurse faculty and because they are internet professionals they may have more facts than the faculty teaching the course (Greene, 2005; Deck, n.d.).

Nursing student incivility is another challenge to nursing faculty. A study performed by Luparell (2007) cited uncivil encounters taking place on a continuum from less severe to more severe. There could be escalating aggression to threats of safety. Faculty were usually caught off guard by these incidents. The attacks from students included yelling, use of profanity 
directed at the faculty, physical touching, and threats to well-being. These incidents created both short- and long-term problems for the faculty. The faculty had many physical and emotional reactions such as decreased self-esteem and loss of confidence in their teaching abilities. Several faculty interviewed for the study by Luparell left teaching after the incidents. These faculty cited these incidents as the reasons they left academia and said "it was not worth it" (Luparell, 2007, p. 17). Minimizing events of student incivility is crucial to reduce faculty shortage.

\section{Budgetary Concerns}

From approximately 1990 to 2000 , there was a downsizing in schools of nursing. Applications to nursing school decreased because many women were applying to and were admitted to male dominated professional schools such as medicine, pharmacy, law, business, and engineering. There was a shift in the attitudes of women who chose not to enter nursing, a predominately female field.

Buerhaus (1998) studied and evaluated the future supply of nurses. He wrote that there was a new nursing shortage present and it would get worse over the coming years. This was the first time in many years that the nursing shortage affected the number of nursing faculty and created a looming shortage of nurse educators (Brewer, 1997). Nursing faculty were not in the pipeline because of the lack of interest in becoming educators. Graduate schools admitted students primarily to advanced practice positions and de-emphasized or deleted training to become a nurse educator.

In an unpublished qualitative study by Lamm (2005), nurse faculty were interviewed and asked questions regarding their satisfaction at the school of nursing in which they taught. The faculty stated that monies had been eliminated over the past years when admissions were dwindling, lines of faculty were taken away from the school of nursing, support staff were 
eliminated, and funds for continuing education and curriculum development were near to nonexistent. These nurses felt that the "showstopper" (Montgomery, 2004) of the nursing shortage was the lack of qualified prepared faculty. Faculty were getting older, retiring earlier, or leaving nursing altogether, as they stated that being a nursing faculty was overwhelming. Salaries had not kept pace with other faculty salaries in the university or the clinical areas. Clinical salaries were many times over $\$ 20,000$ more per year than the salaries of a nurse educator (Washington, 2009). Support from the university was not present nor was there an understanding that to teach nursing is very time-intensive. The infrastructure was not present to support faculty so they could teach nursing students.

One faculty member resented that she had to stand and make copies for her students when several years prior to that, there was a central copy room with people working there to support faculty and students (Lamm, 2005). She felt that her time was better spent teaching nurses - not learning how to use spreadsheets and other computer software programs. All typing was now done by faculty. Much of the time and energy used by faculty was for this type of nonnursing function (Lamm, 2005). All of these reasons cause an increased amount of stress and difficulty when trying to remain focused on one's role of educating nursing students. Money is needed to increase the lines of faculty, add more space to increase the enrollment of students, give secretarial support to faculty, add simulation and technologies to enhance faculty and students needs, and have a sound development program for nursing faculty. Also, meeting the demands and respecting faculty for their education in regards to salary is essential for maintaining faculty morale (Brendtro \& Hegge, 2000). 


\section{Impact of the Nursing Faculty Shortage}

The lack of nursing faculty is the primary reason that qualified nursing students are not admitted to schools of nursing. In 2008, 41,385 qualified applicants were turned away from entry-level baccalaureate programs. In addition, 1,659 RN to BSN students were turned away. The pool of qualified applicants not admitted to nursing masters and doctoral programs were 5,902 and 1,002, respectively (AACN, 2009c). Fay Raines, President of the AACN, states that “academic administrators are facing many barriers to accepting all qualified applicants into their nursing programs, including funding cuts, limited classroom and clinical space, and a diminishing pool of faculty. All efforts to end the nursing shortage and enhance the pipeline of nursing students must focus on addressing these serious concerns" (AACN, 2009c, p.1).

To teach full-time, faculty hired for nursing positions in a baccalaureate school of nursing must have their doctoral degrees or be a doctoral candidate. Nurses must have a baccalaureate degree and a master's degree to enter a doctoral program. Therefore, more students need to enter baccalaureate nursing programs. Moreover, Aiken, Clarke, Cheung, Slone, \& Silber (2003) found that too few RNs with a BSN - as opposed to RNs with associate's degrees - may harm patients because of the educational imbalance. They posit that entry-level nurses need to possess the baccalaureate degree to improve care and safety for patients. The researchers found that a " $10 \%$ increase in the proportion of hospital staff nurses with baccalaureate degrees is associated with a 5\% decline in mortality following common surgical procedures" (Aiken et al., 2003, p. 1617). Therefore, the study shows a positive link between hospital nurses' educational levels and decreased mortality of patients.

Because many nurse educators will leave the profession or retire in the next decade, increasing the number of nursing faculty does not necessarily mean that faculty will stay in the 
profession. Garbee and Killacky (2008) reported many factors inherent in the "slowing of the exodus of faculty" (p. 7). Some of these factors include satisfaction, mentorship, work environment, and leadership. Other comments of nurses were they "love nursing and felt nursing education allowed them to give back to the profession, and make a difference" (p.11).

Many problems overlap for nursing faculty such as increased student load in classes, lack of infrastructure to support an increase in admitting students to nursing programs, and the huge disparity in salaries as compared to the clinical and private-sector settings. Nurse faculty are overworked, unable to complete their work while on the job, and are dealing with many leadership problems associated with incivility, lack of promotions, and nursing curricula that need revision. Additionally, nursing faculty need to maintain clinical competence, promote scholarship, apply for grants, teach students in the classroom and the clinical area, and perform community service. In comparison to those nurses with the same degrees in the clinical and private sectors, nursing faculty have a huge workload imbalance. Therefore, many nurse faculty leave academia for other settings to get relief from the overload of work teaching nurses and also to gain additional benefits and salary.

In "Special Survey on Vacant Faculty Positions for Academic Year 2009-2010," the AACN (2010) posited there are 803 nursing faculty vacancies, which correlates to $9.7 \%$ of schools reporting vacancies. The mean number of vacancies is 1.4 per school. Over $58.8 \%$ of schools reported requiring an earned doctorate to be employed as full-time faculty, while $31.8 \%$ reported a required master's degree but would prefer a doctorate. The survey described four significant reasons that schools of nursing are not hiring additional full-time faculty for the academic year of 2009-2010: (1) "Insufficient funds to hire new faculty," (2) "Unwillingness of administration to commit to additional full-time positions," (3) "Inability to recruit qualified 
faculty because of competition for jobs with other marketplaces," and (4) "Qualified applicants for faculty positions are unavailable in [the] geographic area" (AACN, 2010, p. 13.). Additionally, schools reported state budget constraints and hiring freezes for faculty as rationale for the failure to hire full-time nursing faculty. Also, due to the current economic climate, current faculty are delaying retirement (AACN, 2010, p. 15).

Nursing faculty are very disillusioned, overworked, stressed, and, ultimately, are not paid for their level of education or experiences. Many times, nurses in clinical positions with BSN and masters degrees are paid $\$ 20,000$ to $\$ 40,000$ higher than a nurse educator (J. Allan, personal communication, May 17, 2007).

The number of nurses gaining terminal degrees ( $\mathrm{PhD}, \mathrm{EdD}, \mathrm{DSN}, \mathrm{DNSc})$ has decreased since 1995. In 2007, only 513 doctoral students out of 3843 enrolled received their doctorates. Currently, the Doctor of Nursing Practice (DNP) degree is gaining momentum. The length of years to obtain the $\mathrm{PhD}$ and other research doctorates usually takes an average of eight years and is essential for tenure-track positions. The DNP degree takes a much shorter time frame of two to three years to complete and is now considered a terminal "practice" doctorate. Many schools of nursing are developing the BSN to DNP pathway to make obtaining a terminal degree a better - and easier - option for nursing students (Robert Wood Johnson Foundation, 2007). Once nurses receive their BSN degrees they can enter a BSN to DNP degree program and skip the master's degree. Within the DNP curriculum there is the opportunity to specialize in one of the advanced practice disciplines. Combining these degrees into one step makes nursing on par with other professions such as pharmacists, physical therapists, speech therapists, and social workers. Nurse educators have held doctoral rates at only one-half of their peers across other academic fields. Kathy Kaufman, Director of Research for the National League of Nurses, wrote that "one 
in every three nurse educators has an earned doctorate, compared with 60 percent of all US postsecondary-level faculty" (Kaufman, 2007, p. 144). With nurses having a direct pathway to the DNP, more will be prepared to teach in schools of nursing and expand the role of the nurse into advanced practice. Because nurses will be able to obtain the terminal degree sooner, it is suggested that their career span will be longer. Joynt and Kimball (2008) note that those interested in the faculty role are traditionally older and receive their doctorates between the ages of 45 to 54 , which results in only being able to work approximately fifteen years as a faculty member. Nurses will be able to streamline their education and be in their roles longer with a forward-thinking approach to bring about curricula changes.

Due to the general shortage of nursing faculty along with the high cost to hire full-time nursing educators, part-time (adjunct) faculty have been hired along with preceptors in the clinical institutions where nursing students learn how to practice. Schools of nursing have limited lines for faculty and to increase these may not be in the strategic plans of universities. "The estimated number of part-time baccalaureate faculty has grown 72.5 percent since 2002" (NACNEP, 2008, p. 19). Hiring part-time adjunct nurses to work with students in clinical settings or to lecture classes adds to the number of educators available to teach in nursing schools. It is challenging to integrate part-time faculty into the role of nurse educator, orient them to the goals and mission of the school of nursing, and keep them updated with the nursing institution. Moreover, "often part-time faculty are not an integral part of the design, implementation, and evaluation of the overall program" (NACNEP, 2008, p. 19). Thus, hiring part-time nursing faculty is a short-term answer to a long standing problem.

The cost to pursue a career to become a nurse educator is beginning to be prohibitive due to the ever-increasing costs of graduate schools. Siela, Twibell, and Keller (2009) researched the 
cost of attending a nursing master's degree program and found the cost ranging from $\$ 4,000$ per year in public institutions to more than $\$ 11,000$ per year in private institutions. Moreover, approximately $19 \%$ of nursing schools stated that "lack of affordability" or "high cost of education" was the main deterrent to recruiting students for their programs (NLN, 2009, p. 4). Many institutions traditionally reimbursed graduate programs for courses nurses were taking for advanced development of their degrees, but currently, many hospitals and other institutions have reduced the amount of monies being spent. On-line or distance education provide educational opportunities for nurses. Nurses can study at home and have greater flexibility.

Nursing faculty have responsibilities for scholarship, teaching, and community service. These distinct roles create heavy and demanding workloads and educators leave their positions. This is due to time demands, increased number of students, incivility of students, lack of faculty to help with workload, low pay, long commute, politics of academe, unfriendly work environment, demands by administrators to publish articles, grant requirements, and working in the community (Garbee \& Killacky, 2008). The nurse educator tends to return to jobs in clinical areas that do not make these demands and pay the educator an additional $\$ 20,000$ to $\$ 40,000$ a year.

The impact on nursing educators is vast and the responsibilities are great. New faculty models are necessary to keep faculty satisfied and who stay in academe. Garbee and Killacky (2008) concluded that "[n]ursing faculty should be encouraged to speak up, and work with leaders in order to create a work place and workload in which they can be satisfied, survive, and even thrive" (p. 12). 


\section{Strategies to Increase the Number of Qualified Nursing Faculty}

As the result of many compounding causes and implications of the nursing faculty shortage, availability of qualified nursing faculty has decreased. New strategies to increase the numbers of faculty to teach in schools of nursing must be examined and implemented if the academic community wishes to prevent further losses.

Throughout this section, strategies for increasing nursing educational capacity, such as fostering partnerships with hospitals, forming alliances with other schools of nursing, and streamlining the educational process for acquiring a terminal degree in nursing will be discussed. Moreover, a review of the strategies proposed will be appraised for short-term and long-term solutions to this problem. Thus, it is hoped that through use, whether singularly or combined, these strategies will alleviate the pressing nursing faculty shortage.

A public relations campaign by Johnson and Johnson to support the nursing and nursing faculty shortage has been ongoing since 2002. The mission was expanded in 2007 to support nursing faculty recruitment and retention (Allan \& Aldebron, 2008). Johnson and Johnson partnered with the AACN to provide an initial $\$ 90,000$ in minority scholarships to those nurses pursing a faculty career (AACN, 2008b). The national campaign's goals are to increase the number of nurses, keep nurses in nursing by improving retention, and expand nursing education capacity. They use television advertising, videos, websites with links to professional sites, and the desire to make an impact on the shortage of nursing educators.

Various strategic partnerships have been proposed and developed through the entire system of healthcare to improve and support the nursing faculty role. Schools of nursing have partnered with hospitals and various healthcare institutions by offering clinical nurses who have master's degrees to teach students in the clinical area (Allan \& Aldebron, 2008). Various 
arrangements have been employed to link clinical-based nurses with schools of nursing to enhance the number of faculty that are available to teach nursing students. By linking student nurses to a master's prepared nurse in a specific area, students gain an inside perspective into what is expected of them in the role of a registered nurse. Relationships between hospitals and schools of nursing are needed to expand the diversity of resources, add to the levels of experiences, and improve the transition of nursing students to clinical practice. Thus, partnering with institutions and forming contracts to add to the capacity for nursing education benefits both the schools of nursing and the institutions to transition nursing graduates for the work area.

The mission of the Center to Champion Nursing in America (CCNA) is to coordinate efforts between the public and private sectors to redesign nursing education to prepare the future nursing workforce. Through these initiatives, it has brought together multiple stakeholders from every state and the District of Columbia. In 2008 and 2009, two national summits were held. These summits focused on ways:

1. to increase education capacity by strategic partnerships and alignment of resources, 2. to increase faculty capacity and diversity,

3. to redesign education, and

4. to change policy and regulations (Cleary et al., 2010, p. 43).

As the CCNA summits were comprised of various states, multiple strategies to combat the nursing faculty shortage were proposed, discussed, and implemented by certain states. For instance, the CCNA points to Oregon as a state which has examined the resources and admitting practices for all twenty-one schools of nursing. Their goal is to increase the number of nurses to earn a four-year degree - the BSN, - to partner with organizations, and to seek legislative 
support to expand nursing faculty and increase salaries. "That can-do, collaborative approach has made Oregon a model for states and regions across the country, and CCNA is helping make sure the model is widely shared" (CCNA, 2009, \ 7). Oregon utilizes a team approach that includes representatives from state workforce offices, nursing education, state departments of labor, consumers, local business, philanthropies and others. They posit that open communication will help them reach their goals (CCNA, 2009).

Another example from the CCNA summit is from the State of Mississippi (Lewis, 2010b), where stakeholders were brought together from the Mississippi Board of Nursing, Mississippi Nurse Association, Mississippi Office of Nursing, Mississippi Office of Nursing Workforce, Mississippi Council of Deans and Directors of Schools of Nursing, and the Mississippi Hospital Association. These stakeholders worked to convince legislatures to review and raise salaries for nurse educators. In the 2006-2007 legislative session, policy makers increased faculty pay over a two-year period. Thus, Mississippi witnessed the reduction of unfilled nursing faculty positions, from forty-nine in 2006 to fifteen in 2008 .

Career advancement has since come to the forefront as a reason for lack of nursing faculty - not salary. Another aim is to unite associate degree schools with the bachelor's degree. Currently, Hinds Community College and the University of Mississippi Medical Center are collaborating to advance education that takes students from the associate degree to the master's degree, thereby improving the number of master's prepared nurses that are able to teach in a school of nursing. "New nurses must be ready to step in to teach the next generation" (Lewis, 2010b, p. 7). Challenges still exist to admitting more students to the nursing schools in Mississippi, such as lack of classroom and laboratory space, limited sites for clinical experiences, insufficient funds to hire faculty, and an inability to fill faculty vacancies for the 1,719 qualified 
students that were denied admission to schools of nursing in the 2007 academic year. The survey reports faculty are delaying retirement, citing the decreased economic climate. However, these same faculty noted they will pursue retirement once the economy improves, which will greatly impact the number of nursing students expected to be admitted (Lewis, 2010b).

Another member of the CCNA summit is California (Lewis, 2010a). Policymakers established the California Nurse Education Initiative, a public-private partnership involving nurse educators and nurse employers. The University of California and the California State University systems received funding for baccalaureate and masters programs in nursing. Loan forgiveness programs were also developed. Through these programs, between 2004 and 2008, California nursing programs added 1,240 faculty members - a 57\% increase (Lewis, 2010a, p. 57). The California Student Aid Commission administers a loan assumption program for nursing students committed to becoming nurse educators. Additionally, a goal of California is to develop a nursing workforce that mirrors the diversity of the state. As some minority students may have difficulty with verbal and written communication in English, several programs in California now are targeted towards minority nursing students to improve understanding and retention in the programs (Lewis, 2010a).

Minority students are vastly underrepresented in all health professions. The Dr. Louis W. Sullivan Alliance's (2010) focus is to transform America's health professions. The purpose is to: "1) raise awareness of the importance and value of achieving racial and ethnic diversity in the health professions; (2) disseminate information about 'best practices' and resources that enhance diversity; and (3) stimulate academic programs in the health professions of medicine, dentistry, nursing, psychology and public health to create new - or more effectively implement existing — diversity initiatives," (Sullivan, 2010, $₫ 4$ ). Drawing from the entire society will be a 
strategy to increase nursing and the nursing faculty shortage. Therefore, multiple strategies have been garnered from the CCNA summit gatherings to bring stakeholders in nursing education together to share ideas and give attention to the lack of nursing faculty.

Technology - simulation labs, on-line learning courses, handheld devices such as smart phones, social networking - is a method that enhances the education capacity for schools of nursing. Faculty members can teach on-line courses from their homes or other non-site locations. Distance learning and a common curriculum expand the faculty reach to students (RWJF, 2007). Faculty that are retired or nurses who are working in healthcare can address nursing faculty vacancies. In addition, resources for the support of on-line courses are needed, but office space and clinical locations are not needed when teaching on-line classes. These distance learning courses offer more flexibility for learning that is conducted at the convenience of the student and faculty (Pank, 2007). The on-line format gives students in rural areas the ability to attend traditional university classes. It allows students to complete a nurse educator program and, thus, impact the faculty shortages where they live. It gives access to rural nurses when, traditionally, there was no link to the university setting (Fearing \& Riley, 2005).

Faculty teaching in schools of nursing need to have more faculty development programs to use these technologies to enhance teaching in schools of nursing. An on-line resource center for nursing faculty is a strategy that has been proposed by Hasson, Cornelius, and Suplee (2008) to improve understanding of discussion boards, video tutorials, technology tutorials, continuing education, template location, and additional university resources. This center is easily accessed through Blackboard technology or other on-line learning platforms. Special attention is given to novice faculty to improve their overall understanding of the university, along with giving aids and resources needed to using technologies to enhance student teaching. The nursing resource 
center is continually evolving and changing to meet the needs of those involved. This model can be duplicated at other schools of nursing. Hasson, Cornelius, and Suplee (2008) state that "[t]echnology-driven resource models can provide institutions with a cost-effective system that will aid in quality assurance and continued professional development of their faculty for years to come" (p. 24).

Strategies to improve nursing faculty shortage include methods to streamline basic nursing education and advanced nursing preparation. Traditionally, there has been a wide span of time before nurses at the basic level of a registered nurse return to graduate school. There is a cultural norm supported by past nursing educators that to return to school for a nursing master's degree, the nurse must have had substantial practice in nursing. Nursing lags behind other professions to be doctorally prepared for clinical practice. The inception of a new doctoral degree, the Doctor of Nursing Practice, joins the traditional research-focused Doctor of Philosophy to attain the highest level of education for nurses. One of the innovative ways in which schools of nursing attempt to gain more faculty is through the development and encouragement of the AACN-created Doctor of Nursing Practice (DNP). The DNP was developed as a terminal degree for those nurses focused in clinical practice - not research - such as the master's level nurse practitioner. A DNP, from beginning to completion, typically takes two to three years. Moreover, the DNP is an entirely clinical-based degree in nursing. Additionally, because the DNP is both easier to obtain than the $\mathrm{PhD}$ and is a terminal degree, it has gained widespread acceptance and popularity, not only from master's prepared nurse practitioners, but from master's prepared non-nurse practitioners. Some educators favor the DNP and are transitioning schools of nursing to substitute the DNP for master's degrees in nursing. Thus, a student would complete the undergraduate BSN and then move directly into the 
DNP program, without any gap in time to obtain clinical experience. Much like other disciplines that now require a terminal degree, such as pharmacy, a student can obtain an undergraduate and doctoral degree in nursing in about six to seven years.

Traditionally, the terminal degree for a faculty prepared member would be the Doctor of Philosophy (PhD). Before obtaining the $\mathrm{PhD}$, a nurse had to complete the undergraduate BSN and a master's degree. Because its focus is research, the $\mathrm{PhD}$ could take an average of eight to ten years to complete. Therefore, from the beginning of the undergraduate curriculum to the completion of the $\mathrm{PhD}$, a nurse could expect to spend approximately sixteen to twenty years to reach the terminal degree.

Comparing the two timelines has led schools of nursing to emphasize the DNP as a terminal degree, but as a way to (1) increase student admissions and interest, (2) entice students to remain at the school - and paying tuition - for a longer term of years, and (3) advance students through to obtain a terminal degree to develop more clinicians at a doctoral level, which is the norm for other healthcare professions. Also, as a terminal degree, the DNP increases the number of nurses to teach at a school of nursing. Therefore, the DNP is a method to increase nursing faculty. This is in contrast to the PhD track, where a student might begin the education and then never return to the school to complete the degree due to the extraordinary length of time, effort, and money that the degree costs. Now, not only students, but master's prepared faculty, see the appeal of the DNP as compared to the PhD.

This paradigm shift is analyzed by both the Robert Wood Johnson Foundation (2007) and the AACN (2010). Dr. Fay Raines, President of the AACN, states that "the movement to the DNP is about producing the most competent nursing clinicians possible to meet the nation's healthcare needs" (AACN, 2010, p. 2). Currently, less than 1\% of nurses in the U.S. have 
doctoral preparation. The Commission on Collegiate Nursing Education (CCNE) is an autonomous accrediting agency of the AACN that ensures the quality and integrity of baccalaureate, graduate, and residency programs in nursing (AACN, 2010). Thus, the CCNE evaluates and accredits DNP programs. Thus far, the CCNE has accredited eighteen DNP programs and seventy additional DNP programs are pursuing this accreditation (AACN, 2010). The first DNP program began in 2002 and, as of 2009, there are over 5,165 students enrolled in 119 DNP programs. This number is expected to increase in coming years. With nurses graduating from the DNP programs, it has been considered a new pathway to becoming a nurse educator (RWJF, 2007).

Emerging pathways to become a nurse educator are proposed to be direct and to allow nurses to move forward with their terminal degree without spending time in practice before beginning graduate study. Pathways that have been suggested are from the BSN to DNP, BSN to $\mathrm{DNP}$ to $\mathrm{PhD}$, or second degree program (those with prior undergraduate degrees) to DNP. Each one of these pathways can all lead to the nurse educator role.

To support the advancement of nurses to a terminal degree, financial aid is essential. Both state and federal monies are needed as a resource for nurses to accomplish these degrees along with funds to schools of nursing to increase the number of students admitted to the terminal degree programs. Many state partnerships are creating new models and results. For example, in the State of Maryland, the Health Services Cost Review Commission, which regulates hospital rates, responded with an innovative initiative. It increased the rate structurewhat each insurance company, as well as Medicare and Medicaid, pay a hospital - by 0.1 percent and earmarked the monies for nursing education. This initiative is expected to annually generate $\$ 8.8$ million. The first award of these monies was in 2006 to the University of Maryland School 
of Nursing. These funds have continued - approximately $\$ 2.3$ million - and have supported the new DNP program. Additional monies from this grant will be used to fund a variety of grants and scholarships for nursing students and fellowships for new nursing faculty (RWJF, 2007).

Funds have been proposed for nursing in a new federal program, the Patient Protection and Affordability Care Act (PPACA). Such sources of funding re-authorizes and modernizes Title VIII of the Public Health Service Act funding for $\$ 338$ million in 2010 and will be annually appropriated (American Association of Retired Persons, 2010). The Title VIII program can potentially increase the numbers of advanced degree registered nurses who can provide primary care, chronic care management, and women's health care, and also increase the number of nursing faculty.

In addition, salaries need to be increased for nursing faculty. Dr. Janet Allan, Dean of the University of Maryland School of Nursing, is asking legislators in Maryland to increase funding for faculty salaries. She states that “[i]n Maryland there's currently a $\$ 40,000$ to $\$ 60,000$ gap between what I can pay a master's prepared faculty of nursing and what they can earn in a clinical setting” (RWJF, 2007, p. 3). Nursing faculty are in demand and resources are not available to compensate faculty for the increased number of students, scholarship demands, and work in the community. Also, schools of nursing are not adding tenure to faculty hires as frequently. The number of tenure track positions is insufficient to meet research needs at the schools of nursing. Most schools of nursing hire both part- and full-time faculty off the tenure track on one-year contracts with less formal arrangements. At a time when there should be a renewed value for nursing faculty, there is a decreasing commitment from the institutions to provide a stable, full-time, tenured faculty. With the economic downturn, there is further strain 
on schools of nursing to support an increase in faculty salaries (Yordy, 2006; Joynt \& Kimball, 2008; Benner, Sutphen, Leonard, \& Day, 2010).

\section{Summary}

The nursing faculty shortage is a complex problem in the current nursing education system. There are many causes of the shortage of nursing faculty, such as lack of funding for schools of nursing, lack of infrastructure to educate nurses, length of time traditionally needed to obtain a terminal degree in nursing, advanced age of faculty, improved salaries in clinical areas for nurses at the master's or doctoral levels, and schools not investing in salaries for faculty. The decreased number of nursing faculty has implications for health care of the entire population.

Multiple strategies have been suggested to increase the number of qualified nursing faculty. One main thrust of these strategies is to provide nurses with a faster way of reaching a terminal degree. Nurses traditionally have obtained their basic nursing degree and then worked in the clinical area for many years before pursuing a master's degree in nursing. Once the nurse has a master's degree more time is spent in the clinical area before returning to school for a terminal degree. The $\mathrm{PhD}$ has been the highest level of formal education for a career in research and the scholarship of discovery, but many nurses were not interested in this type of degree. Recent innovations for a doctorally prepared nurse have led to a new degree - the Doctor of Nursing Practice. This degree is one of shorter time spent in education and does not require a dissertation.

With the documented shortage of nursing faculty to teach nurses, new pathways have been developed and promoted by the AACN and the Robert Wood Johnson Foundation with support from the United States Departments of Education and Health and Human Services. Various pathways have been proposed such as the BSN to DNP or the PhD. Nurses would stay 
in education programs until they receive these advanced degrees similar to pharmacy, physical therapy, and audiology. Monies are needed from hospitals, academic centers, the state and federal governments to help nurses pursue these degrees. Giving loans and scholarships, increasing salaries for nurses teaching in schools of nursing, and providing infrastructure such as new technologies with distance education and simulation may help address the nursing faculty shortage. 


\section{Key Terms and Concepts}

For the purposes of this study, the following definitions will be used:

Nursing Faculty Shortage: A critical shortage of nursing faculty that limits the number of students who can be admitted to nursing programs (AACN, 2010; Benner, et al, 2010).

Strategies: Ideas, methods, and programs to improve nursing faculty shortage, nursing shortage, and education of nursing students (Yordy, 2006; AACN, 2005; Joynt \& Kimball, 2008).

Stakeholders: Individuals or groups who have an interest in healthcare and specifically in nursing, and who may or may not be involved in long term planning. Examples include state and federal governments, colleges and universities, healthcare organizations, professional organizations, current and prospective nursing faculty, nursing students, and healthcare consumers (Maurer \& Smith, 2005; Robert Wood Johnson Foundation, 2009; Wulff \& Austin, 2004).

Retention of Nursing Faculty: A process by which schools of nursing continue to employ existing nursing faculty for the purpose of educating nursing students (Gappa, Austin, \& Trice, 2007; Allan \& Aldebron, 2008).

Recruitment of Nursing Faculty: Attracting highly qualified individuals into nursing faculty careers (Yordy, 2006; Gappa, Austin, \& Trice, 2007; Roberts, 2008). 


\section{Chapter Three: Research Design and Method}

\section{Research Design}

This chapter explains the methods used for this qualitative study. A case study approach was the preferred strategy for posing "how" and "when" questions. In addition, a case study focus is helpful when examining a contemporary phenomenon within a real-life context (Yin, 2003). Therefore this method is most applicable to the purpose of this study, which is to examine the strategies academia are utilizing to address the nursing faculty shortage in baccalaureate nursing programs.

\section{Qualitative Research Design}

The qualitative research design places an emphasis on exploration, discovery, and description (Bloomberg \& Volpe, 2008). As the study unfolds, decisions about how to obtain data, from whom to obtain data, and how to schedule data collection are made. An emergent design is the hallmark of a qualitative study. The emergent design is a reflection of the desire to have inquiry based on realities and viewpoints of those under study that are not known at the outset of the examination (Polit \& Beck, 2009).

Characteristics of qualitative research design that apply across all disciplines are:

1. Flexibility to adjust to what is learned during data collection;

2. Merging together (triangulation) of various data collection methods;

3. Being holistic and understanding the whole;

4. Requiring researchers to become intensely involved, often spending longer time in the field collecting data;

5. Analyzing data throughout the study to gain meaning for adjusting data collection methods; 
6. Research taking place in a natural setting. The researcher goes to the site of the participant to conduct the research;

7. Performing data collection through open-ended observations, interviews, documents, and e-mails. Data collection involves text data and image data;

8. Drawing conclusions and filtering data through a personal lens that one brings to the data analysis in order to interpret research;

9. Reflecting on who the researcher is and becoming sensitive to her personal biography and how this will shape the study; and

10. Performing complex reasoning that is multi-faceted, iterative, and simultaneous. Both inductive and deductive reasoning are at play in analyzing the data.

(Polit \& Beck, 2009; Bloomberg \& Volpe, 2008; Denzin \& Lincoln, 2004; Creswell, 2003; Patton, 2002).

The primary reason to use qualitative methods is to facilitate study of issues in-depth and in detail - to describe and give meaning to the study. A researcher needs to ask questions about how the problem affects the participant and what they think about it. Gaining an insight to the participants' experiences through their responses enables the researcher to understand their viewpoints about the world (Patton, 2002).

\section{Participants}

Two baccalaureate/graduate schools of nursing were chosen to do purposeful sampling through the case study method. The schools of nursing were comprehensive doctoral institutions based on the 2005 Carnegie Classification (Carnegie Foundation, 2005). According to Bloomberg and Volpe (2008), purposeful sampling consists of the "selection of information-rich cases, with the objective of yielding insight and understanding of the phenomenon under 
investigations" (p. 69). Using qualitative research allowed the researcher to capture the uniqueness of each setting with its people and contextual factors. The researcher had specific reasons for selecting specific participants, events, and processes.

A case sampling strategy was utilized. Nursing faculty at various levels of rank and administrative assignment were requested to be interviewed in one-to-one interviews with openended questions. A faculty and administrator questionnaire was developed to collect demographic information. The sample of nursing faculty was projected to be eight to ten faculty at each school of nursing. Individuals in a case study were selected because they represented the norm and were not atypical or unusual (Bloomberg \& Volpe, 2008). By using case methods, three sources of evidence were collected: direct observation of the events studied, interviews of the persons involved in the event, and relevant documents (Yin, 2003). One case study institution was visited by the researcher for in person data collection. The researcher contacted participants at the other case study school through telephone. Telephone interviews were requested by the school's dean due to time constraints of faculty and relocation of the school to a different building. Direct observations of the events studied took place at the visited school while the researcher made indirect observations during telephone interviews.

In addition, the researcher undertook a review of relevant documents. The documents requested included institutional reports, program information, and accreditation self-studies. Miller (1997) explained, qualitative researchers are uniquely positioned to study these texts by analyzing the practical social contexts of everyday life within which they are constructed and used. Texts are one aspect of the sense-making activities through which we reconstruct, sustain, 
contest and change our senses of social reality. They are socially constructed realities that warrant study in their own right. (p. 77)

Bloomberg and Volpe (2008) noted the benefits of document review, including that "[d]ata are collected in their natural setting," "[r]ecords, documents, and artifacts provide contextual information and insights into "material culture," and the fact that document review "[f]acilitates discovery of cultural nuances" (p. 195). Although there are several challenges to a review of relevant documents (Patton, 2002, p. 499), synthesizing institutional documents allows for transparency within the institution (Miller, 1997, p. 91).

\section{Overview of Information Needed}

Bloomberg and Volpe (2008) described types of information that should be collected including contextual, perceptual, and demographic information. Collecting data about the context within which the participants work by looking at the culture and environment of the setting is crucial. Observational notes about the culture and setting were taken by the researcher at the school the researcher visited. Notes such as the physical layout, number of classrooms, type of technology within the classrooms, and number of simulation rooms were compiled. Also, it was important to look at the setting of the faculty, their offices, conference rooms, and how they were situated in relation to other faculty, administrative services, library, and other areas that impacted on the interview and gave a description of the setting so readers would gain an understanding of how the faculty worked within the setting of the organization. Participants interviewed via telephone at the second case study institution verbally described the setting of their offices and floors.

The researcher reviewed the culture of the organization and the department of nursing through examining the vision, mission, types of programs being offered, and conducting nursing 
faculty interviews. Gappa, Austin, and Trice (2007) posit that creating an attractive academic workplace is important to establish a place where faculty can feel valued and respected. The goals of the institution can only be met when the contributions of every faculty are recognized. Documents that were requested to triangulate the study included self-study reports for accreditation to the National League for Nurses or the American Association of Colleges of Nurses, committee reports, deans' state of school reports, strategic plans, program brochures, and executive or administrative council reports. These documents were not sent to the researcher by either school due to concerns of transparency. After conducting an on-line search, self-studies, strategic plans, lists of faculty, number of students admitted, and types of programs offered were found in full format.

A faculty and administrator demographic questionnaire was sent to each participant via email before the interview to collect information about age, degrees received, length at institution, rank, types of teaching (lecture, clinical, or both), types of research being performed, number of advisees, number of courses taught each semester, salary range, hours per week spent completing the faculty's required workload, committee participation, and overall satisfaction in the role of nursing faculty (see Appendix A). The questionnaires were completed prior to the interviews. The analysis of this demographic information helped explain individual faculty perceptions among the participants (Bloomberg \& Volpe, 2008) and facilitated a greater understanding of various responses particularly when examining similarities and differences.

The researcher developed an interview protocol - one for nursing administrators and one for nursing faculty - from the literature (see Appendices B-1 and B-2). The interview protocols provided an opportunity for participants to develop their own answers in their own words (Patton, 2002, p. 344). Moreover, the interview protocols required the researcher to ask the same 
questions in the same order that allowed for consistency in the questions (Patton, 2002, p. 344). Interview protocols that are standardized produced data that are analyzed within a singular case study and through a cross-case comparison.

The use of the same interview protocols created the boundaries of what data was collected based upon the focus of the questions included in the interview protocols (see Appendices B-1 and B-2). The use of the same interview protocols for data collection for nursing faculty and administrators at each institution increased the congruency of data analysis in the research process, thereby assisting in the cross-case comparison of each case study. Each interview with nursing faculty and administrators lasted approximately 50 minutes.

Conversational, probing questions were introduced and included in the interview protocols. These probing questions were integral in the development of a full description of the phenomenon under investigation (Patton, 2002). Furthermore, the probing questions allowed interview participants to provide data beyond that which was anticipated by the researcher.

At the top of the interview protocols was the script that the researcher read to each participant that explained the purpose of the study, the ways in which collected data was used in the study, the time limits of the interview, the confidentiality in which the data was collected and stored, as well as the identification of the researcher and the researcher's supporting institution (see Appendices B-1 and B-2).

The nursing administrator interview protocol consisted of fifteen open-ended questions derived from the study's four research questions. The nursing faculty interview protocol consisted of twelve open-ended questions derived from the study's four research questions. One question (question 9) of the nursing administrator interview protocol and two questions (questions 1 and 8) of the nursing faculty interview protocol set the context of the interview. 
The first research question aimed to determine what recent strategies schools of nursing have implemented to address recruitment and retention of nursing faculty at that specific institution. Five questions (questions 1 through 3, 7, and 8) were asked of nursing administrators to gain this information. Joynt and Kimball (2008) note that if schools of nursing seek to increase the number of nursing faculty and thereby the numbers of admitted students, those schools must design innovative solutions specific to each institution.

The second research question examined what strategies at each institution have been shown to increase the number of nursing faculty positions. Two questions (questions 11 and 12) from the nursing administrator interview protocol and three questions (questions 4 through 6) of the nursing faculty interview protocol were designed to elicit this information. Allan and Aldebron (2008) show that the "scope of efforts to find lasting solutions" to the nursing faculty shortage are varied in the four strategy domains of advocacy, educational partnerships, academic innovation, and funding (p. 295). They note that "[t]he exemplar strategies in each domain share the critical elements of being substantial in scope, sustainable and replicable" (Allan \& Aldebron, 2008, p. 295).

The third research question sought to discover what external stakeholders collaborate with nursing faculty. Three questions (questions 4 through 6) from the nursing administrator interview protocol and two questions (questions 2 and 3) from the nursing faculty interview protocol helped to gain this information. The AACN (2005) posits that fostering existing partnerships and creating new partnerships is essential in decreasing the nursing faculty shortage and thereby increasing recruitment and retention of nursing faculty.

The fourth and final research question examined the reasons behind lack of recruitment and retention of faculty within schools of nursing. Five questions (questions 7, 10, and 13 
through 15) from the nursing administrator interview protocol and six questions (questions 7

through 12) from the nursing faculty interview protocol were designed to determine this information. The NLN (2009) notes that workload and compensation are key factors in nurse faculty decisions to remain at their institution.

Table 2 illustrates the linkage of research questions (RQ) and interview protocol items.

Table 2

Alignment of Research Questions (RQ) with Interview Protocol Items

\begin{tabular}{|c|c|c|c|}
\hline Research question (RQ) & $\begin{array}{c}\text { Nursing faculty } \\
\text { interview protocol } \\
\text { items }\end{array}$ & $\begin{array}{l}\text { Nursing administrator } \\
\text { interview protocol items }\end{array}$ & Documents \\
\hline $\begin{array}{l}\text { RQ 1: What recent } \\
\text { strategies have individual } \\
\text { schools of nursing } \\
\text { implemented to address } \\
\text { recruitment and retention of } \\
\text { nursing faculty at their own } \\
\text { institution? }\end{array}$ & & $1,2,3,7,8$ & \\
\hline $\begin{array}{l}\text { RQ 2: Which of these } \\
\text { strategies do nursing school } \\
\text { educators/administrators } \\
\text { believe have been effective } \\
\text { for them? }\end{array}$ & $4,5,6$ & 11,12 & \\
\hline $\begin{array}{l}\text { RQ 3: What external } \\
\text { stakeholders collaborate } \\
\text { with nursing faculty? }\end{array}$ & 2,3 & $4,5,6$ & \\
\hline $\begin{array}{l}\text { RQ 4: What are the reasons } \\
\text { behind the lack of } \\
\text { recruitment and retention of } \\
\text { faculty within schools of } \\
\text { nursing, as perceived by } \\
\text { nursing school faculty and } \\
\text { administrators? }\end{array}$ & $\begin{array}{c}7,8,9 \\
10,11,12\end{array}$ & $\begin{array}{l}7,10 \\
13,14,15\end{array}$ & \\
\hline Demographics & & & $\begin{array}{l}\text { Faculty and } \\
\text { administrator } \\
\text { demographic } \\
\text { questionnaire } \\
\text { items } 1 \text { to } 28\end{array}$ \\
\hline Setting the context & 1,8 & 9 & \\
\hline
\end{tabular}


During the in-person interviews, perceptual data was collected. Perceptual data was the most important kind of information needed in a qualitative study. Through the perceptions of the interviewees the researcher posited questions to help uncover participants' experiences related to how experiences influenced decisions that were made and what participants felt were strategies that should be utilized to assist in increasing recruitment and retention of nursing faculty.

\section{Pilot Study}

\section{Introduction.}

In order to identify and correct any issues with the research design and methodology, a pilot study was conducted in January 2011. The pilot study was conducted at a public university school of nursing located in the Eastern region of the United States. Yin (2003) describes the pilot study as a "final preparation for data collection" and as "formative [in] assisting [the researcher] to develop relevant lines of questions" (pp.78-79).

The objectives of this pilot study were to refine the interview and the demographic questionnaire, to practice and receive feedback on interviewing techniques, and to evaluate the clarity of the cover letters. Documents for analysis were requested in the liaison cover letter. Three individuals - two nursing faculty and one nursing administrator - at the pilot institution were interviewed. Documents related to the strategic plan, self-study report for accreditation, program brochures, general statistics of the nursing program, number of faculty at each rank, dean's state of school report, administrative council reports, admissions committee reports, salary range of nursing at each rank as permitted were requested. Although discussed with the liaison, permission was to be sought from the dean of the school of nursing before documents could be obtained. But, no documents were forwarded after speaking with the liaison. However, after conducting an internet search, some of the documents were retrieved. 


\section{Data collection.}

Nursing faculty from different ranks and areas of responsibilities were interviewed in one-on-one sessions with the interviewer for approximately 50 minutes. Broad details about the interview were given at the beginning of the interview to the participant concerning the request for audio recording, method of posing questions, and confidentiality of interview. Questions were posed to nursing faculty about recruitment and retention of nursing faculty with primary focus on strategies the faculty and specific school administrators utilized to manage the nursing faculty shortage. The researcher took descriptive and reflective notes during the interviews to capture non-verbal communication and emotions that could not be captured on the audiotape. After the pilot study, participants were given an opportunity to opine as to whether any questions were unclear or if they believed that there were questions missing from the interview protocol questions and the faculty and administrator demographic questionnaire. The goal of obtaining constructive feedback was to create a standardized interview protocol for the study.

During the interviews, the researcher asked participants for comments on the clarity of the cover letters. The participants each agreed that the cover letter discussed the purpose of the study and described their participation requirements clearly.

There was no data collected from relevant documents during the pilot study as no documents were provided. Due to the fact that no documents were forthcoming, a search was performed on the internet which provided the self-study for accreditation, the dean's state of school address, the evaluation plan of the nursing program, and various statistics about the program. 


\section{Study participants.}

Three individual interviews (two nursing faculty and one nursing administrator) were conducted as part of the pilot study. Each of these interviews took place in a conference room at the institution. The participants who were interviewed were a clinical nursing instructor (nontenured), a full professor (tenured), and a full professor (tenured) who was the chair of one of the two nursing departments in the school of nursing. The faculty and administrator work with both undergraduates and graduate nursing students. All participants were full-time faculty and worked between ten to twelve months a year. Participants were involved in committee work at the school of nursing. The pilot study represented the participants who were interviewed at the institutions selected for the formal case studies.

\section{Process of selection.}

The pilot institution was selected because of its Carnegie classification as a research university (Carnegie, 2005) and a public institution. The other two case study schools were selected for the same reasons the pilot was chosen as they were research universities and public institutions. The pilot institution was chosen due to convenience, access, and geographic proximity (Yin, 2003, p. 78). Also, the dean and faculty of the pilot institution were eager to assist in the pilot study. Specifically the pilot institution's school of nursing was a state school, had multiple campuses, and offered the BSN, MSN, PhD, and DNP. They also offered accelerated programs such as RN to BSN and RN to MSN curricula based on-line and several post-master's degree programs. The other two case study schools also offered similar programs.

A cover letter was sent to the Dean of the School of Nursing at the site asking for permission to collect data through faculty interviews and a request to set up interviews (see Appendix C). In completing requirements for Human Subjects Exemption from West Virginia 
University's Institutional Board for the Protection of Human Subject (WVU IRB), a written letter of consent from the selected institution granting permission to conduct the study was submitted. A template letter (see Appendix D) was sent to the institution with a request that a letter of consent be returned on that institution's letterhead. In addition, written materials such as self-study for accreditation, student catalog of courses, demographics about the program such as number of students admitted, number of faculty, number of adjuncts, salary ranges for faculty of all ranks, new programs, use of simulation lab, and need for additional faculty were requested. This written material and other artifacts were collected to triangulate the data with the interviews. Validity of communication was vital to reduce the chances of misinterpretation (Bloomberg \& Volpe, 2008). By using multiple methods of data collection, triangulation of data was achieved to clarify meaning of the phenomenon being studied. A statement of anonymity was included in the letter of request to the dean of the nursing program. Also, days that faculty may be available were requested. A tour was completed of the facility and notes taken about the setting of the school and atmosphere. A conference room was requested to interview each administrator and nursing faculty.

After speaking with the researcher, the pilot school liaison immediately set up interviews who met the criteria for the study. The letter to the pilot institution is included in the appendix section (see Appendix C). The liaison requested that the researcher send the participant invitation letter and the demographic questionnaire for faculty and administrators, both found in the appendix (see Appendices A \& C). The liaison distributed these documents to each of the participants of the pilot study. The interviews were scheduled for one day in January 2011. The interviews were audiotaped to provide a permanent record of each that could later be compared with the other data. 


\section{Data analysis.}

Patton (2002) explains that "researchers and evaluators analyzing qualitative data strive to understand a phenomenon or program as a whole" (p. 59). He goes on to posit that to have an essential understanding of what has been observed or said in an interview, the whole must be understood as a complex system where the greater is more than the sum of its parts. An additional aim of the pilot study data was to obtain feedback about the appropriateness of the instruments as they were given or make suggestions to improve them.

In this pilot study, data analysis involved constant comparative analysis of the interviews, audiotapes, field notes, and participant feedback. Participants responded to interview questions with ease. The demographic questionnaire was completed ahead of time and given to the researcher at the interview. Responses to the pilot study questions related to the organization and clarity of the cover letter, interview protocols, and demographic faculty and administrator questionnaire were minimal. It was suggested to split the interview protocol into two sections, one about faculty and the other about administrators. In addition it was suggested that questions about adjunct faculty be combined into one question. There were no suggestions for the cover letter or demographic faculty and administrator questionnaire.

\section{Results and implications.}

Based on the feedback from pilot participants and also consulting the chair for the doctoral dissertation, the interview protocol was separated to make two interview protocols, one for administrators and one for faculty. Questions about the program were removed from the original questionnaire to make a faculty-only interview protocol. Program questions were placed in the administrator questionnaire. Some questions pertaining to faculty were still included on 
the administrator questionnaire. The updated questionnaires are in the appendix (see Appendices B-1 \& B-2).

\section{Summary.}

Preparing for and conducting the pilot study was a very helpful experience that provided legitimacy to the research instruments and the research methodology. By actually going through the entire process of a case study the pilot study refined data collection and procedures followed. The administration of the interview protocol and data collecting methods showed that substantive and reliable data could be collected. Feedback from the participants resulted in refining the interview protocol into two separate protocols, one for faculty and one for administrators. Also, a preliminary experience was gained through sending out the contact letter, following-up by phone to seek permission, and then being specific in the liaison letter about criteria for faculty selection. Although documents were requested, none were sent to the researcher. Lastly, the rich discussion about recruitment and retention of nursing faculty by the participants supported using a qualitative research approach to this study.

\section{Data Collection Methods}

A case-study approach was used to investigate strategies that the school of nursing utilized to increase the number of nursing faculty and to retain nursing faculty to be able to admit additional students to nursing programs. Two research universities were studied. Based on the research questions, the most meaningful way to gather evidence was by the interview method. Interview questions were developed from each of the research questions. Bloomberg and Volpe (2008) stated that the researcher should think about all of the probable responses to the question and then reframe the questions to be posed to those being interviewed (see Table 2, see Appendices B-1 and B-2). Patton (2002) asserted that the purpose of the interview was to find 
out those things we cannot directly observe. Feelings, thoughts, and intentions cannot be observed. In addition, Patton (2002) stated that we are not able to observe how people organize their world and the meanings they attach to what goes on in the world. The open-ended protocol was one in which,

1. The instrument used is available for those using findings to review;

2. The interview is highly focused so there is efficient use of time to collect data; and

3. Responses are easy to find when questions are asked that are planned. (Patton, 2002).

The researcher attempted to understand the holistic worldview of the interviewees to gain an understanding about the phenomenon studied.

The researcher reviewed notes, notations added, and spoke with the interviewee as soon as possible for clarification of any questions that were unclear. Information about the setting, where the interview occurred, under what conditions was the interview given, and how well the researcher thought the interview proceeded were important to add to the notes for that particular interview. According to Patton (2002), "The human factor is the great strength and the fundamental weakness of qualitative inquiry and analysis" (p. 433).

Analyzing documents added to the research as sources of data that have been traditionally untapped. Researchers should study documents due to the significance in nursing practice. By incorporating these documents, the body of knowledge for nursing would be impacted (Miller \& Alvarado, 2005).

\section{Data Analysis and Synthesis}

Upon completion of the interviews, the researcher transcribed the audiotapes of the interview with the school of nursing faculty participants. From these transcripts, field notes were 
included from each interview. Next, the researcher conducted open coding (inductive analysis). Third, the researcher used a constant comparative approach to identify emerging themes.

Subsequently, after the identification of themes, the researcher analyzed documents that reinforced the emerging themes or contradict the themes. Different types of data captured various aspects and the researcher tried to understand the reasons for the differences. Capturing the data from different sources contributed significantly to the overall credibility or trustworthiness of the findings (Patton, 2002).

Next, the researcher engaged in examination of common themes across interviews within each particular case study. The benefits of individual case studies was apparent when viewing the history of each school, its location, what types of programs are offered, and number of faculty. The goal of this study was to capture "the circumstances and conditions" of a school of nursing in a research university (Yin, 2003, p. 41). More than one case study was examined, as Yin (2003) notes that findings are more robust when studying more than one case study.

Additionally, the researcher conducted a cross-case comparison. Cross-case analysis "treats each individual case study as a separate study" (Yin, 2003, p. 134). Rich data was collected to give a better picture of the strategies currently used or proposed to be used to assist in the recruitment and retention of nursing faculty. Finally, the researcher identified overarching themes and links to previous research studies.

\section{Ethical Considerations}

Qualitative researchers need to keep ethical considerations at the forefront during all phases of the study. The researcher-participant relationship, determined by roles, status, and cultural norms, needs to be considered through the study. Human subjects' rights were protected by asking permission of each person to participate in the study. Approval for the study was 
received from the human subjects committee at the education institution where the researcher was enrolled. Permission was sought from the nursing school deans at two research universities to interview eight to ten nursing faculty and appropriate administrators at each institution.

\section{Issues of Trustworthiness}

As a researcher and a nursing faculty member at a research university, the researcher understood the need to recruit and retain nursing faculty and the need for strategies to prevent further shortages as vital to the future of the nursing profession. Without nursing faculty it was very difficult, if not impossible, to keep up with the need for adding to the numbers of needed nurses. Nurses as well as faculty are faced with many issues such as advancing age, heavy workloads, need to keep up technologically, lack of appropriate salaries, and the need for resources to improve the conditions for both nursing and nursing faculty. Also, nursing is changing and there are new expectations with the latest passage of the Patient Protection and Affordability Act. Nursing is expected to advance the profession to add more nurses at the doctoral level and to increase the number of nurse practitioners to care for the many Americans who will begin to be covered by the government mandated health insurance. Therefore, having competent nursing faculty to teach nurses is vital to the wellbeing of the nursing profession. Looking at current strategies used and proposed was the aim of this qualitative research study.

The lessons learned in each case may be generalizable to other settings and useful to others. Rich descriptions were given in the discussion. Thick description was used to communicate to the reader a holistic and accurate picture (Bloomberg \& Volpe, 2008). With adding a rich description that will allow for transferability, the context offered an element of a shared experience for the reader. The researcher was the research instrument and validated 
thoughts through the literature and the rich descriptions through the narrative of the interviews, along with using artifacts to triangulate the data collection.

\section{Limitations of the Study}

Limitations of observations may be an issue if interviewees participated in a guarded manner. The comments may not be entirely truthful. Qualitative research was used in the study to interview individuals in order to construct the reality as it was known at one point in time. Views may distort responses due to personality, bias, anger, anxiety, and/or politics. By using observations, the interviewer verified what was reported in the interview. Interviews were used as a basis of this qualitative study. The number of interviews was a limitation of the study since eight to ten nursing faculty and administrators were asked to participate in this study at each of the two research universities.

The interviewer was not able to get access to documents requested through the institutions. The researcher was able to obtain many of the needed documents after an on-line search.

Another limitation was the time the interviewer was present in person or on the telephone to ask questions of the interviewee. There were potentially multiple other issues that competed for time with the interviewer. By using a variety of methods and sources, the interviewer built on the strengths of each type of data, therefore getting the most complete picture possible about the phenomenon. All sources of data were critical to the problem and provided critical understanding of the situation (Patton, 2002).

Various schools of nursing were asked to participate in this study. Many schools declined without explanation and did not respond to a written letter. Additionally, two schools requested all the researcher's documents and materials prior to granting permission, which the 
researcher declined. Another two schools required the researcher to complete full Institutional Review Board procedures at those schools prior to granting permission, which the researcher also declined.

\section{Summary}

This chapter discussed the methodology of the study. Eight to ten nursing faculty of differing ranks and nursing administrators were selected to participate in each of the two different research universities. Letters were sent to the deans of each nursing school asking permission to interview nursing faculty and administrators. Permission was asked of each participant to audiotape the one-on-one, semi-structured interview. Before the interview, via email, a demographic questionnaire was sent to each nursing faculty or nursing administrator to complete in order to collect demographic information about the interviewee. If the demographic questionnaire was not completed prior to the interview, it was provided to the interviewee prior

to the interview with time allotted for the document to be completed. Additionally, artifacts such as documents and reports about the school of nursing were requested. Field notes that were observational were taken during the interview, as well as before and after the interview. Reviewing different data sources tests consistency and truthfulness in the study. Also, different types of data may yield differing results and will offer more opportunities for deeper insight in the phenomenon.

The audiotapes were transcribed after the interview and information added from the field notes in order to obtain a more complete picture of the phenomenon. The transcribed narratives were then analyzed by open coding using a constant comparative analysis to identify emerging themes. Documents were reviewed and notes were taken and matched with what the interviewees presented to the researcher. 


\section{Chapter Four: Mountain University School of Nursing}

\section{Institutional Background}

Mountain University is designated as a public comprehensive doctoral institution by the Carnegie Foundation (2005). It is located in a rural city in the Mid-Atlantic region of the United States. Founded in 1867 by a land grant under the Morrill Act, the university has a "rich history of academic excellence and progressive programs" (Mountain University History, 2007). The university has more than 35,000 students across various Mountain University campuses in the state.

Enrollment in Fall 2010 at the main Mountain University campus consisted of 29,306 students, with individuals representing all 50 states and approximately 100 other countries. In undergraduate programs, the university enrolled 22,303 students. The university's graduate and professional students are 7,003 in number. Of total enrolled students, 52 percent are male and 48 percent female, with approximately ten percent of students identifying as a minority. The school employs 8,393 individuals, with over 3,000 faculty members.

The university, accredited by the North Central Association of Colleges and Schools, consists of 13 separate colleges and schools offering 193 undergraduate, graduate, and professional degrees. According to Mountain University’s mission, its purpose is to, ... provide high-quality programs of instruction at the undergraduate, graduate, and professional levels; to stimulate and foster both basic and applied research and scholarship; to engage in and encourage other creative and artistic work; and to bring the resources of the University to all segments of society through continuing education, extension, and public service activities. (Mountain University Mission, 2010) 
Mountain University is the state's only research and doctoral degree-granting university (Mountain University Facts, 2010).

Mountain University School of Nursing (MU SON) is one of Mountain University's thirteen schools. MU SON was authorized by the state's legislature in 1951 with the first dean appointed in 1960. In 1964, the school graduated its first class of BSN students and in 1977, the school conferred the degree of Master of Science in Nursing (MSN). The Doctor of Science in Nursing (DSN) program was established at MU SON in 1999 with the degree later converted in 2007 to a Doctor of Philosophy (PhD). More recently, in 2007, the school instituted the Doctor of Nursing Practice (DNP) degree program (MU SON Self Study, 2008).

MU SON is accredited by the Commission on Collegiate Nursing Education (CCNE). The school offers its over 900 students eight degree options: BSN, RN to BSN, RN to MSN, BS/BA to BSN, MSN, Post MSN-NP, DNP, and PhD. The school is comprised of four departments, with two located at the main Mountain University campus and two located in different parts of the state. MU SON employs approximately 60 faculty who are defined as either Research Faculty or Practice Faculty (MU SON Website, 2011).

The school's organization is arranged in a top-to-bottom flow chart. The Dean directly oversees five individuals: three Associate Deans, one Assistant Dean, and one Director of Development. These five individuals supervise Chairs, Directors, and Coordinators who manage the school's various departments, tracks, and programs throughout the state.

According to MU SON's mission statement, the school's goal is to ... serve the people of [Mountain State] and larger society through education, research and service, including faculty practice. This mission is responsive to changing health care needs and emerging national and state changes in technology and health care delivery and 
is enhanced by a supportive and open environment. The faculty's educational effort is directed to providing high quality student-centered programs of instruction at all levels which prepare superb professional nurses to meet basic health care needs; advanced practice nurses to address complex health needs; and doctorally educated nurses to advance nursing knowledge through research, to assist in the formulation of policies to improve health care, and to serve as faculty in higher degree programs. Unique characteristics of the state mandate that the health care needs of rural populations and; vulnerable groups be a major focus of education, research and service, including faculty practice. (MU SON Website, 2011)

In addition to its mission statement, MU SON lists three goals that are corollaries to the overall Mountain University mission statement. These goals are:

1. Education;

2. Scholarly Inquiry; and

3. Service/Practice (MU SON Website, 2011).

Comparing MU SON's mission to that of the university as a whole provides further clarification. The first part of the university's mission focuses on the aspect of education. MU SON recognizes that its goal in education is "to provide excellent, student-centered educational programs which address core competencies/threads in all programs and meet the changing needs of the communities of interest we serve" (MU SON Self Study Appendix I-A.1, 2008). Next, the university's mission addresses research and scholarship. Similarly, MU SON emphasizes scholarly inquiry as one of its goals in that it "seeks to increase scholarship, including funded research and peer-reviewed publications in order to benefit those we serve" (MU SON Self Study Appendix I-A.1, 2008). Finally, the university's mission of bringing its resources to all 
areas of society is expressed through MU SON's goal of service and practice. In this goal, the school aims to "increase the School's service activity in professional organizations, academe, practice, and continuing education in order to benefit those we serve" (MU SON Self Study Appending I-A.1, 2008).

\section{Study Participants}

At MU SON, seven nursing faculty and administrators were interviewed. Each participant was interviewed for approximately 40 minutes during March 2011. Participants were purposefully selected with the guidance of the Chair of one of the four departments. Faculty were selected from the MU SON main campus and were interviewed at this location. The researcher interviewed the following individuals:

- One Professor and Associate Dean for Graduate Affairs (administrator);

- One Associate Professor and Associate Dean for Undergraduate Academic Affairs (administrator);

- One Associate Professor;

- One Assistant Professor; and

- Three Clinical Instructors.

All seven respondents were female and Caucasian (see Table 3). At the time of the visit, four respondents $(57.1 \%)$ held doctoral degrees and three $(42.9 \%)$ held master's degrees. The nursing faculty had a wide background of specialties including adult medical/surgical, community health, pediatrics, obstetrics/gynecology, and nursing education. One of the seven participants (14.3\%), a Clinical Instructor, had certification as a pediatric nurse practitioner. Another Clinical Instructor (14.3\%) was an International Board Certified Lactation Consultant. One participant (14.3\%), an Associate Professor, was a Board Certified Asthma Educator. The number of years in nursing spanned from 11 years to 50 years. 
The type of appointment varied from nine months to 12-month appointments. Clinical faculty had nine-month appointments while the Assistant Professor, Associate Professors, and Professor had 12-month appointments. The number of years participants taught at a school of nursing ranged from 2.5 years to 50 years. Additionally, the participants taught at MU SON from 2.5 years to 30 years. Out of the seven participants, only two individuals $(28.6 \%)$ had tenure. At MU SON, faculty were employed as tenure track, clinical track, or non-tenure (other) lines. Should faculty wish to later obtain tenure, they can follow promotion procedures through MU SON and Mountain University (MU SON Self Study, 2008, p. 34). 
Table 3

Characteristics of MU SON Interview Respondents

\begin{tabular}{|c|c|c|c|c|c|c|c|}
\hline Participant & Title & $\begin{array}{l}\text { Education } \\
\text { and specialty }\end{array}$ & $\begin{array}{l}\text { Type of } \\
\text { appoint } \\
\text {-ment }\end{array}$ & $\begin{array}{l}\text { Years in } \\
\text { nursing }\end{array}$ & $\begin{array}{l}\text { Years } \\
\text { at } \\
\text { SONs }\end{array}$ & $\begin{array}{l}\text { Years at } \\
\text { current } \\
\text { SON }\end{array}$ & Tenure \\
\hline 1 & $\begin{array}{l}\text { Clinical } \\
\text { Instructor }\end{array}$ & $\begin{array}{l}\text { MSN, PNP } \\
\text { Pediatrics }\end{array}$ & 9 months & 11 & 2.5 & 2.5 & No \\
\hline 2 & $\begin{array}{l}\text { Associate } \\
\text { Professor }\end{array}$ & $\begin{array}{l}\text { PhD } \\
\text { Adult } \\
\text { Medical/ } \\
\text { Surgical }\end{array}$ & $\begin{array}{l}12 \\
\text { months }\end{array}$ & 21 & 17 & 9 & Yes \\
\hline 3 & $\begin{array}{l}\text { Clinical } \\
\text { Instructor }\end{array}$ & $\begin{array}{l}\text { MS } \\
\text { Community } \\
\text { Health }\end{array}$ & 9 months & 34 & 5 & 5 & No \\
\hline 4 & $\begin{array}{l}\text { Assistant } \\
\text { Professor }\end{array}$ & $\begin{array}{l}\text { PhD } \\
\text { Community } \\
\text { Health }\end{array}$ & $\begin{array}{l}12 \\
\text { months }\end{array}$ & 36 & 20 & 4 & No \\
\hline 5 & $\begin{array}{l}\text { Associate } \\
\text { Professor } \\
\text { (admini- } \\
\text { strator) }\end{array}$ & $\begin{array}{l}\text { PhD } \\
\text { Community } \\
\text { Health, } \\
\text { Pediatrics, } \\
\text { Nursing } \\
\text { Education }\end{array}$ & $\begin{array}{l}12 \\
\text { months }\end{array}$ & 39 & 20 & 10 & No \\
\hline 6 & $\begin{array}{l}\text { Clinical } \\
\text { Instructor }\end{array}$ & $\begin{array}{l}\text { MSN } \\
\text { OB/GYN, } \\
\text { IBCLC }\end{array}$ & 9 months & 40 & 27 & 4 & No \\
\hline 7 & $\begin{array}{l}\text { Professor } \\
\text { (admini- } \\
\text { strator) }\end{array}$ & $\begin{array}{l}\text { PhD } \\
\text { Adult } \\
\text { Medical/ } \\
\text { Surgical }\end{array}$ & $\begin{array}{l}12 \\
\text { months }\end{array}$ & 50 & 45 & 30 & Yes \\
\hline
\end{tabular}

The age of participants ranged from 30 years old to 74 years old. Five out of seven faculty $(71.4 \%)$ were 45 years or older (see Table 4$)$. 
Table 4

Age of Participants - MU SON

\begin{tabular}{ccc}
\hline Age & $\mathrm{N}=7$ & Percentage (\%) \\
\hline $30-44$ & 2 & 28.6 \\
\hline $45-59$ & 2 & 28.6 \\
\hline $60-74$ & 3 & 42.8 \\
\hline
\end{tabular}

A wide range of salaries existed for the nursing faculty participants. Three of the individuals (42.9\%) reported salaries of less than $\$ 60,000$ per year. The remaining four participants $(57.1 \%)$ noted salaries of at least $\$ 70,000$ per year. The two administrators interviewed (28.6\%) had salaries of more than $\$ 100,000$ per year (see Table 5).

Table 5

Current Salary of Participants - MU SON

\begin{tabular}{lcc}
\hline \multicolumn{1}{c}{ Salary } & $N=7$ & Percentage $(\%)$ \\
\hline$\$ 40,000$ to $\$ 50,000$ per year & 1 & 14.2 \\
\hline$\$ 50,001$ to $\$ 60,000$ per year & 2 & 28.6 \\
\hline$\$ 60,001$ to $\$ 70,000$ per year & 0 & 0 \\
\hline$\$ 70,001$ to $\$ 80,000$ per year & 2 & 28.6 \\
\hline$\$ 80,001$ to $\$ 90,000$ per year & 0 & 0 \\
\hline$\$ 90,001$ to $\$ 100,000$ per year & 0 & 0 \\
\hline Above $\$ 100,000$ per year & 2 & 28.6 \\
\hline
\end{tabular}

Five out of seven participants (71.4\%) taught both didactic and clinical courses. The remaining two individuals $(28.6 \%)$ only taught didactic courses. The nursing faculty that taught in didactic courses were administrators at MU SON (see Table 6). 
Table 6

Typical Teaching Responsibility - MU SON

\begin{tabular}{cccc}
\hline Participant & Didactic & Clinical & Both \\
\hline 1 & & & $\mathrm{X}$ \\
\hline 2 & & $\mathrm{X}$ \\
\hline 3 & & $\mathrm{X}$ \\
\hline 4 & & $\mathrm{X}$ \\
\hline 5 & $\mathrm{X}$ & \\
\hline 6 & $\mathrm{X}$ & $\mathrm{X}$ \\
\hline 7 & $\mathrm{X}$ & \\
\hline
\end{tabular}

Three nursing faculty (42.8\%) taught at the undergraduate program level. One individual (14.3\%), the Associate Dean for Graduate Affairs, taught at the graduate program level. The remaining three participants (42.9\%) taught at both the undergraduate and graduate levels (see Table 7).

Table 7

Program Level - MU SON

\begin{tabular}{cccc}
\hline Participant & Graduate & Undergraduate & Both \\
\hline 1 & & $\mathrm{X}$ & \\
\hline 2 & & $\mathrm{X}$ \\
\hline 3 & & $\mathrm{X}$ & $\mathrm{X}$ \\
\hline 4 & & & $\mathrm{X}$ \\
\hline 5 & & & \\
\hline 6 & & $\mathrm{X}$ & \\
\hline 7 & $\mathrm{X}$ & & \\
\hline
\end{tabular}

Six of the faculty participants $(85.7 \%)$ spent less than four hours per week in class-based instruction (see Table 8). One individual (14.3\%), a Clinical Instructor, devoted five to nine hours per week in class-based instruction. In on-line instruction, five out of the seven interviewees (71.4\%) invested up to four hours per week. One faculty (14.3\%), a Clinical Instructor, instructed on-line five to nine hours per week. The remaining individual (14.3\%), a Professor and Associate Dean for Graduate Affairs, spent 15 to 19 hours per week in on-line 
instruction. As to clinical instruction, two participants (28.6\%) instructed up to four hours per week. Three faculty (42.8\%) facilitated five to nine hours per week of clinical instruction. The remaining two participants (28.6\%) provided 10 to 14 hours per week in clinical instruction. Four faculty (57.1\%) spent up to four hours per week in required office hours. One faculty (14.3\%), a Clinical Instructor, invested 10 to 14 hours per week in required office hours. Another faculty member (14.3\%), a Clinical Instructor, had 15 to 19 hours per week of required office hours. The final individual (14.3\%), the Associate Dean for Undergraduate Academic Affairs, had 40 to 44 hours per week of required office hours. At home, one faculty member (14.3\%), the Associate Dean for Graduate Affairs, spent less than four hours per week in facultyrelated duties. Two participants (28.6\%) spent five to nine hours per week at home in facultyrelated duties. Another two interviewees (28.6\%) invested 10 to 14 hours per week at home. One out of the seven individuals (14.3\%) interviewed, a Clinical Instructor, devoted 20 to 24 hours per week at home working on her university nursing responsibilities. The final faculty member (14.3\%), a Clinical Instructor, spent over 30 hours per week at home for duties related to her position.

Table 8

Hours Per Week Spent in Instruction, Office Hours, and At Home - MU SON

\begin{tabular}{lllllllll}
\hline \multicolumn{1}{c}{ Number of hours per week } \\
N=7 (\%)
\end{tabular}


Four out of seven individuals interviewed (57.1\%) taught one course per semester (see Table 9). The remaining three nursing faculty (42.9\%) taught two courses per semester. The course credits ranged from one credit per semester to nine credits per semester. Three participants $(42.8 \%)$ did not teach any clinicals. Three out of the seven nursing faculty $(42.8 \%)$ facilitated one clinical course per semester. The final individual (14.3\%), a Clinical Instructor, taught two clinicals per semester. Of those who taught clinicals each semester, the number of clinical credits varied from two clinical credits to five clinical credits.

Table 9

Number of Courses, Clinicals, and Credits Per Semester - MU SON

\begin{tabular}{ccccc}
\hline Participant & $\begin{array}{c}\text { Number of } \\
\text { courses }\end{array}$ & $\begin{array}{c}\text { Number of course } \\
\text { credits }\end{array}$ & $\begin{array}{c}\text { Number of } \\
\text { clinicals }\end{array}$ & $\begin{array}{c}\text { Number of clinical } \\
\text { credits }\end{array}$ \\
\hline 1 & 1 & 2 & 1 & 2 \\
\hline 2 & 2 & 8 & 0 & 0 \\
\hline 3 & 2 & 8 & 1 & 5 \\
\hline 4 & 2 & 6 & 1 & 5 \\
\hline 5 & 1 & 1 & 0 & 0 \\
\hline 6 & 1 & 4 & 2 & 4 \\
\hline 7 & 1 & 9 & 0 & 0 \\
\hline
\end{tabular}

The four faculty participants $(57.1 \%)$ who taught in the clinical area have differing student-to-faculty ratios. One individual (14.3\%), a Clinical Instructor, had a six to one ratio while two nursing faculty $(28.6 \%)$ had a seven to one student-to-faculty ratio. The final participant (14.3\%) teaching in the clinical area, a Clinical Instructor, had a student-to-faculty ratio of fourteen to one (see Table 10).

Six of the seven nursing faculty $(85.7 \%)$ served as advisors for nursing students (see Table 10). The number of advisees ranged from six to ten students. Additionally, all seven faculty served on nursing program and university committees, which vary in number from two committees to 12 committees. 
Table 10

Clinicals, Advisees, and Committees Per Year - MU SON

\begin{tabular}{cccc}
\hline Participant & $\begin{array}{c}\text { Student-faculty ratio in } \\
\text { clinicals }\end{array}$ & Number of advisees & Number of committees \\
\hline 1 & $6: 1$ & 9 & 2 \\
\hline 2 & -- & 8 & 4 \\
\hline 3 & $14: 1$ & 7 & 8 \\
\hline & $7: 1$ & 6 & 5 \\
\hline 5 & -- & 0 & 12 \\
\hline 6 & $7: 1$ & 7 & 3 \\
\hline 7 & -- & 10 & 10 \\
\hline
\end{tabular}

Of the seven interviewees, five (71.4\%) were currently revising or creating a course.

Course subjects involved didactic and clinical areas in community health, maternal-child health, the RN-to-BSN curriculum, sophomore nursing curriculum, master's nursing education, and

Ph.D. theory (see Table 11).

Table 11

Revising or Creating a Course Per Year - MU SON

\begin{tabular}{cll}
\hline Participant & $\begin{array}{l}\text { Revising or } \\
\text { creating a } \\
\text { course? }\end{array}$ & \multicolumn{1}{c}{ Course area } \\
\hline 1 & No & \\
\hline 2 & No & Community Health \\
\hline 3 & Yes & $\begin{array}{l}\text { Community Health } \\
\text { Clinical }\end{array}$ \\
\hline 4 & Yes & $\begin{array}{l}\text { Master's Nursing } \\
\text { Education, RN to BSN } \\
\text { Curriculum, Sophomore } \\
\text { Nursing Curriculum }\end{array}$ \\
\hline 5 & Yes & $\begin{array}{l}\text { Maternal-Child Health } \\
\text { Concepts }\end{array}$ \\
\hline 6 & Yes & PhD Theory \\
\hline 7 & Yes & \\
\hline
\end{tabular}


Three of the seven faculty members $(42.9 \%)$ spent 41 to 50 hours per week completing duties as nursing faculty. The remaining four individuals (57.1\%) reported 51 to 60 hours per week utilized in completing duties as nursing faculty (see Table 12).

Table 12

Hours Per Week Spent Completing Duties - MU SON

\begin{tabular}{lcc}
$\begin{array}{l}\text { Hours per week spent } \\
\text { completing duties as nursing } \\
\text { faculty }\end{array}$ & $\mathrm{N}=7$ & Percentage (\%) \\
40 hours/week & 0 & 0 \\
\hline $41-50$ hours/week & 3 & 42.9 \\
\hline $51-60$ hours/week & 4 & 57.1 \\
\hline $61-70$ hours/week & 0 & 0 \\
\hline $70+$ hours/week & 0 & 0 \\
\hline
\end{tabular}

Six out of seven faculty members $(85.7 \%)$ conducted research. One individual $(14.3 \%)$, an Associate Professor, reported that she was involved in research to a great extent while three participants (42.9\%) reported doing research to some extent. One faculty (14.3\%) reported doing very little research. The final participant (14.3\%), a Clinical Instructor, stated she did no research (see Table 13).

Table 13

Involvement in Research - MU SON

\begin{tabular}{lcc}
\hline $\begin{array}{l}\text { Involvement in } \\
\text { research }\end{array}$ & $\mathrm{N}=7$ & Percentage $(\%)$ \\
\hline To a great extent & 1 & 14.3 \\
\hline To some extent & 3 & 42.8 \\
\hline Very little & 2 & 28.6 \\
\hline Not involved & 1 & 14.3 \\
\hline
\end{tabular}

Four of the seven interviewees $(57.1 \%)$ published in the past three years. The number of publications ranged from one to five publications in the last three years (see Table 14). 
Table 14

Number of Publications in the Past Three Years - MU SON

\begin{tabular}{ccc}
\hline Participant & Published in the past three (3) years? & Number of publications \\
\hline 1 & No & 5 \\
\hline 2 & Yes & \\
\hline 3 & No & 2 \\
\hline 4 & Yes & 1 \\
\hline 5 & Yes & 5 \\
\hline 7 & No & 5 \\
\hline
\end{tabular}

All seven nursing faculty anticipated remaining in their current role as nursing faculty for the next three years.

Only two of the seven participants (28.6\%) interviewed believed they were appropriately compensated at MU SON for their credentials. The remaining five participants $(71.4 \%)$ indicated that they were not fully compensated. Faculty reported the main reason listed for their beliefs included low salary as compared to nurses in clinical areas, lack of resources at MU SON, and lack of administrative support for increased salaries (see Table 15).

Table 15

Faculty Beliefs of Full Compensation for Credentials and Reasons - MU SON

\begin{tabular}{cll}
\hline $\begin{array}{c}\text { Participant } \\
1\end{array}$ & Fully compensated? & \multicolumn{1}{c}{ Reason(s) } \\
\hline 2 & No & $\begin{array}{l}\text { Low salary, would make more as } \\
\text { a staff nurse without advanced } \\
\text { degrees }\end{array}$ \\
\hline 3 & Yes & Salary "pathetic" \\
\hline 4 & No & $\begin{array}{l}\text { Low faculty salary as compared } \\
\text { to clinical nurse salary }\end{array}$ \\
\hline 5 & No & $\begin{array}{l}\text { Lack of resources from } \\
\text { university, dean not effective as } \\
\text { advocate for faculty salaries }\end{array}$ \\
\hline 6 & No & $\begin{array}{l}\text { Low salary, would make more as } \\
\text { hospital nurse }\end{array}$ \\
\hline 7 & Yes & \\
\hline
\end{tabular}


Six of seven nursing faculty $(85.7 \%)$ were satisfied in their current roles. One individual (14.3\%), an Assistant Professor, indicated that she was not satisfied in her current role. The reason for this feeling focused upon multiplicity of time demands (see Table 16).

Table 16

Satisfaction in Current Role and Reasons - MU SON

\begin{tabular}{ccc}
\hline Participant & $\begin{array}{c}\text { Satisfied in } \\
\text { current role? }\end{array}$ & Reason(s) \\
\hline 1 & Yes & \\
\hline 2 & Yes & \\
\hline 3 & Yes & \\
\hline 4 & No & Multiplicity of time demands \\
\hline 5 & Yes & \\
\hline 6 & Yes & \\
\hline 7 & Yes & \\
\hline
\end{tabular}

\section{Responses to Interview Protocol}

Two administrators were interviewed through a separate interview protocol (see Appendix B-1) and their responses are analyzed and reported below. Five nursing faculty were interviewed with a different interview protocol (see Appendix B-2) and their responses are examined. Common questions for faculty and administrators are reported under the appropriate research question.

Setting the context: Reasons to teach nursing - Administrator and faculty responses.

At MU SON, five nursing faculty of varying ranks were interviewed. They were first asked to explain why they taught nursing at MU SON. Responses varied among faculty members. Three individuals (60\%) explained that they chose to teach at MU SON in order to collaborate with other faculty. Two participants (40\%) noted that teaching at MU SON would afford them additional research opportunities. One Clinical Instructor (20\%) stated that her 
family moved to the area and another Clinical Instructor (20\%) mentioned that she was a recent graduate of MU SON (see Table 17).

Table 17

Reasons for Teaching at MU SON

$\begin{array}{lcc}\begin{array}{l}\text { Interview response: Reasons } \\ \text { for teaching at }\end{array} & \text { Number of responses } & \begin{array}{c}\text { Percentage (\%) based upon } \\ \text { number of respondents } \\ \text { MU SON }=5\end{array} \\ \begin{array}{l}\text { Collaboration with other } \\ \text { faculty }\end{array} & 3 & 60 \\ \text { Carry out research goals } & 2 & 40 \\ \text { Moved to area } & 1 & 20 \\ \text { Recent graduate } & 1 & 20\end{array}$

Administrators and faculty were asked the reasons they and other faculty remained at MU SON. The culture of the school of nursing was a major reason that faculty remained. For example, all administrator and faculty individuals $(n=7)$ agreed that their fellow faculty members were extremely supportive and helpful. Five of the seven interviewees (71.4\%) stressed the autonomy and flexibility provided to faculty members. Four participants $(57.1 \%)$ stated that MU SON was a very collegial environment which influenced their decision to remain. Passion for teaching was cited by three of the seven nursing faculty (42.9\%). Similarly, two individuals (28.6\%) explained that the team effort at MU SON was an impetus for faculty to remain. Finally, a Professor and Associate Dean for Graduate Affairs (14.3\%) noted that she remained as faculty to inspire students (see Table 18). 
Table 18

Reasons for Remaining as Nursing Faculty - MU SON

\begin{tabular}{lcc}
\hline $\begin{array}{l}\text { Interview response: Reasons } \\
\text { for remaining as nursing } \\
\text { faculty }\end{array}$ & Number of responses & $\begin{array}{c}\text { Percentage (\%) based upon } \\
\text { number of respondents } \\
\mathrm{N}=7\end{array}$ \\
\hline Supportive faculty & 7 & 100 \\
\hline Autonomy and flexibility & 5 & 71.4 \\
\hline Collegial environment & 4 & 57.1 \\
\hline Passion for teaching & 3 & 42.9 \\
\hline Team effort & 2 & 28.6 \\
\hline Inspire students & 1 & 14.3 \\
\hline
\end{tabular}

\section{Research question 1: Enrollment management - Administrator responses.}

Research question one pertains to identifying recent strategies schools of nursing implemented to address recruitment and retention of nursing faculty. Connected to this focus is also gaining a better understanding of the enrollment management plan since student recruitment is tied to the availability of nursing faculty and the availability of resources such as clinical placements.

At MU SON, two nursing faculty administrators were interviewed. Administrators were asked whether MU SON has an enrollment management program and, if so, to describe its components. The Associate Dean for Undergraduate Academic Affairs explained that there is no written enrollment management program, but that enrollment is evaluated each year dependent upon number of student applications, number of faculty, and availability of clinical sites. She stated the goal is to admit as many students as possible and if there is not a sufficient number of full-time faculty, then additional faculty are hired. However, the main difficulty in admitting students was clinical placements for specialty areas. She explained, "Our problem comes with the specialty areas. OB, pediatrics, and pysch are the things that really limit how many we can 
take because there is limited capability of our units here. We admit the students and then we find the faculty if we need to.”

Similarly, in MU SON's graduate programs, the Associate Dean for Graduate Affairs explained that student enrollment is also limited by the number of available faculty. She noted that under certain specialties, the certifying agencies only allow a six to one student-to-faculty ratio. However, in specialties such as neonatal nurse practitioner, women's health nurse practitioner, geriatric nurse practitioner, and pediatric nurse practitioner, there are very few students who apply. She described this challenge:

I keep telling the dean we have to do something about it and she says we have to recruit more. We have a HRSA [Health Resources Services Agency] Grant for the past three years, but that's all they've done and we still don't have enough. So, a lot of schools are closing those programs. I don't know how much longer we can keep the programs with only one or two students. Those students in pediatrics and in neonatal and in geriatrics only have one teacher for practical courses. That's not a good educational environment to just have one teacher.

The undergraduate administrator explained that MU SON receives three times as many applications compared with available spaces. For instance, in the past year, the school had 60 direct freshman admissions, which left only 68 spaces for the remaining 240 applicants. Therefore, MU SON turned away approximately 70 percent of qualified undergraduate applicants. In response, the school has increased its direct admission criteria to a $3.6 \mathrm{GPA}$ to be competitive with other applicants. In the BA/BS to BSN program, the Associate Dean for Undergraduate Academic Affairs noted: 
It's getting more competitive. We had about 90 qualified applicants for 30 slots this year. In the past it hasn't been as competitive, but it's really catching on. A lot of the students that can't be admitted to the basic BSN program go on to get another degree and then try to get into the second-degree program. So it's that backlog that's occurring, that's getting more competitive. We've also gotten some really good scholarships too for that, for that so it's really attracting more people from other places too. Approximately 30 percent of that second degree applicant pool were from out of state. That's always been the case since I've been here in the basic program. I mean we have 30 to 40 percent of the students here are out of state students. That's kind of the way the University is trending too.

She further explained that final decisions to accept students are based upon overall GPA, motivation to become a nurse, and through a two-person faculty interview process with the applicant. Additionally, she noted that in Fall 2011, MU SON was removing the interview from the admissions process due to its subjectivity and length of time for faculty to interview. Finally, she stated that MU SON is seeking to increase the diversity of students and its admission pool. In the graduate programs, qualified students are not turned away. However, according to the Associate Dean for Graduate Affairs, there have been limitations in clinical placements due to the high number of students in certain programs, such as family nurse practitioner. This year, she explained, there were 70 applicants for the master's program, of which 45 students were qualified and submitted complete applications.

The administrators were then asked about limitations to increasing student admissions (see Table 19). Both administrators discussed the lack of resources for clinical placements and the need for additional faculty lines. The Associate Dean for Undergraduate Academic Affairs 
$(50 \%)$ noted that while MU SON is placing more emphasis on the graduate program due to higher tuition, the school is "holding the line on how much we can give in faculty salaries." She further commented that "as the resources are being directed towards the graduate programs, they're, from my perspective, being stripped away from the undergraduate program so that we really can't take anymore students then we already have.” After further probing about limitations, she explained that she does not foresee any change in faculty salaries in the near future based upon the current economy.

Table 19

Limitations to Increasing Student Admissions - MU SON

\begin{tabular}{lcc}
$\begin{array}{l}\text { Interview response: } \\
\text { Limitations to increasing } \\
\text { student admissions }\end{array}$ & Number of responses & $\begin{array}{c}\text { Percentage (\%) based upon } \\
\text { number of respondents } \\
\mathrm{N}=2\end{array}$ \\
\hline $\begin{array}{l}\text { Lack of resources for clinical } \\
\text { placements }\end{array}$ & $\mathrm{N}=2$ & 100 \\
Lack of faculty lines & 2 & 100 \\
Limited faculty salaries & 2 & 50
\end{tabular}

\section{Research question 1: Recruitment and retention of nursing faculty - Administrator responses.}

Administrators were asked how MU SON recruits nursing faculty and the challenges in recruiting them. MU SON has three separate faculty tracks: clinical faculty, non-tenure teaching, and tenure teaching. The Associate Dean for Undergraduate Academic Affairs described that the approach to recruiting differs based upon which track is needed at the school. For the clinical and non-tenure teaching tracks, she $(50 \%)$ noted that recruitment was primarily by word of mouth. As to the tenure teaching track, both administrators mentioned advertisements on websites, in journals and newspapers, and at conferences. Additionally, the Associate Dean for Graduate Affairs (50\%) explained that new faculty apply if a spouse moves to teach at Mountain University or is employed in the area. Finally, the Associate Dean for Undergraduate Academic 
Affairs (50\%) stated that new faculty are hired from MU SON's graduate programs (see Table 20).

Table 20

Recruitment Strategies - MU SON

\begin{tabular}{lcc}
$\begin{array}{l}\text { Interview response: } \\
\text { Recruitment strategies }\end{array}$ & $\begin{array}{c}\text { Number of responses } \\
\mathrm{N}=2\end{array}$ & $\begin{array}{c}\text { Percentage (\%) based upon } \\
\text { number of respondents } \\
\mathrm{N}=2\end{array}$ \\
\hline Advertisement on website & 2 & 100 \\
\hline $\begin{array}{l}\text { Advertisement in journals and } \\
\text { newspapers }\end{array}$ & 2 & 100 \\
Advertisement at conferences & 2 & 100 \\
\hline Word of mouth & 1 & 50 \\
Moved to area with family & 1 & 50 \\
\hline MU SON graduates & 1 & 50
\end{tabular}

One of the benefits to working at MU SON, according to the Associate Dean for Undergraduate Academic Affairs, is that faculty who are nurse practitioners can continue their clinical practice while they teach at the school. She stated that faculty contracts provide different practice percentages for these individuals, whether in clinical practice, research, or teaching.

Both administrators also mentioned various challenges to recruitment of nursing faculty. The Associate Dean for Graduate Affairs (50\%) remarked that potential faculty "have to have a reason to come here," whether it is a family move with a spouse receiving a job in the area, caring for elderly parents, or being a former graduate. The Associate Dean for Undergraduate Academic Affairs (50\%) explained that recruitment of nursing faculty in specialty areas is difficult because there were less numbers of faculty in these areas. Table 21 shows these challenges. 
Table 21

Recruitment Challenges - MU SON

\begin{tabular}{lcc}
$\begin{array}{l}\text { Interview response: } \\
\text { Recruitment challenges }\end{array}$ & Number of responses & $\begin{array}{l}\text { Percentage (\%) based upon } \\
\text { number of respondents } \\
\mathrm{N}=2\end{array}$ \\
$\begin{array}{l}\text { Purposeful reason to come to } \\
\text { MU SON }\end{array}$ & 1 & 50 \\
\hline Lack of specialties & 1 & 50
\end{tabular}

Both administrators observed that MU SON currently has multiple nursing faculty vacancies. According to MU SON's website, the following positions are needed:

- Associate Dean for Research;

- Full-time tenure track research faculty (multiple);

- Full-time and part-time medical/surgical nursing faculty (multiple);

- Full-time and part-time pediatric nursing faculty (multiple);

- Full-time and part-time OB nursing faculty (multiple);

- Full-time and part-time clinical track faculty (multiple); and

- Part-time psychiatric/mental health clinical faculty (MU SON Website, 2011).

The Associate Dean for Undergraduate Academic Affairs explained that MU SON has been searching for an Associate Dean for Research for over two years without any accepted offers.

\section{Research question 2: Effective strategies to recruit and retain nursing faculty. Designing courses: Faculty perceptions.}

Research question two examines the effective strategies to recruit and retain nursing faculty. Giving faculty autonomy to design courses is a facet of this research question as well. Nursing faculty were asked if they have freedom in designing and conducting their own courses. All faculty (100\%) explained that they must keep the same course objectives and must follow the 
curriculum, but are given flexibility in designing and conducting their courses. A Clinical Instructor stated,

There are certain things, our syllabus, between the different campuses that have to be the same. They want us to cover the basics and same topics, but we have complete freedom as to how we do that and can change the order of the schedule and incorporating the major topics of course we have to cover, but at least I feel like I have complete freedom to do whatever I want.

Furthermore, a Clinical Instructor observed that “everybody's really flexible and easy to get along with." The five nursing faculty (100\%) also noted that they use a template syllabus, but are allowed to change learning activities, the schedule, and are able to adjust the course (see Table 22). Additionally, all faculty (100\%) explained that course content must be kept current and any textbook change must go through the nursing curriculum committee for approval.

\section{Table 22}

Freedom in Designing and Conducting Courses - MU SON

\begin{tabular}{lcc}
$\begin{array}{l}\text { Interview response: Freedom } \\
\text { in designing and conducting } \\
\text { courses }\end{array}$ & Number of responses & $\begin{array}{c}\text { Percentage (\%) based upon } \\
\text { number of respondents } \\
\mathrm{N}=5\end{array}$ \\
\hline Academic freedom & 5 & 100 \\
\hline Template syllabus & 5 & 100 \\
Flexibility & 5 & 100 \\
Textbook approval & 5 & 100 \\
Current content & 5 & 100
\end{tabular}

\section{Tenure requirements: Administrator and faculty perceptions.}

Both administrators and faculty were asked about the requirements needed to obtain tenure at MU SON and, if they had tenure, whether it was difficult to obtain. MU SON uses a Faculty Retention and Ten-Year Promotion (FRTP) committee to determine tenure. The FRTP requires publications, a doctorate, external funding for grant money, good teaching evaluations, 
performance of research, service on committees, and service to the community. If faculty were on MU SON's tenure-track, their contract was divided into three parts: teaching, research, and service. The Chair of one of the four departments evaluated faculty for tenure based on the FRTP. Additionally, faculty must have either "excellent" or "good" ratings in all categories to be considered for tenure. Currently, faculty were given time to accomplish the three areas stated in their contracts.

However, due to teaching and grading demands, it was difficult for some faculty to meet the FRTP. As one Assistant Professor explained, "The assistant professor role, that's made for younger women. I'm not willing to put forward 120 hours worth of effort to do tenure. I'll be 61 in my tenure year. How many more years do I have to work?" Moreover, faculty did not have research support because the Assistant Dean for Research position was vacant for over two years.

\section{Research question 3: Collaboration with external stakeholders - Administrator perceptions.}

Administrators were asked about external partners. Both noted partnerships with local hospitals, clinics, health and community centers, and the County Health Department. Moreover, both administrators noted that nurses were used as preceptors and that MU SON collaborated with Mountain University's School of Medicine (SOM) and the local health system (see Table 23). In addition, the Associate Dean for Undergraduate Academic Affairs explained that the University's hospital provides support for two to three faculty salaries, but will be decreasing this support due to financial constraints. Moreover, some clinic partnerships are in jeopardy as various clinics have lost state funding, federal funding, or both. Additionally, both administrators stated that preceptors are unpaid by MU SON and "are a huge resource." 
Table 23

External Partnerships - MU SON

\begin{tabular}{lcc}
$\begin{array}{l}\text { Interview response: External } \\
\text { partnerships }\end{array}$ & Number of responses & $\begin{array}{c}\text { Percentage (\%) based upon } \\
\text { number of respondents } \\
\text { N=2 }\end{array}$ \\
Local hospitals & 2 & 100 \\
\hline Clinics & 2 & 100 \\
\hline Health and community centers & 2 & 100 \\
County health department & 2 & 100 \\
\hline Nurses as preceptors & 2 & 100 \\
$\begin{array}{l}\text { Collaboration between MU } \\
\text { SON, MU SOM, and health } \\
\text { system }\end{array}$ & & 100 \\
\hline
\end{tabular}

\section{Distance education and simulation lab: Administrator and faculty perceptions.}

Both administrator and faculty participants were questioned about whether distance education has been implemented at MU SON. All seven interviewees answered that distance education was offered. The participants explained that distance education is utilized in all programs except in the undergraduate program. Primarily, the faculty taught synchronous online courses and in real time, in which faculty and students talked to each other, but did not view each other. In the RN to BSN, MSN, DNP, and PhD programs, all didactic courses were on-line and clinical practicums set up in the community in which the student was located. The nursing faculty believed that on-line students needed to be supported in additional ways because of student withdrawals from on-line programs. A Professor and Associate Dean for Undergraduate Academic Affairs explained, "I think some work needs to be done with the kinds of support students need within those programs to be able to be successful and stay in, you know, and keep going, because they don't have the cheerleaders like they have with the face-to-face kind of interaction." All faculty (100\%) agreed that distance education increased student admissions and it "does open doors to people that otherwise would be closed." 
MU SON had a simulation lab and it was recently updated at the beginning of 2010 , according to all faculty. It was shared with the School of Medicine at Mountain University. The nursing curriculum will change in Fall 2011 at MU SON and the simulation lab will be used for the first time with the sophomore class for health assessment. Therefore, the simulation lab will act as a substitute for clinical days for beginning students due to a lack of clinical sites. All interviewees agreed that the simulation lab had not impacted student admissions, but it was a benefit for specialties such as OB, pediatrics, and ICU/critical care, because faculty set up various scenarios for the students' practice. For instance, due to a decrease in births at hospitals and birthing centers, students had little opportunity to attend a live birth. However, with the simulation lab, students were able to observe a simulated birth. Additionally, all respondents stated that the simulation lab assisted in preparing students for clinicals. One Associate Professor explained that "it helps the students feel more confident before they go in and take care of a real patient."

\section{Research question 4: Lack of recruitment and retention.}

Faculty perceptions of the university working conditions are examined since these conditions can affect recruitment and retention of nursing faculty. In addition, a lack of recruitment and retention can affect faculty persistence.

\section{Working conditions: Faculty responses.}

Nursing faculty were asked about working conditions at MU SON. All five interviewees $(100 \%)$ expressed the belief that faculty salaries were too low. An Associate Professor even stated, "I think the salaries suck compared to the rest of the world. We're in the $10^{\text {th }}, 20^{\text {th }}$ percentile for pay compared to other nursing faculty." All five nursing faculty $(100 \%)$ also 
appreciated the flexibility that they were provided. Three participants (60\%) explained that they enjoyed the collegial and friendly atmosphere of MU SON.

However, faculty did have some issues. Two individuals (40\%) noted that they work more than 40 hours per week. One Assistant Professor (20\%) explained that working conditions are "not perfect," and an Associate Professor (20\%) observed that MU SON did not support research (see Table 24).

Table 24

Working Conditions at MU SON

\begin{tabular}{lcc}
$\begin{array}{l}\text { Interview response: Working } \\
\text { conditions at } \\
\text { MU SON }\end{array}$ & Number of responses & $\begin{array}{c}\text { Percentage (\%) based upon } \\
\text { number of respondents } \\
\mathrm{N}=5\end{array}$ \\
Low salaries & $\mathrm{N}=5$ & 100 \\
\hline Flexible schedule & 5 & 100 \\
Collegial environment & 5 & 60 \\
Work more than 40 & 3 & 40 \\
hours/week & 2 & 20 \\
"Not perfect" & 1 & 20 \\
\hline Research not supported & 1 &
\end{tabular}

\section{Lack of recruitment and retention of nursing faculty: Administrator and faculty perceptions.}

Six of the interviewees $(85.7 \%)$ felt that recruitment and retention was negatively impacted by low salaries offered by MU SON. Four faculty (57.1\%) explained that lack of assistance in grant writing impacted recruitment and retention of nursing faculty. In addition, three respondents (42.9\%) noted the lack of research faculty and support and the rural location of MU SON detrimentally impacted its recruitment and retention efforts. Three individuals (42.9\%) also explained that new faculty needed a focused mentoring program in order to increase retention rates (see Table 25). 
Table 25

Reasons Impacting Recruitment and Retention - MU SON

\begin{tabular}{lcc}
$\begin{array}{l}\text { Interview response: Reasons } \\
\text { impacting recruitment and } \\
\text { retention }\end{array}$ & Number of responses & $\begin{array}{c}\text { Percentage (\%) based upon } \\
\text { number of respondents } \\
\text { N=7 }\end{array}$ \\
$\begin{array}{l}\text { Low salary } \\
\begin{array}{l}\text { Lack of assistance in grant } \\
\text { writing }\end{array}\end{array}$ & 6 & 85.7 \\
\hline Lack of research faculty & 4 & 57.1 \\
\hline Rural location of MU SON & 3 & 42.9 \\
\hline Need for mentorship program & 3 & 42.9 \\
\hline
\end{tabular}

The interviewees were questioned about the reasons nursing faculty leave their positions at MU SON. Six out of seven respondents (85.7\%) explained that low salaries were the primary motivator for why faculty leave MU SON. One Associate Professor observed, "I think the main reason is they can make more money in clinical practice. I think that's the main reason." Coupled with salary, according to four interviewees (57.1\%), was increased workload. One Assistant Professor explained, "I think they sometimes think that nursing education is going to be easy. They are able to go into nursing education, but then when they get here and they look at the salary difference and they look at the work related to the salary, they move. They go elsewhere." Additionally, three faculty (42.9\%) noted that faculty often leave to set up independent clinical practices. Another response provided by three participants $(42.9 \%)$ was that faculty leave MU SON if their families left the area. Moreover, two faculty $(28.6 \%)$ mentioned that faculty left due to a weak research infrastructure. Retirement of faculty was also noted by two participants $(28.6 \%)$. Two interviewees $(28.6 \%)$ explained that the pressure of tenure can cause faculty to leave MU SON. Finally, an Assistant Professor (14.3\%) observed that faculty with unreasonable expectations for their position left the school (see Table 26). 
Table 26

Reasons Nursing Faculty Leave MU SON

\begin{tabular}{lcc}
$\begin{array}{l}\text { Interview response: Reasons } \\
\text { nursing faculty leave MU } \\
\text { SON }\end{array}$ & Number of responses & $\begin{array}{c}\text { Percentage (\%) based upon } \\
\text { number of respondents } \\
\text { N=7 }\end{array}$ \\
\hline Low salary & 6 & 85.7 \\
\hline Increased workload & 4 & 57.1 \\
\hline Independent practice & 3 & 42.9 \\
\hline Family relocation & 3 & 42.9 \\
\hline Weak research infrastructure & 2 & 28.6 \\
\hline Retirement & 2 & 28.6 \\
\hline Pressure of tenure & 2 & 28.6 \\
\hline Unreasonable expectations & 1 & 14.3 \\
\hline
\end{tabular}

\section{Strategies to increase nursing faculty in the profession: Administrator and faculty perceptions.}

All participants were asked what strategies would be helpful to increase the number of nursing faculty in the profession. Six of the seven individuals $(85.7 \%)$ explained that increased salaries would assist in recruiting nursing faculty. As a Professor and Associate Dean for Undergraduate Academic Affairs explained,

Higher salaries would be the number one thing because, you know, the reason people don't go into teaching, I think in large part is because of the salary issue and I know that the University doesn't see the need to increase salaries. They have increased salaries in business. The School of Medicine obviously has increased salaries. So does engineering. But it hasn't transferred to nursing.

Three respondents (42.9\%) noted that tuition reimbursement would be effective. Continuing education was also suggested by three individuals (42.9\%), as was autonomy and flexibility. Two of the seven participants $(28.6 \%)$ explained that mentoring was needed to increase recruitment efforts. Finally, one Professor and Associate Dean for Graduate Affairs (14.3\%) suggested continuous education without any breaks to the doctorate (see Table 27). 
Table 27

Strategies to Recruit Nursing Faculty in the Profession - MU SON

\begin{tabular}{lcc}
\hline $\begin{array}{l}\text { Interview response: Strategies } \\
\text { to recruit nursing faculty in } \\
\text { the profession }\end{array}$ & Number of responses & $\begin{array}{c}\text { Percentage (\%) based upon } \\
\text { number of respondents } \\
\mathrm{N}=7\end{array}$ \\
\hline Higher salaries & 6 & 85.7 \\
\hline Tuition reimbursement & 3 & 42.9 \\
\hline Continuing education & 3 & 42.9 \\
\hline Autonomy and flexibility & 3 & 42.9 \\
\hline Mentorship & 2 & 28.6 \\
\hline Continuous education & 1 & 14.3 \\
\hline
\end{tabular}

Finally, the seven participants were questioned as to what should be done to retain nursing faculty in education. Six of the seven nursing faculty and administrators $(85.7 \%)$ said that increased salaries would positively impact retention of nursing faculty. Four individuals $(57.1 \%)$ noted that recognition and support would be beneficial. Two nursing faculty $(28.6 \%)$ explained that tuition reimbursement would be effective. Moreover, increasing technical competence was suggested by two individuals (28.6\%). Another two participants $(28.6 \%)$ explained that equality of rewards between genders and professions would assist in retaining nursing faculty. An excellent statement was provided by a Professor and Associate Dean for Undergraduate Academic Affairs, "I understand that practice brings in money. Research brings in money. Education doesn't bring in money, but it's our core reason for being here" (see Table 28). 
Table 28

Strategies to Retain Nursing Faculty in the Profession - MU SON

\begin{tabular}{lcc}
\hline $\begin{array}{l}\text { Interview response: Helpful } \\
\text { strategies to retain nursing } \\
\text { faculty in the profession }\end{array}$ & Number of responses & $\begin{array}{c}\text { Percentage (\%) based upon } \\
\text { number of respondents } \\
\mathrm{N}=7\end{array}$ \\
\hline Increase salaries & $\mathrm{N}=7$ & 85.7 \\
\hline Recognition & 4 & 57.1 \\
\hline Support & 4 & 57.1 \\
\hline Tuition reimbursement & 2 & 28.6 \\
\hline Increased technical competence & 2 & 28.6 \\
\hline Equality of rewards & 2 & 28.6 \\
\hline
\end{tabular}

\section{Summary of Findings}

Data were collected from interviews with two administrators and five nursing faculty at MU SON. The first research question was addressed by participants' descriptions of recent strategies MU SON had implemented to address recruitment and retention of nursing faculty. The administrators explained that many approaches were used to recruit new faculty, including advertisements, word of mouth, and the hiring of recent MU SON graduates. However, the respondents agreed that due to the low salaries offered by MU SON coupled with its rural location, recruitment was difficult unless nursing faculty had a purposeful reason behind seeking a job with the school. Additionally, the administrators noted that recruitment was also negatively affected by a lack of available faculty in certain specialties. This evidence was supported by MU SON's website which showed a significant number of positions that the school needed to fill.

For the second research question, interviewees were queried about what strategies were effective for recruitment and retention at MU SON. Faculty expressed the belief that autonomy and flexibility in creating and conducting their courses was a significant motivator. Moreover, the participants explained that the positive culture of the MU SON environment was a major contributor. The process of obtaining tenure was also addressed by the administrators and 
nursing faculty. Many agreed that the process to obtain tenure was difficult. The requirements often involved much more effort in certain areas, such as research. Older faculty were unwilling to conduct research because there was limited guidance available at MU SON to help develop research agendas.

The third research question involved what external stakeholders collaborated with the nursing faculty. All respondents agreed that hospital, clinics, health and community centers, and county health departments were key to their clinical placements. In fact, according to some participants, the University's hospital contributed to some clinical faculty salaries, which was of great benefit to the school. However, many faculty noted that due to decreases in state and federal funding, many clinic partnerships were ending. As a result, MU SON needed to increase the use of its simulation lab to include not only upperclassmen, but sophomore nursing students in order to introduce the students to different nursing situations. Nursing education was also expanding on-line programs, with all degrees except for the undergraduate program.

Finally, the fourth research question focused on the reasons behind the lack of recruitment and retention of nursing faculty within schools of nursing. The overwhelming response by the participants indicated that the low salary for nursing faculty was the primary contributor in recruitment and retention issues. While salaries in other fields have increased in recent years, according to the interviewees, nursing faculty salaries have not changed. Additionally, the administrators and faculty pointed to increased workloads, lack of mentorship, unsupported research, unavailable support, and the need for recognition as impacting nursing faculty recruitment and retention. The interviewees noted that recruitment and retention efforts would be positively impacted by higher salaries, tuition reimbursement, increased recognition, and administrative support. 


\section{Chapter Five: Central University School of Nursing}

\section{Institutional Background}

The Carnegie Foundation (2005) classifies Central University as a comprehensive public doctoral institution. The university is located in a metropolitan city in the Central region of the United States. While its origins began in the nineteenth century, Central University is a composite of two different universities operating in the same state. This joinder was created in 1968, in which the partnership between the two universities was formed. Central University, home to over 30,000 students throughout its many campuses, considers itself "a leader in fostering collaborative relationships" and is the academic and health sciences arm of the larger university system (Central University Statement of Values, 2011).

Enrollment in Fall 2009 at Central University was unprecedented, with 30,383 individuals enrolled at its various campuses. While 89 percent of the student body is in-state, the university has a healthy out-of-state enrollment of eleven percent with over four percent of international students. In undergraduate programs, the university enrolled 22,100 students. The university's graduate and professional students number over 8,200 individuals. Of total enrolled students, 58 percent are female and 42 percent are male, with approximately 15 percent of students identifying as a minority. The university employs over 2,500 faculty members in its various schools (Central University Facts, 2011).

The university, accredited by the North Central Association of Colleges and Schools, consists of 21 separate colleges and schools offering over 250 undergraduate, graduate, and professional degrees. According to the university's mission, its purpose is to,

... advance the State [] and the intellectual growth of its citizens to the highest levels nationally and internationally through research and creative activity, teaching and 
learning, and civic engagement. By offering a distinctive range of bachelor's, master's, professional, and Ph.D. degrees, [Central University] promotes the educational, cultural, and economic development of central [State] and beyond through innovative collaborations, external partnerships, and a strong commitment to diversity. (Central University Mission, 2011)

Central University is the state's largest urban public research university, housing over 100 research centers (Central University Facts, 2011).

Central University School of Nursing (CU SON) is one of Central University's 21 schools. Founded in 1914, CU SON was a "system school" until 2008, offering programs at eight different Central University campuses. Subsequently, the organization of CU SON was decentralized, with eight different CU SON campuses coming into existence. According to CU SON's self study (2010), a federation-type model provides for greater autonomy by allowing the individual campuses to develop programs of study best suited to each campus's student population (p. 2). However, Central University, along with two other of its campuses located throughout the state, operate as "core" schools with degree granting authority granted to the larger Central University.

CU SON first awarded the BSN in 1950. While the school also developed an Associate of Science in Nursing (ASN) degree in 1966, the ASN was later discontinued at CU SON's campuses by 2008. In 1945, the university first began the Master of Science in Nursing (MSN) degree and currently offers eight specialty tracks at the main Central University campus. The first Doctor of Nursing Science (DNS) degree was awarded in 1981, with the DNS converting to the Doctor of Philosophy (PhD) in 1996. More recently, the school instituted the Doctor of Nursing Practice degree program (CU SON Self Study, 2010). 
CU SON is accredited by the Commission on Collegiate Nursing Education (CCNE). The school offers its 1,400 students nine degree options: BSN, RN to BSN, RN to MSN, BS/BA to BSN, MSN, Post MSN-NP, DNP, BSN to PhD, and PhD. The school operates at three campuses throughout the state. Approximately 191 faculty are employed by CU SON (CU SON Self Study, 2010). The school has been identified by the National League for Nursing (NLN) as a Center of Excellence in Nursing Education based upon the pedagogical expertise of its faculty. It was first recognized as a Center of Excellence in 2006, with re-designation occurring in 2009 (CU SON Website, 2011).

The school's organization is arranged in a top-to-bottom flow chart. The Dean reports directly to the Chancellor of Central University and directly oversees five individuals: one Executive Associate Dean, two Associate Deans, one Assistant Dean, and one Director. These five individuals supervise other Associate Deans, Assistant Deans, Directors, Department Chairs, and Coordinators who manage the school's various departments, tracts, and programs throughout the state.

According to CU SON's mission statement, the school's goal is to, to lead the 'knowledge work' of nurses of today and tomorrow to positively influence the health of communities served by: inspiring learning through excellence in teaching; creating and advancing knowledge through science and research; shaping care through evidence-based practices, innovations and partnerships; and appreciating, developing, and recognizing faculty, staff, and students. (CU SON Website, 2011)

In addition to its mission statement, CU SON lists four core values fundamental to the success of CU SON's programs and the school's community. These core values are: 


\section{Respect;}

2. Responsibility;

3. Trust; and

4. Dialogue (CU SON Website, 2011).

Comparing CU SON's mission to that of the university as a whole shows congruence between the two institutions. It is important to note that Central University, under which CU SON is governed, is part of a larger university system in the state. Central University is the urban research and health sciences center for the larger university and its specific mission is the one compared with CU SON's mission. CU SON's mission aims to "[1]ead the 'knowledge work' of nurses today and tomorrow to positively influence the health of communities" throughout the state and region (CU SON Self Study, 2010, p. 18). This statement aligns with Central University's goal to "[a]dvance the State [] and the intellectual growth of its citizens to the highest levels nationally and internationally through research and creative activity, teaching and learning, and civic engagement" (CU SON Self Study, 2010, p. 18). More importantly, CU SON's core values of respect, responsibility, trust, and dialogue are in alignment with Central University's mission to "promote[] the educational, cultural, and economic development of central [State] and beyond through innovative collaborations, external partnerships, and a strong commitment to diversity" (Central University Website, 2011).

\section{Study Participants}

At CU SON, nine nursing faculty and administrators were interviewed. Each participant was interviewed for approximately 40 minutes via telephone during March 2011. Participants were purposefully selected with the guidance of the Executive Associate Dean for Academic Affairs. The researcher interviewed the following individuals: 
- One Professor and Assistant Dean (administrator);

- One Associate Professor and Interim Associate Dean for Graduate Programs (administrator);

- One Associate Professor and Associate Dean for Undergraduate Programs (administrator);

- Two Associate Professors;

- Two Assistant Professors; and

- Two Clinical Instructors.

All nine respondents were female and were Caucasian. At the time of the interviews, six individuals (66.7\%) held doctoral degrees and one participant (11.1\%) was a doctoral candidate. The remaining two faculty (22.2\%) held master's degrees: one was an Assistant Professor and one was a Clinical Instructor. The nursing faculty had a wide background of specialties including adult medical/surgical, community health, critical care/ICU, psychiatric/mental health, operating room, nursing education, and administration/management. One of the nine participants, a Clinical Instructor, (11.1\%) had certification as an operating room nurse. The number of years in nursing spanned from seven years to 41 years.

The type of appointment for each participant varied from part-time to 10-month and 12month full-time appointments. One Clinical Instructor (11.1\%) had a part-time appointment and one Clinical Instructor (11.1\%) had a 10-month full-time appointment. One Assistant Professor (11.1\%) had a 10-month full-time appointment and one Assistant Professor (11.1\%) had a 12month full-time appointment. One Associate Professor (11.1\%) had a 10-month full-time appointment and one Associate Professor (11.1\%) had a 12-month full-time appointment. The three administrators (33.3\%) - two Associate Professors and one Professor - had 12-month fulltime appointments. 
The number of years participants taught at a school of nursing ranged from less than one year to 30 years. Additionally, the participants taught at CU SON from less than one year to 30 years. Out of the nine participants, five individuals (55.6\%) had tenure (see Table 29).

Table 29

Characteristics of CU SON Interview Respondents

\begin{tabular}{|c|c|c|c|c|c|c|c|}
\hline Participant & Title & $\begin{array}{l}\text { Education } \\
\text { and specialty }\end{array}$ & $\begin{array}{l}\text { Type of } \\
\text { appoint } \\
\text {-ment }\end{array}$ & $\begin{array}{l}\text { Years in } \\
\text { nursing }\end{array}$ & $\begin{array}{l}\text { Years } \\
\text { at } \\
\text { SONs }\end{array}$ & $\begin{array}{l}\text { Years at } \\
\text { current } \\
\text { SON }\end{array}$ & Tenure \\
\hline 1 & $\begin{array}{l}\text { Clinical } \\
\text { Instructor }\end{array}$ & $\begin{array}{l}\text { MSN, PhD } \\
\text { (c) } \\
\text { Critical Care, } \\
\text { ICU }\end{array}$ & Part-Time & 7 & 5.5 & 5.5 & No \\
\hline 2 & $\begin{array}{l}\text { Clinical } \\
\text { Instructor }\end{array}$ & $\begin{array}{l}\text { MS } \\
\text { Adult } \\
\text { Medical/ } \\
\text { Surgical, OR }\end{array}$ & $\begin{array}{l}\text { Full- } \\
\text { Time, } \\
10 \\
\text { months }\end{array}$ & 19 & $<1$ & $<1$ & No \\
\hline 3 & $\begin{array}{l}\text { Associate } \\
\text { Professor }\end{array}$ & $\begin{array}{l}\text { PhD } \\
\text { Psych/Mental } \\
\text { Health }\end{array}$ & $\begin{array}{l}\text { Full- } \\
\text { Time, } \\
10 \\
\text { months }\end{array}$ & 25 & 20 & 12 & Yes \\
\hline 4 & $\begin{array}{l}\text { Associate } \\
\text { Professor }\end{array}$ & $\begin{array}{l}\text { PhD } \\
\text { Psych/Mental } \\
\text { Health, } \\
\text { Educational } \\
\text { Researcher }\end{array}$ & $\begin{array}{l}\text { Full- } \\
\text { Time, } \\
12 \\
\text { months }\end{array}$ & 25 & 10 & 10 & Yes \\
\hline 5 & $\begin{array}{l}\text { Assistant } \\
\text { Professor }\end{array}$ & $\begin{array}{l}\text { MSN } \\
\text { Adult } \\
\text { Medical/ } \\
\text { Surgical, } \\
\text { Administra- } \\
\text { tion/Mgmt. }\end{array}$ & $\begin{array}{l}\text { Full- } \\
\text { Time, } \\
10 \\
\text { months }\end{array}$ & 29 & 8 & 7 & No \\
\hline
\end{tabular}


Table 29

Characteristics of CU SON Interview Respondents (continued)

\begin{tabular}{|c|c|c|c|c|c|c|c|}
\hline Participant & Title & $\begin{array}{l}\text { Education } \\
\text { and specialty }\end{array}$ & $\begin{array}{l}\text { Type of } \\
\text { appoint } \\
\text {-ment }\end{array}$ & $\begin{array}{l}\text { Years in } \\
\text { nursing }\end{array}$ & $\begin{array}{l}\text { Years } \\
\text { at } \\
\text { SONs }\end{array}$ & $\begin{array}{l}\text { Years at } \\
\text { current } \\
\text { SON }\end{array}$ & Tenure \\
\hline 6 & $\begin{array}{l}\text { Associate } \\
\text { Professor } \\
\text { (admini- } \\
\text { strator) }\end{array}$ & $\begin{array}{l}\text { EdD } \\
\text { Psych/Mental } \\
\text { Health, } \\
\text { Administra- } \\
\text { tion/Mgmt., } \\
\text { Education }\end{array}$ & $\begin{array}{l}\text { Full- } \\
\text { Time, } \\
12 \\
\text { months }\end{array}$ & 29 & 18 & $<1$ & Yes \\
\hline 7 & $\begin{array}{l}\text { Assistant } \\
\text { Professor }\end{array}$ & $\begin{array}{l}\text { DNP } \\
\text { Administra- } \\
\text { tion/Mgmt. }\end{array}$ & $\begin{array}{l}\text { Full- } \\
\text { Time, } \\
12 \\
\text { months }\end{array}$ & 41 & 12 & 12 & No \\
\hline 8 & $\begin{array}{l}\text { Associate } \\
\text { Professor } \\
\text { (admini- } \\
\text { strator) }\end{array}$ & $\begin{array}{l}\text { PhD } \\
\text { Adult } \\
\text { Medical/ } \\
\text { Surgical, } \\
\text { Administra- } \\
\text { tion/Mgmt. }\end{array}$ & $\begin{array}{l}\text { Full- } \\
\text { Time, } \\
12 \\
\text { months }\end{array}$ & 41 & 13 & 11 & Yes \\
\hline 9 & $\begin{array}{l}\text { Professor } \\
\text { (admini- } \\
\text { strator) }\end{array}$ & $\begin{array}{l}\text { PhD } \\
\text { Community } \\
\text { Health }\end{array}$ & $\begin{array}{l}\text { Full- } \\
\text { Time, } \\
12 \\
\text { months }\end{array}$ & 40 & 30 & 30 & Yes \\
\hline
\end{tabular}

The age of participants ranged from 28 years old to 64 years old. Five out of nine faculty $(55.6 \%)$ were 48 years or older (see Table 30$)$.

Table 30

Age of Participants - CU SON

\begin{tabular}{ccc}
\hline Age & $\mathrm{N}=9$ & Percentage $(\%)$ \\
\hline $28-37$ & 1 & 11.1 \\
\hline $38-47$ & 3 & 33.3 \\
\hline $48-57$ & 2 & 22.2 \\
\hline $58-67$ & 3 & 33.3 \\
\hline
\end{tabular}


A wide range of salaries existed for the nursing faculty participants. Four of the individuals (44.4\%) reported salaries of less than $\$ 60,000$ per year. The remaining five participants $(55.6 \%)$ noted salaries of at least $\$ 70,000$ per year. One administrator $(11.1 \%)$ interviewed, the Interim Associate Dean for Graduate Programs, had a salary of at least $\$ 90,000$ per year while the other two administrators $(22.2 \%)$ had salaries over $\$ 100,000$ per year (see

Table 31).

Table 31

Current Salary of Participants - CU SON

\begin{tabular}{lcc} 
Salary & $N=9$ & Percentage $(\%)$ \\
Under $\$ 40,000$ per year & 1 & 11.1 \\
$\$ 40,000$ to $\$ 50,000$ per year & 1 & 11.1 \\
$\$ 50,001$ to $\$ 60,000$ per year & 2 & 22.2 \\
$\$ 60,001$ to $\$ 70,000$ per year & 0 & 0 \\
$\$ 70,001$ to $\$ 80,000$ per year & 1 & 11.1 \\
$\$ 80,001$ to $\$ 90,000$ per year & 1 & 11.1 \\
$\$ 90,001$ to $\$ 100,000$ per year & 1 & 11.1 \\
Above $\$ 100,000$ per year & 2 & 22.2 \\
\hline
\end{tabular}

Four of the nine participants $(44.4 \%)$ taught both didactic and clinical courses. Four individuals (44.4\%) taught only didactic courses. The remaining nursing faculty $(11.1 \%)-\mathrm{a}$ Professor and Assistant Dean - provided only clinical instruction (see Table 32).

Table 32

Typical Teaching Responsibility of Participants - CU SON

\begin{tabular}{|c|c|c|c|}
\hline Participant & Didactic & Clinical & Both \\
\hline 1 & & & $\mathrm{X}$ \\
\hline 2 & & & $\mathrm{X}$ \\
\hline 3 & $\mathrm{X}$ & & \\
\hline 4 & $\mathrm{X}$ & & \\
\hline 5 & & & $\mathrm{X}$ \\
\hline 6 & X & & \\
\hline 7 & & & $\mathrm{X}$ \\
\hline 8 & X & & \\
\hline 9 & & X & \\
\hline
\end{tabular}


Four nursing faculty (44.4\%) taught at the undergraduate program level. Two individuals $(22.2 \%)$ taught at the graduate program level. The remaining three participants (33.3\%) taught at both the undergraduate and graduate levels (see Table 33).

Table 33

Program Level - CU SON

\begin{tabular}{cccc}
\hline Participant & Graduate & Undergraduate & Both \\
\hline 1 & & $\mathrm{X}$ & \\
\hline 2 & & $\mathrm{X}$ & \\
\hline 3 & $\mathrm{X}$ & & $\mathrm{X}$ \\
\hline 4 & & & \\
\hline 5 & $\mathrm{X}$ & & $\mathrm{X}$ \\
\hline 6 & & & $\mathrm{X}$ \\
\hline 7 & & $\mathrm{X}$ & \\
\hline 8 & & & $\mathrm{X}$ \\
\hline 9 & & & \\
\hline
\end{tabular}

Eight of the faculty participants (88.9\%) spent less than four hours per week in classbased instruction. One individual (11.1\%), an Associate Professor, spent five to nine hours per week in class-based instruction. In on-line instruction, seven out of the nine interviewees (88.9\%) invested up to four hours per week. One faculty (11.1\%), a Clinical Instructor, taught on-line five to nine hours per week. An Assistant Professor (11.1\%) instructed on-line 30 to 34 hours per week. As to clinical instruction, six participants (66.7\%) instructed up to four hours per week. One nursing faculty (11.1\%), a Professor and Assistant Dean, facilitated five to nine hours per week in clinical instruction. The remaining two participants (22.2\%) spent 20 to 24 hours per week in clinical instruction. Seven faculty (77.8\%) spent up to four hours per week in required office hours. One faculty (11.1\%), a Clinical Instructor, invested five to nine hours per week in required office hours. The final individual (11.1\%), an Associate Professor and Interim Associate Dean for Graduate Programs, had 40 to 44 hours per week of required office hours. At home, three faculty members (33.3\%) spent less than four hours per week in faculty-related 
duties. Two participants (22.2\%) spent five to nine hours per week at home in faculty-related duties. Another two interviewees (22.2\%) invested 10 to 14 hours per week at home. One out of the nine individuals (11.1\%) interviewed, an Associate Professor, facilitated 15 to 19 hours per week at home in a job-related capacity. The final faculty member (11.1\%), a Clinical Instructor, spent 20 to 24 hours per week at home for duties related to her position (see Table 34).

Table 34

Hours Per Week Spent in Instruction, Office Hours, and At Home - CU SON

Number of hours per week $\mathrm{N}=9(\%)$

\begin{tabular}{llllllllll}
$\begin{array}{l}\text { Instruction } \\
\text { and hours } \\
\text { spent }\end{array}$ & $\begin{array}{l}0-4 \\
\text { hours }\end{array}$ & $\begin{array}{l}5-9 \\
\text { hours }\end{array}$ & $\begin{array}{l}10-14 \\
\text { hours }\end{array}$ & $\begin{array}{l}15-19 \\
\text { hours }\end{array}$ & $\begin{array}{l}20-24 \\
\text { hours }\end{array}$ & $\begin{array}{l}25-29 \\
\text { hours }\end{array}$ & $\begin{array}{l}30-34 \\
\text { hours }\end{array}$ & $\begin{array}{l}35-39 \\
\text { hours }\end{array}$ & $\begin{array}{l}40-44 \\
\text { hours }\end{array}$ \\
\hline Class-based & $8(88.9)$ & $1(11.1)$ & & & & & & & \\
\hline $\begin{array}{l}\text { On-line } \\
\text { Clinical }\end{array}$ & $6(77.8)$ & $1(11.1)$ & & & & & $1(11.1)$ & & \\
\hline $\begin{array}{l}\text { Required } \\
\text { office hours }\end{array}$ & $7(77.8)$ & $1(11.1)$ & $1(11.1)$ & & & & & & \\
\hline $\begin{array}{l}\text { Hours spent } \\
\text { at home }\end{array}$ & $3(33.3)$ & $2(22.2)$ & $2(22.2)$ & $1(11.1)$ & $1(11.1)$ & & & \\
\hline
\end{tabular}

Five out of the nine individuals (55.6\%) interviewed taught one course per semester. Three nursing faculty (33.3\%) taught two courses per semester. The remaining interviewee (11.1\%), a Professor and Assistant Dean, did not teach any didactic courses each semester. The course credits ranged from three credits per semester to six credits per semester. Four participants (44.4\%) did not teach any clinicals. Three of the nine nursing faculty $(33.3 \%)$ had one clinical course per semester. One individual (11.1\%), a Clinical Instructor, taught two clinicals per semester. The remaining participant (11.1\%), an Assistant Professor, taught three clinicals per semester. Of those who teach clinicals each semester, the number of clinical credits varied from two to six clinical credits (see Table 35). 
Table 35

Number of Courses, Clinicals, and Credits Per Semester - CU SON

\begin{tabular}{ccccc}
\hline Participant & $\begin{array}{c}\text { Number of } \\
\text { courses }\end{array}$ & $\begin{array}{c}\text { Number of } \\
\text { course } \\
\text { credits }\end{array}$ & $\begin{array}{c}\text { Number of } \\
\text { clinicals }\end{array}$ & $\begin{array}{c}\text { Number of } \\
\text { clinical credits }\end{array}$ \\
\hline 1 & 1 & 3 & 1 & 2 \\
\hline 2 & 1 & 3 & 2 & 6 \\
\hline 3 & 2 & 6 & 0 & 0 \\
\hline 4 & 2 & 6 & 0 & 0 \\
\hline 5 & 1 & 3 & 3 & 6 \\
\hline 6 & 1 & 3 & 0 & 0 \\
\hline 7 & 1 & 3 & 1 & 2 \\
\hline 8 & 2 & 4 & 0 & 0 \\
\hline 9 & 0 & 0 & 1 & 2 \\
\hline
\end{tabular}

The four faculty participants (44.4\%) who taught in the clinical area reported a studentto-faculty ratio of ten to one. Four of the nine nursing faculty (44.4\%) were advisors for students. The number of advisees ranged from zero students to 56 students. Additionally, seven faculty $(77.8 \%)$ were members of committees, which varied in number from two committees to over 20 committees (see Table 36).

Table 36

Clinicals, Advisees, and Committees Per Year - CU SON

\begin{tabular}{cccc}
\hline Participant & $\begin{array}{c}\text { Student- } \\
\text { faculty ratio } \\
\text { in clinicals }\end{array}$ & $\begin{array}{c}\text { Number of } \\
\text { advisees }\end{array}$ & $\begin{array}{c}\text { Number of } \\
\text { committees }\end{array}$ \\
\hline 1 & -- & 0 & 0 \\
\hline 2 & $10: 1$ & 0 & 2 \\
\hline 3 & -- & 56 & 8 \\
\hline 4 & -- & 5 & 12 \\
\hline 5 & $10: 1$ & 1 & 0 \\
\hline 6 & -- & 0 & 3 \\
\hline 7 & $10: 1$ & 0 & 8 \\
\hline 8 & -- & 6 & 12 \\
\hline 9 & $10: 1$ & 0 & 3 \\
\hline
\end{tabular}


Of the nine interviewees, seven (77.8\%) were currently revising or creating a course. Course subjects involved didactic and clinical areas in critical care, operating room nursing, pathopharmacology, psychiatric clinical management, co-occurring disorders, alterations in health, inter-professional safety and quality, and curriculum revision of more than one course (see Table 37).

Table 37

Revising or Creating a Course Per Year - CU SON

\begin{tabular}{ccl}
\hline Participant & $\begin{array}{c}\text { Revising or } \\
\text { creating a } \\
\text { course? }\end{array}$ & \multicolumn{1}{c}{ Course area } \\
\hline 1 & Yes & Critical Care Didactic \\
\hline 2 & Yes & $\begin{array}{l}\text { Operating Room Nursing, Patho- } \\
\text { Pharmacology }\end{array}$ \\
\hline 3 & Yes & $\begin{array}{l}\text { Psychiatric Clinical } \\
\text { Management }\end{array}$ \\
\hline 4 & Yes & Co-Occurring Disorders \\
\hline 5 & Yes & Alterations in Health \\
\hline 6 & Yes & $\begin{array}{l}\text { Curriculum revision (more than one } \\
\text { course) }\end{array}$ \\
\hline 7 & No & \\
\hline 8 & Yes & Inter-professional Safety and Quality \\
\hline 9 & No & \\
\hline
\end{tabular}

One nursing faculty (11.1\%), a part-time Clinical Instructor, spent 11 to 20 hours per week completing duties as nursing faculty. Five participants $(55.6 \%)$ spent 41 to 50 hours per week completing nursing faculty duties. One nursing faculty (11.1\%), an Associate Professor, used 51 to 60 hours per week in completion of nursing faculty responsibilities. The final two individuals (22.2\%) invested 61 to 70 hours per week in job-related duties (see Table 38). 
Table 38

Hours Per Week Spent Completing Duties - CU SON

\begin{tabular}{lcc}
$\begin{array}{l}\text { Hours per week spent } \\
\text { completing duties as } \\
\text { nursing faculty }\end{array}$ & $\mathrm{N}=9$ & Percentage $(\%)$ \\
$11-20$ hours/week & 1 & 11.1 \\
$21-30$ hours/week & 0 & 0 \\
\hline $1-40$ hours/week & 1 & 11.1 \\
$41-50$ hours/week & 5 & 55.6 \\
\hline $51-60$ hours/week & 0 & 0 \\
\hline $61-70$ hours/week & 2 & 22.2 \\
$70+$ hours/week & 0 & 0 \\
\hline
\end{tabular}

Six out of the nine faculty members $(66.7 \%)$ conducted research endeavors. Three individuals (33.3\%) noted that they are involved in research to a great extent. Three participants $(33.3 \%)$ reported involvement in research to some extent. The final three faculty $(33.3 \%)$ noted they did no research (see Table 39).

Table 39

Involvement in Research - CU SON

\begin{tabular}{lcc}
$\begin{array}{l}\text { Involvement in } \\
\text { research }\end{array}$ & $\mathrm{N}=9$ & Percentage (\%) \\
\hline To a great extent & 3 & 33.3 \\
\hline To some extent & 3 & 33.3 \\
\hline Very little & 0 & 0 \\
\hline Not involved & 3 & 33.3 \\
\hline
\end{tabular}

Six of the nine interviewees $(66.7 \%)$ published in the past three years. The number of publications ranged from three publications to 18 publications (see Table 40). 
Table 40

Number of Publications in the Past Three Years - CU SON

\begin{tabular}{ccc}
\hline Participant & $\begin{array}{c}\text { Published in } \\
\text { the past three } \\
\text { (3) years? }\end{array}$ & $\begin{array}{c}\text { Number of } \\
\text { publications }\end{array}$ \\
\hline 1 & Yes & 5 \\
\hline 2 & No & 7 \\
\hline 3 & Yes & 18 \\
\hline 4 & Yes & \\
\hline 5 & No & 7 \\
\hline 6 & No & 3 \\
\hline 7 & Yes \\
\hline 8 & Yes & \\
\hline 9 & Yes & \\
\hline
\end{tabular}

Eight nursing faculty $(88.9 \%)$ anticipated remaining in their role as nursing faculty for three years. One individual (11.1\%), a Professor and Assistant Dean, noted that she will not remain in her role due to retirement (see Table 41).

Table 41

Anticipation of Remaining in Role as Nursing Faculty for Three Years - CU SON

\begin{tabular}{cccc}
\hline Participant & Yes & No & Reason(s) for leaving role \\
\hline 1 & $\mathrm{X}$ & & \\
2 & $\mathrm{X}$ & & \\
3 & $\mathrm{X}$ & & \\
\hline 4 & $\mathrm{X}$ & & \\
\hline 5 & $\mathrm{X}$ & & \\
\hline 6 & $\mathrm{X}$ & & \\
\hline 7 & $\mathrm{X}$ & & \\
\hline 8 & $\mathrm{X}$ & & Retirement \\
\hline 9 & & $\mathrm{X}$ & \\
\hline
\end{tabular}

Four of the nine participants $(44.4 \%)$ interviewed believed they were fully compensated at CU SON for their credentials. The remaining five participants $(55.6 \%)$ indicated that they were not fully compensated. The reasons listed for this belief included low salary, additional 
duties not factored into salary, unpaid summer responsibilities, and lack of mentorship and support for clinical faculty (see Table 42).

Table 42

Faculty Belief of Full Compensation for Credentials and Reasons - CU SON

\begin{tabular}{ccl}
\hline Participant & $\begin{array}{c}\text { Fully } \\
\text { compensated? }\end{array}$ & \multicolumn{1}{c}{ Reason(s) } \\
\hline 1 & No & $\begin{array}{l}\text { Time spent grading and writing lectures not } \\
\text { factored into part-time salary }\end{array}$ \\
\hline 2 & Yes & Responsibilities in summer are unpaid \\
\hline 4 & No & $\begin{array}{l}\text { I work } 70 \text { hours/week, am highly productive, } \\
\text { and have been between 25-100\% funded by } \\
\text { research for the past 10 years, yet make a } \\
\text { very modest salary }\end{array}$ \\
\hline 5 & No & $\begin{array}{l}\text { Faculty should get better compensation; } \\
\text { should increase upon completion of } \\
\text { doctorate }\end{array}$ \\
\hline 6 & No & $\begin{array}{l}\text { Clinical faculty not supported or mentored; } \\
\text { received doctorate with no pay increase even } \\
\text { though it was a past trend to do so }\end{array}$ \\
\hline 7 & Yes & No \\
\hline 9 & Yes & \\
\hline Yes &
\end{tabular}

Eight of the nursing faculty $(88.9 \%)$ were satisfied in their current role. One individual (11.1\%), an Assistant Professor, indicated that she was not satisfied in her current role, but did not list reasons for this feeling (see Table 43). 
Table 43

Satisfaction in Current Role and Reasons - CU SON

\begin{tabular}{ccl}
\hline Participant & $\begin{array}{c}\text { Satisfied in } \\
\text { current role? }\end{array}$ & \multicolumn{1}{c}{ Reason(s) } \\
\hline 1 & Yes & \\
\hline 2 & Yes & \\
\hline 3 & Yes & $\begin{array}{l}\text { Great deal of autonomy and } \\
\text { good colleagues to work with }\end{array}$ \\
\hline 4 & Yes & $\begin{array}{l}\text { Fun, interesting, great students } \\
\text { and colleagues }\end{array}$ \\
\hline 5 & Yes & \\
\hline 6 & Yes & \\
\hline 7 & No & \\
\hline 8 & Yes & \\
\hline 9 & Yes & \\
\hline
\end{tabular}

\section{Responses to Interview Protocol}

Three administrators were interviewed through a separate interview protocol (see Appendix B-1) and their responses are analyzed and reported below. Six nursing faculty were interviewed with a different interview protocol (see Appendix B-2) and their responses are examined. Common questions for faculty and administrators are reported under the appropriate research question.

Setting the context: Reasons to teach nursing - Administrator and faculty responses.

At CU SON, six nursing faculty of varying ranks were interviewed. They were first asked to explain why they taught nursing at CU SON. Responses varied among faculty members. Three individuals $(50 \%)$ explained that they chose to teach at CU SON because they were from the geographic area. Two participants (33\%) noted that they decided to teach at CU SON based on its positive reputation. One Clinical Instructor (16.7\%) mentioned that she was a recent graduate of CU SON. One Assistant Professor (16.7\%) stated that she chose to teach at 
CU SON to collaborate with other faculty. Finally, one Assistant Professor (16.7\%) explained that she was requested to apply by the Dean in order to coordinate a new program (see Table 44).

Table 44

Reasons for Teaching at CU SON

\begin{tabular}{lcc}
\hline $\begin{array}{l}\text { Interview response: Reasons } \\
\text { for teaching at }\end{array}$ & $\begin{array}{c}\text { Number of responses } \\
\text { CU SON }\end{array}$ & $\begin{array}{c}\text { Percentage (\%) based upon } \\
\text { number of respondents } \\
\mathrm{N}=6\end{array}$ \\
\hline Familiarity with area & 3 & 50 \\
\hline Reputation & 2 & 33 \\
\hline Recent graduate & 1 & 16.7 \\
\hline $\begin{array}{l}\text { Collaboration with other } \\
\text { faculty }\end{array}$ & 1 & 16.7 \\
\hline Requested to apply by Dean & 1 & 16.7 \\
\hline
\end{tabular}

Administrators and faculty were asked the reasons they and other faculty remained at CU SON. Satisfaction in their role as nursing faculty was a major reason that faculty remained.

Four of the nine interviewees $(44.4 \%)$ stressed that they were pleased with their position and role as nursing faculty. Two participants $(22.2 \%)$ stated that CU SON was a very collegial environment which influenced their decision to remain. Mentoring new faculty was a benefit cited by two of the nine nursing faculty $(22.2 \%)$. One individual, a Clinical Instructor (11.1\%), explained that support given to nursing faculty was an impetus for faculty to remain. Another Clinical Instructor (11.1\%) noted that CU SON's resources were a primary motivator. An Assistant Professor (11.1\%) explained that her family lived in the area. Finally, one Assistant Professor (11.1\%) noted that she remained as faculty for economic reasons (see Table 45). 
Table 45

Reasons for Remaining as Nursing Faculty - CU SON

\begin{tabular}{lcc}
\hline $\begin{array}{l}\text { Interview response: Reasons } \\
\text { for remaining as nursing } \\
\text { faculty }\end{array}$ & Number of responses & $\begin{array}{c}\text { Percentage (\%) based upon } \\
\text { number of respondents } \\
\mathrm{N}=9\end{array}$ \\
\hline Satisfaction in role & 4 & 44.4 \\
\hline Collegial environment & 2 & 22.2 \\
\hline Mentoring new faculty & 2 & 22.2 \\
\hline Support & 1 & 11.1 \\
\hline CU SON resources & 1 & 11.1 \\
\hline Family in area & 1 & 11.1 \\
\hline Economic reasons & 1 & 11.1 \\
\hline
\end{tabular}

Research question 1: Enrollment management - Administrator responses.

Research question one pertains to identifying recent strategies schools of nursing implemented to address recruitment and retention of nursing faculty. Connected to this focus is also gaining a better understanding of the enrollment management plan since student recruitment is tied to the availability of nursing faculty and the availability of resources such as clinical placements.

At CU SON, three nursing faculty administrators were interviewed. Administrators were asked whether CU SON has an enrollment management program and, if so, to describe its components. The Associate Dean for Undergraduate Programs explained that CU SON has an enrollment management program for its undergraduate curricula. She noted that "we actually make quite a substantial projection of how many students to take and we project out how much income that will bring in for us and compare it to what we've got in terms of faculty." She also observed that there were dual limiting factors: number of available faculty and number of clinical placements. These factors affected decisions about the number of undergraduates who could be accepted into the undergraduate nursing degree program. 
Similarly, in CU SON's graduate programs, the Interim Associate Dean for Graduate Programs explained that student enrollment is also limited by the number of available faculty. However, the application process differed from the undergraduate program. In the graduate program, prospective students applied on-line and then applications were sent to the various departments of CU SON for admissions decisions. She noted that "there are ballpark figures in terms of the numbers that the departments are looking at but not as specific as the undergraduate numbers."

The graduate administrator explained that CU SON turned away 60 to 70 percent of qualified applications in its undergraduate program. For instance, in the past year, the school accepted 180 traditional students. But, as the Assistant Dean noted, "in any given year we turn away three to four qualified students for every one we can admit." Furthermore, the Interim Associate Dean for Graduate Programs observed that the school did not have plans to increase their undergraduate program due to limited clinical placements and available nursing faculty. The Associate Dean for Undergraduate Programs explained that the school had no limit on accepting RN to BSN students because it did not take as many resources to educate them. She further noted that for Fall 2011, CU SON removed the interview from the admissions process and instead would give a pre-admission test so that subjectivity would be decreased. Additionally, she explained that the length of time required to administer these interviews was too great for nursing faculty.

The administrators were then asked about limitations to increasing student admissions (see Table 46). All three administrators discussed the lack of resources for clinical placements. Two administrators (67\%) noted that limitations on existing faculty resources impacted any increase in student admissions. Finally, the Assistant Dean (33\%) explained that even if her 
budget provided for the hiring of additional faculty, it would be difficult for her to find qualified faculty.

Table 46

Limitations to Increasing Student Admissions - CU SON

\begin{tabular}{|c|c|c|}
\hline $\begin{array}{l}\text { Interview response: } \\
\text { Limitations to increasing } \\
\text { student admissions }\end{array}$ & $\begin{array}{l}\text { Number of responses } \\
\qquad \mathrm{N}=3\end{array}$ & $\begin{array}{l}\text { Percentage }(\%) \text { based upon } \\
\text { number of respondents } \\
\mathrm{N}=3\end{array}$ \\
\hline $\begin{array}{l}\text { Lack of resources for clinical } \\
\text { placements }\end{array}$ & 3 & 100 \\
\hline Limited faculty resources & 2 & 67 \\
\hline Lack of qualified faculty & 1 & 33 \\
\hline
\end{tabular}

\section{Research question 1: Recruitment and retention of nursing faculty - Administrator responses.}

Administrators were asked how CU SON recruits nursing faculty and the challenges in recruiting them. CU SON had two tracks: tenure track and clinical track. Recruiting did not differ based upon which track the school needed. All three administrators explained that search committees are used to recruit new nursing faculty members. Additionally, the three administrators noted that nursing faculty were recruited from advertisements in journals and on the school's website. The recruitment of CU SON doctoral students was also mentioned by all three administrators, as was recruitment via word of mouth. Finally, the Interim Associate Dean for Graduate Programs (33\%) observed that conferences were used to recruit new nursing faculty (see Table 47). 
Table 47

Recruitment Strategies - CU SON

\begin{tabular}{|c|c|c|}
\hline $\begin{array}{l}\text { Interview response: } \\
\text { Recruitment strategies }\end{array}$ & $\begin{array}{l}\text { Number of responses } \\
\qquad \mathrm{N}=3\end{array}$ & $\begin{array}{l}\text { Percentage }(\%) \text { based upon } \\
\text { number of respondents } \\
\mathrm{N}=3\end{array}$ \\
\hline Search committees & 3 & 100 \\
\hline $\begin{array}{l}\text { Advertisements in journals } \\
\text { and on school's website }\end{array}$ & 3 & 100 \\
\hline CU SON doctoral students & 3 & 100 \\
\hline Word of mouth & 3 & 100 \\
\hline Conferences & 1 & 33 \\
\hline
\end{tabular}

All three administrators mentioned various challenges to recruitment of nursing faculty (see Table 48). The Associate Dean for Undergraduate Programs (33\%) remarked that the location of CU SON's and its various campuses throughout the state made recruitment difficult. She also noted (33\%) that recruitment of nursing faculty in specialty areas was difficult because there were less qualified faculty in these areas. Additionally, she explained (33\%) that it was difficult for CU SON to recruit chairpersons due to the large amount of responsibility involved in the position. Finally, the Assistant Dean (33\%) observed that low salaries and the requirement of a doctorate in order to be hired into a full-time faculty position hindered recruitment:

It used to be difficult to get the people to leave the practice setting and come to teach with us with a master's and now everyone, whether it's clinical track or tenure track has to do a doctorate. It's hard to attract people away from a practice setting where maybe they are making very big salaries and ask them to come and teach for less. Salaries are, I think, one of the biggest issues. 
Table 48

Recruitment Challenges - CU SON

\begin{tabular}{|c|c|c|}
\hline $\begin{array}{l}\text { Interview response: } \\
\text { Recruitment challenges }\end{array}$ & $\begin{array}{l}\text { Number of responses } \\
\qquad \mathrm{N}=3\end{array}$ & $\begin{array}{c}\text { Percentage }(\%) \text { based upon } \\
\text { number of respondents } \\
\mathrm{N}=3\end{array}$ \\
\hline Location of CU SON & 1 & 33 \\
\hline Lack of specialties & 1 & 33 \\
\hline $\begin{array}{l}\text { High amount of responsibility } \\
\text { for chairpersons }\end{array}$ & 1 & 33 \\
\hline Low salaries & 1 & 33 \\
\hline
\end{tabular}

The Associate Dean for Undergraduate Programs observed the CU SON always has multiple nursing faculty vacancies. According to CU SON's website, 14 positions are advertised and listed below:

- Tenure track adult health clinical nurse specialist (3 positions);

- Tenure track community health nursing faculty (2 positions);

- Tenure track leadership/health systems nursing faculty;

- Tenure track acute care nurse practitioner nursing faculty;

- Tenure track adult nurse practitioner nursing faculty;

- Tenure track medical/surgical/management/health assessment nursing faculty (2 positions);

- Tenure track pediatric nursing faculty;

- Clinical track acute care nurse practitioner nursing faculty;

- Clinical track pediatric nursing faculty; and

- Full-time visiting lecturer in Department of Adult Health (CU SON Website, 2011). 


\section{Research question 2: Effective strategies to recruit and retain nursing faculty. Designing courses: Faculty perceptions.}

Research question two examines the effective strategies to recruit and retain nursing faculty. Giving faculty autonomy to design courses is a facet of this research question as well. Nursing faculty were asked if they have freedom in designing and conducting their own courses. All faculty (100\%) explained that they must follow the curriculum and keep the same course objectives, but are given flexibility in designing and conducting their own courses. An Associate Professor explained,

We really have total freedom to select our own text, create our own activities and evaluation strategies. The syllabus is the format. We are trying to make those all uniform so that it's easier for students to navigate. We have kind of a structure for it, but within that structure there is absolute flexibility.

Furthermore, an Assistant Professor observed that "as long as you teach to the objectives you allowed to handle your course however, basically, you want to." All nursing faculty also noted that they are required to use a template syllabus, but are allowed to change learning activities, the schedule, and are able to adjust the course. Three of the six nursing faculty (50\%) explained they can create individual section exams within the same course (see Table 49).

Table 49

Freedom in Designing and Conducting Courses - CU SON

\begin{tabular}{lcc}
$\begin{array}{l}\text { Interview response: Freedom } \\
\text { in designing and conducting } \\
\text { courses }\end{array}$ & Number of responses & $\begin{array}{c}\text { Percentage (\%) based upon } \\
\text { number of respondents } \\
\mathrm{N}=6\end{array}$ \\
\hline Academic freedom & 6 & 100 \\
\hline Template syllabus & 6 & 100 \\
\hline Flexibility & 6 & 100 \\
\hline Individual section exams & 3 & 50 \\
\hline
\end{tabular}




\section{Tenure requirements: Administrator and faculty perceptions.}

Both administrators and faculty were asked about the requirements needed to obtain tenure at CU SON and, if they had tenure, whether it was difficult to obtain. Nursing faculty are eligible for tenure and for promotion after six years. But, even before applying for tenure, nursing faculty must go through a three-year review in order to be eligible for tenure after six years. According to an Associate Professor, tenure is based upon a dossier submitted by nursing faculty and must demonstrate excellence in one of three areas: research, teaching, or service. She further noted that "although service is very valued it is not an area that you can go up in research or up in tenure in. It can't be your area of excellence. So, it really is either teaching or research." In addition to the identification of an area of excellence in one of the three categories, nursing faculty must be satisfactory in the remaining two areas to be considered for tenure.

Moreover, faculty must demonstrate scholarship, primarily in published works. An Associate Professor explained, "we look for one to two publications a year. You should have around twelve publications at the time of an application for tenure." She also noted that research funding or smaller amounts of funding are recommended. According to an Assistant Dean, the tenure and promotion guidelines change each year. However, nursing faculty who are successful in obtaining tenure receive a $\$ 10,000$ to $\$ 12,000$ salary increase, so nursing faculty have an incentive to reach this milestone. One Assistant Professor in the clinical track explained that "our dean does not support clinical faculty so you have to have a doctorate degree to be on tenure. You can be on tenure with a DNP or PhD. But it has to meet the approval of the dean if you can be on that track or not." She further noted that nursing faculty originally hired as clinical faculty were not required to have a doctorate, but in order to obtain tenure, a doctorate was required. Those clinical faculty possessing their doctorate have not had a similar increase in 
their salaries as those faculty originally hired on the tenure track. Moreover, clinical faculty have fewer opportunities to apply for tenure due to a lack of administrative support, according to the Assistant Professor.

\section{Research question 3: Collaboration with external stakeholders - Administrator perceptions.}

Administrators were asked about external partnerships. All administrators noted a strong collaboration between CU SON, CU's School of Medicine (SOM), and Central University's health system, which is comprised of hospitals, clinics, and outpatient centers throughout the region. The administrators explained that there was a strong impetus for coordination among the three entities including shared faculty. An Associate Dean for Undergraduate Programs explained that CU SON had eight nursing faculty whose salaries were paid for by Central University's health system, where the nursing faculty work $20 \%$ for the health system and $80 \%$ for CU SON. Two administrators (67\%) observed that CU SON heavily relied upon the use of nurses as preceptors in both undergraduate and graduate programs (see Table 50).

Moreover, two administrators (67\%) explained a unique facet of nursing education at CU SON entitled the Practice Education Program (PEP). The PEP is comprised of various hospital units at more than one hospital within Central University's health system in which the nursing floor is specifically set up to train students. Nurses who work on those floors are preceptors to students and the CU SON nursing faculty work hand-in-hand with the floor's nurse manager to provide training to students. The administrators noted that while PEP units are training floors, nursing students are giving care to actual admitted patients. Finally, the Assistant Dean (33\%) stated that CU SON partnered with various community health partners in towns surrounding CU SON's campuses. These partners included other hospitals and extended care facilities. 
Table 50

External Partnerships

\begin{tabular}{lcc}
\hline $\begin{array}{l}\text { Interview response: External } \\
\text { partnerships }\end{array}$ & Number of responses & $\begin{array}{c}\text { Percentage (\%) based upon } \\
\text { number of respondents } \\
\mathrm{N}=3\end{array}$ \\
\hline $\begin{array}{l}\text { Collaboration between CU } \\
\text { SON, CU SOM, and Central }\end{array}$ & 3 & 100 \\
University health system & 3 & 100 \\
\hline Hospitals & 2 & 67 \\
\hline Nurses as preceptors & 2 & 67 \\
\hline Practice Education Program & 1 & 33 \\
\hline Community health partners & & \\
\hline
\end{tabular}

Distance education and simulation lab: Administrator and faculty perceptions.

Both administrators and faculty participants were questioned about whether distance education had been implemented at CU SON. All nine interviewees answered that distance education was offered. The participants explained that distance education methods, including synchronous and asynchronous, were utilized in all undergraduate and graduate programs. One Associate Professor stated that "distance education has been fully embraced by the university and the faculty." She also noted that she received a grant in order to create CU SON's on-line and distance accessible psychiatric/mental health graduate program. Furthermore, she observed that due to this program, enrollment was doubled. This fact was echoed by four participants (44.4\%) who stated that distance education increased student enrollment.

CU SON applies technology in an innovative way through the design of a simulation or "virtual" hospital. This simulation hospital was a joint venture between CU SON, CU SOM, and Central University's health system. It had operating rooms, emergency rooms, basic nursing rooms, delivery rooms, and outpatient procedures. An intraprofessional staff of nursing, medicine, pharmacy, and emergency medical technicians ran the simulation hospital. A Clinical Instructor stated that the simulation hospital is "state of the art and high fidelity." Each rotation 
of nursing students went to the simulation hospital to run simulations prior to any clinicals. The participants stated that the simulation hospital was very successful and increased students' confidence. An Assistant Professor said that "due to the reality that we have less faculty and less clinical sites available, students don't get opportunities to see many situations in the clinical setting. We feel that a well prepared simulation activity can take the place of a clinical site activity." She noted, the simulation hospital is a "journey" in which students "get a tangible experience to hold onto." An Assistant Dean explained that "the Dean has suggested looking at as much as $20 \%$ to $30 \%$ of a clinical course being in simulation." But, the Interim Associate Dean for Graduate Programs suggested additional research was needed to determine outcomes after using the simulation hospital.

\section{Research question 4: Lack of recruitment and retention.}

Faculty perceptions of the university working conditions are examined since these conditions can affect recruitment and retention of nursing faculty. In addition, a lack of recruitment and retention can negatively affect faculty's positive feelings about their working environment.

\section{Working conditions: Faculty responses.}

Nursing faculty were asked about working conditions at CU SON. While four out of six nursing faculty $(66.7 \%)$ explained that they enjoyed great flexibility and the collegial environment of CU SON, just as many nursing faculty (66.7\%) observed that they were overworked and "asked to do more with less." While three of the participants (50\%) were appreciative that they received support from senior faculty or the Dean within 24 hours of a request, one Associate Professor observed that "sometimes it feels like way too much for what we get paid." Another three interviewees (50\%) enjoyed interaction with students. Two 
participants (33.3\%) stated that they were dissatisfied with their salaries based on their current workload. Two interviewees (33.3\%) noted that nursing faculty were given less workload unit credits per course, which thereby increased their required workload. As an Assistant Professor explained, "your pay doesn't increase, but your workload is increased." One individual, an Associate Professor, stated that two years ago, CU SON had 140 full-time nursing faculty but now had only 100 full-time nursing faculty. Thus, she observed, the number of nursing faculty had decreased and the number of students had increased. Finally, one Assistant Professor (16.7\%) explained that she felt working conditions at CU SON were "positive" (see Table 51).

Table 51

Working Conditions at CU SON

\begin{tabular}{lcc}
\hline $\begin{array}{l}\text { Interview response: Working } \\
\text { conditions at }\end{array}$ & Number of responses & $\begin{array}{c}\text { Percentage (\%) based upon } \\
\text { number of respondents } \\
\text { CU SON }\end{array}$ \\
\hline Flexibility & $\mathrm{N}=6$ & 66.7 \\
\hline Collegial environment & 4 & 66.7 \\
\hline Overworked & 4 & 66.7 \\
\hline "Asked to do more with less" & 4 & 66.7 \\
\hline $\begin{array}{l}\text { Support from senior faculty } \\
\text { and Dean }\end{array}$ & 4 & 50 \\
\hline $\begin{array}{l}\text { Enjoyed interaction with } \\
\text { students }\end{array}$ & 3 & 50 \\
\hline Dissatisfied with salaries & 3 & 33.3 \\
\hline Increased workload & 2 & 33.3 \\
\hline "Positive" & 2 & 16.7 \\
\hline
\end{tabular}

\section{Lack of recruitment and retention of nursing faculty: Administrator and faculty perceptions.}

Seven of the interviewees (77.8\%) felt that recruitment and retention was negatively impacted by low salaries offered by CU SON. One Clinical Instructor said there was a "constant issue with money." Three faculty (33.3\%) explained that the requirement of a doctorate impacted recruitment and retention of nursing faculty. In addition, three respondents (33.3\%) 
noted the rural location of some of CU SON's campuses detrimentally impacted its recruitment and retention efforts. Two individuals $(22.2 \%)$ also explained that there was no promotion or pay raise upon completion of the doctorate. Finally, an Assistant Dean (11.1\%) observed that the lack of clinical faculty negatively impacted recruitment and retention of nursing faculty (see Table 52).

Table 52

Reasons Impacting Recruitment and Retention - CU SON

\begin{tabular}{lcc}
$\begin{array}{l}\text { Interview response: Reasons } \\
\text { impacting recruitment and } \\
\text { retention }\end{array}$ & Number of responses & $\begin{array}{c}\text { Percentage (\%) based upon } \\
\text { number of respondents } \\
\mathrm{N}=9\end{array}$ \\
$\begin{array}{l}\text { Low salary } \\
\text { Requirement of doctorate }\end{array}$ & 7 & 77.8 \\
$\begin{array}{l}\text { Rural location of some } \\
\text { campuses }\end{array}$ & 3 & 33.3 \\
$\begin{array}{l}\text { No promotion or pay raise } \\
\text { upon doctorate completion }\end{array}$ & 2 & 33.3 \\
\hline $\begin{array}{l}\text { Lack of clinical faculty } \\
\text { nom }\end{array}$ & 1 & 22.2 \\
\hline
\end{tabular}

The interviewees were questioned about the reasons nursing faculty leave their positions at CU SON. Six out of nine respondents $(66.7 \%)$ explained that low salaries were the primary motivator for why faculty leave CU SON (see Table 53). One Clinical Instructor observed that nursing faculty left CU SON for private schools and for-profit universities because those institutions paid higher salaries. Coupled with salary, according to four interviewees (44.4\%) was increased workload. Additionally, four faculty (44.4\%) noted that nursing faculty often leave to set up independent clinical practices. Another response provided by four participants (44.4\%) was that faculty left MU SON due to retirement. Moreover, two faculty $(22.2 \%)$ noted that student incivility caused faculty to leave. Finally, two faculty $(22.2 \%)$ observed that the requirement to obtain a doctorate led to nursing faculty leaving the school. As one Associate Professor explained, 
Our dean has mandated that everybody is to work on their doctorate and we have faculty in their " 50 s or late ' 50 s and even in their " 60 s going back and working on their PhDs now. I think that's created a lot of stress in the system and I think it's a wonderful long term idea if we would have said 'by 2015, if you're under this age you should be working on your doctorate,' but this sort of a blanket mandate was not a team building approach. We lost faculty because of that and then faculty that have gotten their doctorates, we don't have promotion positions for them. So, you can mandate the people to go back to school, but then when they get done with that, they kind of want some acknowledgment. If you don't have any money and you don't have any new positions, then people feel resentful.

\section{Table 53}

Reasons Nursing Faculty Leave CU SON

\begin{tabular}{lcc}
\hline $\begin{array}{l}\text { Interview response: Reasons } \\
\text { nursing faculty leave CU SON }\end{array}$ & $\begin{array}{c}\text { Number of responses } \\
\text { N=9 }\end{array}$ & $\begin{array}{c}\text { Percentage (\%) based upon } \\
\text { number of respondents } \\
\mathrm{N}=9\end{array}$ \\
\hline Low salary & 6 & 66.7 \\
\hline Increased workload & 4 & 44.4 \\
\hline Independent practice & 4 & 44.4 \\
\hline Retirement & 4 & 44.4 \\
\hline Student incivility & 2 & 22.2 \\
\hline Doctorate requirement & 2 & 22.2 \\
\hline
\end{tabular}

\section{Strategies to increase nursing faculty in the profession: Administrator and faculty perceptions.}

All participants were asked what strategies would be helpful to increase the number of nursing faculty in the profession. The nine participants (100\%) explained that increased salaries would assist in recruiting nursing faculty (see Table 54). As a Clinical Instructor observed,

It's a cultural thing. In any other profession you work hard and you are more productive, you get paid more, but we just kind of get recognized and 'oh that's so wonderful what 
you did for your profession.' But where's the actual, tangible reward for that? I do believe most nurses feel like, 'this is my profession, I'm a caring nurse. I should be selfless and do this,' but at some point you can't pay your bills anymore. There's no way these younger nurses are going to go to grad school if they hear this from the other faculty who are leaving that 'I couldn't even make it on the salary.'

Nine individuals (100\%) noted that flexibility in teaching schedules, required office hours, and days nursing faculty need to be on campus would be effective. Recognition was also suggested by eight interviewees (88.9\%). They explained that certificates of appreciation and recognition dinners or ceremonies for a job well done would be beneficial. Five of the nine participants (55.6\%) explained that a decreased workload was needed to increase recruitment efforts. As one Associate Professor stated, "the new generation of graduates want a controlled lifestyle. I think for us to be successful in recruiting the talent, we're going to need to do a better job of boundaries." Another four nursing faculty (44.4\%) suggested building a progression from undergraduate to graduate education into the curriculum, because it is "rare that nursing students ever think beyond working in the hospital." Finally, three participants (33.3\%) explained that tuition reimbursement would be effective in recruitment of nursing faculty (see Table 54).

Table 54

Strategies to Recruit Nursing Faculty in the Profession - CU SON

\begin{tabular}{lcc}
$\begin{array}{l}\text { Interview response: Strategies } \\
\text { to recruit nursing faculty in } \\
\text { the profession }\end{array}$ & Number of responses & $\begin{array}{c}\text { Percentage (\%) based upon } \\
\text { number of respondents } \\
\mathrm{N}=9\end{array}$ \\
\hline Higher salaries & $\mathrm{N}=9$ & 100 \\
\hline Flexibility & 9 & 100 \\
\hline Recognition & 8 & 88.9 \\
\hline Decreased workload & 5 & 55.6 \\
\hline Progression of education & 4 & 44.4 \\
\hline Tuition reimbursement & 3 & 33.3 \\
\hline
\end{tabular}


Finally, the nine participants were questioned as to what should be done to retain nursing faculty in education. Eight out of nine individuals (88.9\%) explained that both "realistic" workloads and flexibility in teaching would be beneficial. An Associate Professor observed that allowing nursing faculty to work at home, telecommute, and attend meetings on-line through programs like Skype would positively impact retention efforts. Seven individuals (77.8\%) stated that recognition was needed to increase retention. An Assistant Professor stated that CU SON has improved its recognition of nursing faculty and held a small Christmas recognition dinner at which faculty received certificates of appreciation. She said that efforts such as this greatly improved retention efforts. Seven out of nine nursing faculty and administrators $(77.8 \%)$ said that increased salaries would positively impact retention of nursing faculty. Five nursing faculty $(55.6 \%)$ explained that tuition reimbursement would be effective. Moreover, changing the culture of student incivility was suggested by three individuals $(33.3 \%)$ as was creating a mentoring program for new faculty. A Clinical Instructor (11.1\%) suggested that nursing faculty should be paid a bonus for bringing research money to the school. An Associate Dean for Undergraduate Programs (11.1\%) posited that shared faculty between interprofessional groups would increase retention. Ultimately, as an Associate Professor concluded, retention would be greatly improved if there was "more money, less work, less responsibility, and easier to get tenure" (see Table 55). 
Table 55

Strategies to Retain Nursing Faculty in the Profession - CU SON

\begin{tabular}{lcc}
$\begin{array}{l}\text { Interview response: Strategies } \\
\text { to retain nursing faculty in the } \\
\text { profession }\end{array}$ & Number of responses & $\begin{array}{c}\text { Percentage (\%) based upon } \\
\text { number of respondents } \\
\mathrm{N}=9\end{array}$ \\
Realistic workloads & 8 & 88.9 \\
\hline Flexibility in teaching & 8 & 88.9 \\
\hline Recognition & 7 & 77.8 \\
\hline Increased salaries & 7 & 77.8 \\
\hline Tuition reimbursement & 5 & 55.6 \\
\hline Change student incivility & 3 & 33.3 \\
\hline Bonus for research money & 1 & 11.1 \\
\hline Shared faculty & 1 & 11.1 \\
\hline
\end{tabular}

\section{Summary of Findings}

Data were collected from interviews with three administrators and six nursing faculty at CU SON. The first research question was addressed by participants' descriptions of recent strategies CU SON had implemented to address recruitment and retention of nursing faculty. The administrators explained that many approaches were used to recruit new faculty, including search committees, advertisements, word of mouth, and the hiring of CU SON doctoral students. However, the respondents agreed that due to the low salaries offered by CU SON coupled with the location of some campuses, recruitment was difficult. Additionally, the administrators noted that recruitment was also negatively affected by a lack of available faculty in certain specialties and the high amount of responsibilities required of chairpersons. This evidence was supported by CU SON's website which showed a significant number of positions in both the clinical and tenure tracks that the school needed to fill.

For the second research question, interviewees were queried about what strategies were effective for recruitment and retention at CU SON. Faculty believed that autonomy and flexibility in creating and conducting their courses was a significant motivator. Moreover, the 
participants explained that the positive culture and collegial environment of CU SON was a major contributor.

The process of obtaining tenure was also addressed by the administrators and nursing faculty. Many agreed that the process to obtain tenure was difficult and time consuming. The requirements involved excellence in research, teaching, or service, with satisfaction in the remaining two categories. Additionally, scholarship was also emphasized. The participants explained that tenure and promotion guidelines changed each year. However, successful tenure track faculty received a significant salary increase. But, clinical faculty who obtained a doctorate and acquired tenure did not receive a similar salary increase and had fewer opportunities to apply for tenure due to a lack of administrative support.

The third research question involved what external stakeholders collaborated with nursing faculty. All faculty agreed that collaboration between CU SON, CU SOM, and the Central University health system were key to their clinical practicums. In fact, according to some participants, the health system provided salaries for eight nursing faculty. In addition, the interviewees noted that CU SON had a unique program for students, the PEP, in which students were placed on training floors and gave care to actual patients. However, due to decreases in clinical availability and placements, CU SON increased the use of simulation and, in particular, created a simulation hospital. The simulation hospital was used by each rotation of nursing students prior to clinical placements. Nursing education at CU SON also had strong on-line undergraduate and graduate programs, which some participants explained increased student enrollment.

Finally, the fourth research question focused on the reasons behind the lack of recruitment and retention of nursing faculty within schools of nursing. A primary response by 
the participants indicated that low salaries for nursing faculty was the primary contributor in recruitment and retention issues. Coupled with low salary was increased workload. Participants also noted that the requirement of a doctorate, student incivility, the lack for recognition, inflexibility in teaching, and inadequate tuition reimbursement impacted nursing faculty recruitment and retention. In order for recruitment and retention to increase, according to the interviewees, realistic workloads, flexibility, and increased salaries were suggested, as was increased recognition and tuition reimbursement. 


\section{Chapter Six: Cross Site Analysis of Two Schools of Nursing}

\section{Introduction}

Two schools of nursing were studied for this qualitative research analysis. Both public universities are comprehensive doctoral institutions as classified by the Carnegie Foundation (2005). MU SON and CU SON are located in a major city in their respective states and have various campuses throughout those states. Total enrollment for each school is similar, with over 30,000 enrolled at Central University and over 35,000 enrolled at Mountain University. The numbers of faculty at each school is also comparable, with 3,000 faculty at Mountain University and 2,500 faculty at Central University. Additionally, both institutions are accredited by the North Central Association of Colleges and Schools and have multiple colleges present with a similar number of degrees offered.

Founded in 1914, CU SON is older than MU SON, which was created in 1951. The organization of each school differs, with MU SON following a top-to-bottom flow chart and CU SON applying a federation-type model in which eight separate CU SON provide nursing education to its regional population, with three CU SON campuses functioning as the "core" administrative unit. Both schools offer undergraduate and graduate programs - BSN, RN to BSN, RN to MSN, BS/BA to BSN, MSN, Post MSN-NP, DNP, and PhD. CU SON also offers a BSN to PhD program.

At MU SON, over 900 students are taught by approximately 60 faculty, which results in a 15 to 1 student-to-faculty ratio. CU SON's 1,400 students are educated by approximately 191 faculty, for a 7 to 1 student-to-faculty ratio. Moreover, the missions of both schools are similar in that each school's goal is to provide for excellence in nursing education and training in order to benefit the citizens of each state. 


\section{Study Participants}

Sixteen nursing faculty and administrators were interviewed at both schools. Five administrators and eleven nursing faculty participated. All interviewees were women and Caucasian. A diverse group of participants were interviewed with ranks from a part-time Clinical Instructor to full Professors.

At MU SON, the mean age of faculty was 51.7 years of age with a range of 41 years of age. At CU SON, the mean age of faculty was 50 years of age with a range from 36 years of age. The majority of participants at MU SON were 55 years of age or older and 40 years of age or older at CU SON. When both schools were viewed, 13 out of 16 participants $(81.3 \%)$ were over 40 years of age (see Table 56).

Table 56

Combined Age of Participants

\begin{tabular}{cccc}
\hline Age & $\begin{array}{c}\text { MU SON } \\
\mathrm{N}=7(\%)\end{array}$ & $\begin{array}{c}\text { CU SON } \\
\mathrm{N}=9(\%)\end{array}$ & $\begin{array}{c}\text { Total } \\
\mathrm{N}=16(\%)\end{array}$ \\
\hline $25-39$ & $2(28.6)$ & $1(11.1)$ & $3(18.8)$ \\
\hline $40-54$ & $1(14.3)$ & $5(55.6)$ & $6(37.5)$ \\
\hline $55-69$ & $3(42.9)$ & $3(33.3)$ & $6(37.5)$ \\
\hline $70-84$ & $1(14.3)$ & 0 & $1(6.3)$ \\
\hline
\end{tabular}

At MU SON, salaries ranged from $\$ 40,000$ per year to over $\$ 100,000$ per year, with administrators earning the highest amount of money. Similarly, at CU SON, salaries ranged from under $\$ 40,000$ per year to over $\$ 100,000$ per year, with administrators receiving the largest salaries. Once the five administrators were removed from salary considerations, the majority of nursing faculty at both schools $(n=11,63.6 \%)$ earned salaries under $\$ 60,000$ per year. Four nursing faculty $(n=11,36.4 \%)$ earned between $\$ 70,001$ and $\$ 90,000$ per year and generally held the rank of Associate Professor. The five administrators interviewed all earned salaries of $\$ 90,001$ or more per year (see Table 57). 
Table 57

Combined Current Salary of Participants

\begin{tabular}{lccc}
\hline \multicolumn{1}{c}{ Salary } & $\begin{array}{c}\text { MU SON } \\
\mathrm{N}=7(\%)\end{array}$ & $\begin{array}{c}\text { CU SON } \\
\mathrm{N}=9(\%)\end{array}$ & $\begin{array}{c}\text { Total } \\
\mathrm{N}=16(\%)\end{array}$ \\
\hline Under $\$ 40,000$ per year & 0 & $1(11.1)$ & $1(6.3)$ \\
\hline$\$ 40,000$ to $\$ 50,000$ per year & $1(14.3)$ & $1(11.1)$ & $2(12.5)$ \\
\hline$\$ 50,001$ to $\$ 60,000$ per year & $2(28.6)$ & $2(22.2)$ & $4(25)$ \\
\hline$\$ 60,001$ to $\$ 70,000$ per year & 0 & 0 & 0 \\
\hline$\$ 70,001$ to $\$ 80,000$ per year & $2(28.6)$ & $1(11.1)$ & $3(18.8)$ \\
\hline$\$ 80,001$ to $\$ 90,000$ per year & 0 & $1(11.1)$ & $1(6.3)$ \\
\hline$\$ 90,001$ to $\$ 100,000$ per year & 0 & $1(11.1)$ & $1(6.3)$ \\
\hline Above $\$ 100,000$ per year & $2(28.6)$ & $2(22.2)$ & $4(25)$ \\
\hline
\end{tabular}

At MU SON, five out of seven participants (71.4\%) taught both didactic and clinical courses. Two faculty (28.6\%), both administrators, taught only didactic courses. At CU SON, four individuals $(44.4 \%)$ taught both clinical courses and the same amount provided just didactic instruction. The remaining interviewee, an administrator, taught only clinical courses. Thus, at MU SON, the majority of nursing faculty taught both didactic and clinical instruction, while at CU SON, the faculty is generally split between didactic responsibilities or didactic and clinical instruction. At CU SON, those nursing faculty that taught only didactic courses are at the Associate Professor level or higher, while individuals who provided both didactic and clinical instruction were either Assistant Professors or Clinical Instructors.

Regarding program level teaching responsibilities, nursing faculty were split at both schools. At MU SON, three individuals (42.9\%) taught in the undergraduate program while the same amount taught in both the undergraduate and graduate programs. The participant (14.3\%) who taught exclusively in the graduate program was an administrator. The three individuals who taught solely at the undergraduate level were at the Clinical Instructor level, while those who taught in both the undergraduate and graduate programs were either Assistant Professors or Associate Professors. At CU SON, four nursing faculty (44.4\%) taught in the undergraduate 
program while three interviewees (33.3\%) instructed in both the undergraduate and graduate programs. Two individuals (22.2\%), one Associate Professor and one Assistant Professor, instructed exclusively in the graduate program. The three individuals who instructed at both the undergraduate and graduate levels were Associate Professors. Moreover, the nursing faculty who taught exclusively in the undergraduate program were either Clinical Instructors or Assistant Professors.

When comparing both schools, the hours per week nursing faculty spend in class-based and on-line instruction was similar. However, there was less congruence in clinical instruction, required office hours per week, and hours per week spent at home. In all three categories, MU SON nursing faculty spent more hours per week invested than their counterparts at CU SON. The difference in clinical instruction was 1.7 hours per week additional for MU SON faculty as compared to CU SON faculty. MU SON nursing faculty also spent 4.6 hours per week additional in required office hours and 4.2 hours per week additional spent at home (see Table $58)$.

Table 58

Combined Hours Per Week Spent in Instruction, Office Hours, and At Home

\begin{tabular}{lllllll}
\hline $\begin{array}{l}\text { Instruction and } \\
\text { hours spent }\end{array}$ & $\begin{array}{l}\text { MU SON } \\
\text { mean } \\
\mathrm{N}=7\end{array}$ & $\begin{array}{l}\text { MU SON } \\
\text { range } \\
\mathrm{N}=7\end{array}$ & $\begin{array}{l}\text { CU SON } \\
\text { mean } \\
\mathrm{N}=9\end{array}$ & $\begin{array}{l}\text { CU SON } \\
\text { range } \\
\mathrm{N}=9\end{array}$ & $\begin{array}{l}\text { Combined } \\
\text { mean }\end{array}$ & $\begin{array}{l}\text { Combined } \\
\text { range }\end{array}$ \\
\hline Class-based & 3.3 & 8 & 3.1 & 6 & 3.2 & $\mathrm{~N}=16$ \\
\hline On-line & 4.3 & 16 & 4.7 & 30 & 4.5 & 30 \\
\hline Clinical & 6.4 & 12 & 4.7 & 24 & 5.4 & 24 \\
\hline $\begin{array}{l}\text { Required office } \\
\text { hours }\end{array}$ & 10.3 & 40 & 5.7 & 40 & 7.7 & 40 \\
\hline $\begin{array}{l}\text { Hours spent at } \\
\text { home }\end{array}$ & 12.3 & 30 & 8.1 & 20 & 9.9 & 30 \\
\hline
\end{tabular}

Nursing faculty at both MU SON and CU SON taught a similar number of didactic courses and clinical courses. While the amount of clinical credits was generally consistent, MU 
SON faculty carried a heavier course credit amount than their peers at CU SON. The difference between the two schools is 2.3 credits per didactic course (see Table 59).

Table 59

Combined Number of Courses, Clinicals, and Credits Per Semester

\begin{tabular}{lllllll}
\hline $\begin{array}{l}\text { Courses, } \\
\text { clinicals, and } \\
\text { credits }\end{array}$ & $\begin{array}{l}\text { MU SON } \\
\text { mean } \\
\mathrm{N}=7\end{array}$ & $\begin{array}{l}\text { MU SON } \\
\text { range }\end{array}$ & $\begin{array}{l}\text { CU SON } \\
\text { mean }\end{array}$ & $\begin{array}{l}\text { CU SON } \\
\text { range }\end{array}$ & $\begin{array}{l}\text { Combined } \\
\text { mean } \\
\text { N=9 }\end{array}$ & $\begin{array}{l}\text { Combined } \\
\text { range }\end{array}$ \\
\hline Courses & 1.4 & 1 & 1.1 & 2 & 1.3 & 2 \\
\hline Course credits & 5.4 & 8 & 3.1 & 6 & 4.1 & 9 \\
\hline Clinicals & 0.7 & 2 & 0.8 & 3 & 0.8 & 3 \\
\hline Clinical credits & 2.3 & 5 & 1.8 & 6 & 2.0 & 6 \\
\hline
\end{tabular}

The number of advisees and committees per year differed for each school. CU SON nursing faculty had a higher number of advisees and were on a greater amount of committees than nursing faculty at MU SON (see Table 60). However, one Associate Professor at CU SON was the Coordinator of the Psychiatric Clinical Nurse Specialist Program in the Department of Environments for Health and advised all 56 students in the program. Thus, CU SON's higher number of advisees was a result of this fact, even though six of seven (85.7\%) of MU SON's nursing faculty had at least six advisees compared to only four of nine faculty (44.4\%) at CU SON who had at least one advisee (see Tables 10 and 36).

Table 60

Combined Advisees and Committees Per Year

\begin{tabular}{lllllll} 
Advisees and & $\begin{array}{l}\text { MU SON } \\
\text { mean }\end{array}$ & $\begin{array}{l}\text { MU SON } \\
\text { Range }\end{array}$ & $\begin{array}{l}\text { CU SON } \\
\text { Mean }\end{array}$ & $\begin{array}{l}\text { CU SON } \\
\text { Range }\end{array}$ & $\begin{array}{l}\text { Combined } \\
\text { Mean }\end{array}$ & $\begin{array}{l}\text { Combined } \\
\text { Range }\end{array}$ \\
committees & $\mathrm{N}=7$ & $\mathrm{~N}=7$ & $\mathrm{~N}=9$ & $\mathrm{~N}=9$ & $\mathrm{~N}=16$ & $\mathrm{~N}=16$ \\
\hline Advisees & 6.7 & 10 & 7.5 & 56 & 7.2 & 56 \\
\hline Committees & 6.3 & 10 & 7.2 & 20 & 6.8 & 20 \\
\hline
\end{tabular}

The majority of nursing faculty at both schools were involved in currently revising or creating a course. At MU SON, five of seven participants (71.4\%) were currently revising or 
creating a course. Similarly, seven of nine interviewees $(77.8 \%)$ were undertaking these duties at CU SON.

Nursing faculty at both schools generally spent more than 40 hours per week completing their duties as nursing faculty. Only two faculty (12.5\%), both part-time faculty, spent less than 40 hours per week in their roles. The remainder of faculty $(87.5 \%)$ undertook over 40 hours per week in their responsibilities (see Table 61).

Table 61

Combined Hours Per Week Spent Completing Duties

\begin{tabular}{lccc}
\hline $\begin{array}{l}\text { Hours per week spent completing } \\
\text { duties as nursing faculty }\end{array}$ & $\begin{array}{c}\text { MU SON } \\
\mathrm{N}=7(\%)\end{array}$ & $\begin{array}{c}\text { CU SON } \\
\mathrm{N}=9(\%)\end{array}$ & $\begin{array}{c}\text { Total } \\
\mathrm{N}=16(\%)\end{array}$ \\
\hline $11-20$ hours/week & 0 & $1(11.1)$ & $1(6.3)$ \\
\hline $21-30$ hours/week & 0 & 0 & 0 \\
\hline $31-40$ hours/week & 0 & $1(11.1)$ & $8(50.3)$ \\
\hline $41-50$ hours/week & $3(42.9)$ & $5(55.6)$ & $4(25)$ \\
\hline $51-60$ hours/week & $4(57.1)$ & 0 & $2(12.5)$ \\
\hline $61-70$ hours/week & 0 & $2(22.2)$ & 0 \\
\hline $70+$ hours/week & 0 & 0 & \\
\hline
\end{tabular}

Both MU SON and CU SON nursing faculty were also involved in research efforts, with CU SON individuals generally more active in research. At CU SON, six interviewees (66.7\%) noted that they engage in research "to a great extent" or "to some extent" as opposed to only four individuals $(57.1 \%)$ at MU SON. The same number of participants at both schools indicated that they undertake research "very little" or are "not involved." A comparison shows that ten out of 16 participants $(62.5 \%)$ indicated active research efforts (see Table 62). 
Table 62

Combined Involvement in Research

\begin{tabular}{lccc}
\cline { 2 - 4 } Involvement in research & $\begin{array}{c}\text { MU SON } \\
\mathrm{N}=7(\%)\end{array}$ & $\begin{array}{c}\text { CU SON } \\
\mathrm{N}=9(\%)\end{array}$ & $\begin{array}{c}\text { Total } \\
\mathrm{N}=16(\%)\end{array}$ \\
\cline { 2 - 4 } To a great extent & $1(14.3)$ & $3(33.3)$ & $4(25)$ \\
To some extent & $3(42.8)$ & $3(33.3)$ & $6(37.5)$ \\
Very little & $2(28.6)$ & 0 & $2(12.5)$ \\
Not involved & $1(14.3)$ & $3(33.3)$ & $4(25)$ \\
\hline
\end{tabular}

Nursing faculty at both institutions had been published in the past three (3) years. Individuals at CU SON were more likely to be published (66.7\%) than their counterparts at MU SON (57.1\%). Additionally, of those published nursing faculty at CU SON, the mean is 7.2 publications in the past three years, with a range of 15. MU SON interviewees had a mean of 3.3 publications in the past three years, with a range of 4 (see Table 63).

Table 63

Combined Number of Publications in the Past Three Years

\begin{tabular}{|c|c|c|c|c|c|c|c|c|c|}
\hline $\begin{array}{l}\text { Published in } \\
\text { the past three } \\
\text { (3) years? }\end{array}$ & $\begin{array}{c}\text { MU } \\
\text { SON } \\
\mathrm{N}=7 \\
(\%)\end{array}$ & $\begin{array}{c}\text { MU } \\
\text { SON } \\
\text { mean } \\
\mathrm{N}=4\end{array}$ & $\begin{array}{c}\text { MU } \\
\text { SON } \\
\text { range } \\
\mathrm{N}=4\end{array}$ & $\begin{array}{c}\text { CU } \\
\text { SON } \\
\mathrm{N}=9 \\
(\%)\end{array}$ & $\begin{array}{c}\mathrm{CU} \\
\mathrm{SON} \\
\text { mean } \\
\mathrm{N}=5\end{array}$ & $\begin{array}{l}\mathrm{CU} \\
\mathrm{SON} \\
\text { range } \\
\mathrm{N}=5\end{array}$ & $\begin{array}{c}\text { Total } \\
\mathrm{N}=16 \\
(\%)\end{array}$ & $\begin{array}{c}\text { Com- } \\
\text { bined } \\
\text { mean } \\
\mathrm{N}=9\end{array}$ & $\begin{array}{c}\text { Com- } \\
\text { bined } \\
\text { range } \\
\mathrm{N}=9\end{array}$ \\
\hline Yes & $\begin{array}{c}4 \\
(57.1)\end{array}$ & 3.3 & 4 & $\begin{array}{c}5 \\
(66.7)\end{array}$ & 7.2 & 15 & $\begin{array}{c}10 \\
(62.5)\end{array}$ & 6.2 & 17 \\
\hline No & $\begin{array}{c}3 \\
(42.9)\end{array}$ & -- & -- & $\begin{array}{c}3 \\
(33.3)\end{array}$ & -- & -- & $\begin{array}{c}6 \\
(37.5)\end{array}$ & -- & -- \\
\hline
\end{tabular}

Nursing faculty at MU SON were more likely than their counterparts at CU SON to feel undercompensated for their credentials. Five out of seven individuals (71.4\%) at MU SON believed they were not fully compensated as compared to five of nine interviewees $(55.6 \%)$ at CU SON. Only two participants $(28.6 \%)$ at MU SON believed they were fully compensated, while four nursing faculty (44.4\%) held that belief at CU SON. When the responses were combined, ten participants $(62.5 \%)$ believed they were not fully compensated by their respective schools for their credentials. 
The majority of nursing faculty at both schools (87.5\%) were satisfied in their current role as nursing faculty. Only one individual (14.3\%) from MU SON and one participant (11.1\%) from CU SON were unsatisfied.

\section{Responses to Interview Protocol}

\section{Setting the context: Reasons to teach nursing - Combined administrator and faculty responses.}

The reason that nursing faculty decided to teach at their schools of nursing were compared. Both MU SON and CU SON participants noted collaboration with other faculty, familiarity with the area or moved to the area, and their recent graduate status. MU SON faculty mentioned that they chose to teach at MU SON to carry out research goals, while CU SON faculty observed they chose that school for its reputation and because one nursing faculty was requested to apply. MU SON faculty $(60 \%)$ more frequently suggested faculty collaboration than their CU SON peers (16.7\%). However, CU SON faculty (50\%) were more likely to choose their school based on familiarity with the area or a recent move to the area than individuals at MU SON (20\%). When responses were combined, four individuals (36.4\%) stated they chose their respective school in order to collaborate with other faculty and because they were familiar with or moved to the area (see Table 64). 
Table 64

Combined Reasons for Teaching at School of Nursing

\begin{tabular}{lccc}
\hline Reasons for teaching & $\begin{array}{l}\text { MU SON } \\
\mathrm{N}=5(\%)\end{array}$ & $\begin{array}{c}\text { CU SON } \\
\mathrm{N}=6(\%)\end{array}$ & $\begin{array}{c}\text { Total } \\
\mathrm{N}=11(\%)\end{array}$ \\
\cline { 2 - 4 } $\begin{array}{l}\text { Collaboration with other } \\
\text { faculty }\end{array}$ & $3(60)$ & $1(16.7)$ & $4(36.4)$ \\
\hline $\begin{array}{l}\text { Familiar with/moved to } \\
\text { area }\end{array}$ & $1(20)$ & $3(50)$ & $4(36.4)$ \\
\hline $\begin{array}{l}\text { Recent graduate } \\
\text { Carry out research goals }\end{array}$ & $1(20)$ & $1(16.7)$ & $2(18.2)$ \\
\hline $\begin{array}{l}\text { Reputation } \\
\text { Requested to apply by } \\
\text { Dean }\end{array}$ & $2(40)$ & 0 & $2(18.2)$ \\
\hline
\end{tabular}

All participants were asked to explain why they remained in their schools as educators. All seven interviewees at MU SON explained they remained due to supportive faculty, while only one participant (11.1\%) noted this reason at CU SON. Similarly, six MU SON participants $(85.7 \%)$ remained due to the collegial environment and "team effort" at the school as compared to only two interviewees $(22.2 \%)$ at CU SON. Autonomy and flexibility was suggested by five MU SON nursing faculty and administrators (71.4\%) and was not offered by any CU SON individuals. CU SON participants (44.4\%) were more likely to remain due to satisfaction in their current role, which was a reason not suggested by MU SON faculty. Similarly, four MU SON interviewees (57.1\%) explained they remained due to their passion for teaching and to inspire students, which was not reported by CU SON participants. CU SON individuals also suggested the school's resources, family in the area, and economic incentives as reasons for remaining as nursing faculty, none of which were offered by MU SON nursing faculty (see Table 65). 
Table 65

Combined Reasons for Remaining as Nursing Faculty

\begin{tabular}{lccc}
\hline $\begin{array}{l}\text { Reasons for remaining as nursing } \\
\text { faculty }\end{array}$ & $\begin{array}{c}\text { MU SON } \\
\mathrm{N}=7(\%)\end{array}$ & $\begin{array}{c}\text { CU SON } \\
\mathrm{N}=9(\%)\end{array}$ & $\begin{array}{c}\text { Total } \\
\mathrm{N}=16(\%)\end{array}$ \\
\hline $\begin{array}{l}\text { Supportive faculty/support } \\
\text { Collegial environment/team effort }\end{array}$ & $7(100)$ & $1(11.1)$ & $8(50)$ \\
\hline $\begin{array}{l}\text { Autonomy and flexibility } \\
\text { Satisfaction in role }\end{array}$ & $5(85.7)$ & $2(22.2)$ & $8(50)$ \\
\hline $\begin{array}{l}\text { Passion for teaching/inspire } \\
\text { students }\end{array}$ & $5(71.4)$ & 0 & $5(31.3)$ \\
Mentoring new faculty & $4(57.1)$ & $4(44.4)$ & $4(25)$ \\
\hline CU SON resources & 0 & 0 & $4(25)$ \\
\hline Family in area & 0 & $2(22.2)$ & $2(12.5)$ \\
\hline Economic reasons & 0 & $1(11.1)$ & $1(6.3)$ \\
\hline
\end{tabular}

\section{Research question 1: Enrollment management - Combined administrator responses.}

Nursing administrators were questioned about limitations to increasing student admissions. All administrators at both MU SON and CU SON responded that student admissions were negatively impacted due to lack of resources for clinical placements. This reason was the only limitation offered by administrators at both schools. The additional reasons noted were focused on faculty issues: lack of faculty lines, limited faculty resources, limited faculty salaries, and lack of qualified faculty (see Table 66).

Table 66

Combined Limitations to Increasing Student Admissions

\begin{tabular}{lccc}
\hline $\begin{array}{l}\text { Limitations to increasing student } \\
\text { admissions }\end{array}$ & $\begin{array}{l}\text { MU SON } \\
\mathrm{N}=2(\%)\end{array}$ & $\begin{array}{l}\text { CU SON } \\
\mathrm{N}=3(\%)\end{array}$ & $\begin{array}{c}\text { Total } \\
\mathrm{N}=5(\%)\end{array}$ \\
\hline $\begin{array}{l}\text { Lack of resources for clinical } \\
\text { placements }\end{array}$ & $2(100)$ & $3(100)$ & $5(100)$ \\
Lack of faculty lines & $2(100)$ & 0 & $2(40)$ \\
\hline Limited faculty resources & 0 & $2(66.7)$ & $2(40)$ \\
\hline Limited faculty salaries & $1(50)$ & 0 & $1(20)$ \\
\hline Lack of qualified faculty & 0 & $1(33.3)$ & $1(20)$ \\
\hline
\end{tabular}




\section{Research question 1: Recruitment and retention of nursing faculty - Combined administrator responses.}

Administrators at both schools were also queried about recruitment strategies. Both MU SON and CU SON have similar recruitment strategies, with both utilizing advertisements $(100 \%)$, word of mouth (80\%), and the recruitment of recent graduates/doctoral students $(80 \%)$.

CU SON used search committees, while MU SON did not. Additionally, one MU SON administrator suggested that recruitment was impacted by individuals who moved to the area with their families (see Table 67).

Table 67

\section{Combined Recruitment Strategies}

\begin{tabular}{lccc} 
Recruitment strategies & $\begin{array}{l}\text { MU SON } \\
\mathrm{N}=2(\%)\end{array}$ & $\begin{array}{l}\text { CU SON } \\
\mathrm{N}=3(\%)\end{array}$ & $\begin{array}{c}\text { Total } \\
\mathrm{N}=5(\%)\end{array}$ \\
\hline $\begin{array}{l}\text { Advertisements (newspapers, } \\
\text { journals, website, conferences) }\end{array}$ & $2(100)$ & $3(100)$ & $5(100)$ \\
Word of mouth & $1(50)$ & $3(100)$ & $4(80)$ \\
Recent graduates/doctoral students & $1(50)$ & $3(100)$ & $4(80)$ \\
\hline Search committees & 0 & $3(100)$ & $3(60)$ \\
Moved to area with family & $1(50)$ & 0 & $1(20)$ \\
\hline
\end{tabular}

When questioned about challenges to recruitment, one administrator from both MU SON $(50 \%)$ and $\mathrm{CU}$ SON (33\%) noted lack of qualified educators in certain specialties, as well as the location of the school, explaining that individuals had to make a purposeful decision to work at the school. Moreover, one administrator from CU SON (33\%) explained that low salaries negatively affected recruitment as did the high amount of responsibility required of chairpersons (see Table 68). 
Table 68

Combined Recruitment Challenges

\begin{tabular}{lccc}
\hline Recruitment challenges & $\begin{array}{c}\text { MU SON } \\
\mathrm{N}=2(\%)\end{array}$ & $\begin{array}{c}\text { CU SON } \\
\mathrm{N}=3(\%)\end{array}$ & $\begin{array}{c}\text { Total } \\
\mathrm{N}=5(\%)\end{array}$ \\
\hline Lack of specialties & $1(50)$ & $1(33.3)$ & $2(40)$ \\
\hline Location/purposeful reason to move & $1(50)$ & $1(33.3)$ & $2(40)$ \\
\hline Low salaries & 0 & $1(33.3)$ & $1(20)$ \\
\hline $\begin{array}{l}\text { High amount of responsibility for } \\
\text { chairpersons }\end{array}$ & 0 & $1(33.3)$ & $1(20)$ \\
\hline
\end{tabular}

Research question 2: Effective strategies to recruit and retain nursing faculty. Designing courses: Combined faculty perceptions.

Nursing faculty were queried about whether they had freedom in designing and conducting their courses. Unanimously across both schools, faculty explained that while they based their courses on a template syllabus and must follow the curriculum and objectives, they had academic freedom and flexibility as to all aspects of the course. All MU SON nursing faculty noted that they were required to seek approval if they desired to change the course's textbook. Moreover, MU SON participants observed that their course content had to be updated and remain current. Three of CU SON's nursing faculty (50\%) explained that individual sections of a course were permitted to create different exams (see Table 69).

Table 69

Combined Freedom in Designing and Conducting Courses

\begin{tabular}{lccc} 
Freedom in designing and & MU SON & CU SON & Total \\
conducting courses & $\mathrm{N}=5(\%)$ & $\mathrm{N}=6(\%)$ & $\mathrm{N}=11(\%)$ \\
\hline Academic freedom & $5(100)$ & $6(100)$ & $11(100)$ \\
\hline Template syllabus & $5(100)$ & $6(100)$ & $11(100)$ \\
\hline Flexibility & $5(100)$ & $6(100)$ & $11(100)$ \\
\hline Textbook approval & $5(100)$ & 0 & $5(45.5)$ \\
\hline Current content & $5(100)$ & 0 & $5(45.5)$ \\
\hline Individual section exams & 0 & $3(50)$ & $3(27.3)$ \\
\hline
\end{tabular}




\section{Research question 3: Collaboration with external stakeholders - Combined administrator perceptions.}

Administrators at both schools were questioned about external partnerships. All nursing administrators explained that local hospitals and community health partners, consisting of clinics, health and community centers, and the county health department, were utilized, as was collaboration between the school of nursing, school of medicine, and local health system. Both schools used nurses as preceptors. CU SON administrators listed another external partnership unique to their school, the Practice Education Program (PEP), which is not available at MU SON. The PEP created entire training floors for students at various hospital in which admitted patients are cared for by nursing students with supervision by instructors (see Table 70).

Table 70

\section{Combined External Partnerships}

\begin{tabular}{lccc} 
External partnerships & $\begin{array}{l}\text { MU SON } \\
\mathrm{N}=2(\%)\end{array}$ & $\begin{array}{c}\text { CU SON } \\
\mathrm{N}=3(\%)\end{array}$ & $\begin{array}{c}\text { Total } \\
\mathrm{N}=5(\%)\end{array}$ \\
$\begin{array}{l}\text { Local hospitals } \\
\begin{array}{l}\text { Community health partners (clinics, } \\
\text { health and community centers, } \\
\text { health department) }\end{array}\end{array}$ & $2(100)$ & $3(100)$ & $5(100)$ \\
$\begin{array}{l}\text { Collaboration between SON, SOM, } \\
\text { and health system }\end{array}$ & $2(100)$ & $3(100)$ & $5(100)$ \\
$\begin{array}{l}\text { Nurses as preceptors } \\
\text { Practice Education Program }\end{array}$ & $2(100)$ & $3(100)$ & $5(100)$ \\
\hline
\end{tabular}

\section{Research question 4: Lack of recruitment and retention.}

\section{Working conditions: Combined faculty responses.}

Nursing faculty at both schools were asked to describe working conditions at their respective schools. Nine of the eleven nursing faculty $(81.8 \%)$ surveyed explained that flexibility was a positive working condition and seven $(63.6 \%)$ noted that they enjoyed the collegial environment of their school. However, seven faculty $(63.6 \%)$ explained that they 
received low salaries or were dissatisfied with their salaries, with all MU SON nursing faculty making this observation compared to only two (33.3\%) of their CU SON counterparts.

Similarly, six of eleven nursing faculty $(64.5 \%)$ mentioned that they were overworked, subjected to an increased workload, or spent more than 40 hours per week completing their duties. All CU SON nursing faculty made this observation while only two individuals (40\%) commented on this working condition at MU SON. Participants at CU SON explained that they were "asked to do more with less" $(66.7 \%)$, but that they were supported by senior faculty and the Dean (50\%) and enjoyed interaction with their students (50\%). One individual at MU SON (20\%) observed that working conditions were "not perfect" and that research was not supported, while one CU SON faculty (16.7\%) said working conditions were "positive" (see Table 71).

\section{Table 71}

Combined Working Conditions at Schools of Nursing

\begin{tabular}{lccc}
\hline $\begin{array}{l}\text { Working conditions at schools of } \\
\text { nursing }\end{array}$ & $\begin{array}{c}\text { MU SON } \\
\mathrm{N}=5(\%)\end{array}$ & $\begin{array}{c}\text { CU SON } \\
\mathrm{N}=6(\%)\end{array}$ & $\begin{array}{c}\text { Total } \\
\mathrm{N}=11(\%)\end{array}$ \\
\hline $\begin{array}{l}\text { Flexibility } \\
\begin{array}{l}\text { Low salaries/dissatisfied with } \\
\text { salaries }\end{array}\end{array}$ & $5(100)$ & $4(66.7)$ & $9(81.8)$ \\
\hline $\begin{array}{l}\text { Collegial environment } \\
\text { Overworked/increased }\end{array}$ & $5(100)$ & $2(33.3)$ & $7(63.6)$ \\
$\begin{array}{l}\text { workload/work more than 40 } \\
\text { hours/week }\end{array}$ & $3(60)$ & $4(66.7)$ & $7(63.6)$ \\
\hline "Asked to do more with less" & $2(40)$ & $6(100)$ & $6(54.5)$ \\
\hline $\begin{array}{l}\text { Support from senior faculty and } \\
\text { Dean }\end{array}$ & 0 & $4(66.7)$ & $4(36.3)$ \\
\hline $\begin{array}{l}\text { Enjoyed interaction with students } \\
\text { "Not perfect" }\end{array}$ & 0 & $3(50)$ & $3(27.3)$ \\
\hline $\begin{array}{l}\text { Research not supported } \\
\text { "Positive" }\end{array}$ & $1(20)$ & $3(50)$ & $3(27.3)$ \\
\hline
\end{tabular}




\section{Lack of recruitment and retention of nursing faculty: Combined administrator and faculty perceptions.}

All participants explained factors impacting recruitment and retention at each school.

The highest response offered by 13 of the 16 interviewees $(81.2 \%)$ was the low salary offered to nursing faculty. A high number of participants at both MU SON (85.7\%) and CU SON (77.8\%) mentioned this barrier. Three respondents at each school explained that the rural location of the school or some of its campuses negatively affected recruitment and retention. Additionally, three individuals at MU SON (42.9\%) and one participant at CU SON (11.1\%) noted that a lack of availability of qualified faculty in certain specialties impacted recruitment and retention. However, each school experienced different barriers to recruitment and retention not experienced by the other school. MU SON was impacted by a lack of grant writing assistance (57.1\%) and a need for a mentorship program (42.9\%). CU SON's recruitment and retention efforts were affected by the requirement of a doctorate for existing faculty $(33.3 \%)$ and by a lack of promotion or increase in salary upon completion of the doctorate $(22.2 \%)$ (see Table 72 ). Table 72

Combined Reasons Impacting Recruitment and Retention

\begin{tabular}{lccc}
$\begin{array}{l}\text { Reasons impacting recruitment and } \\
\text { retention }\end{array}$ & $\begin{array}{l}\text { MU SON } \\
\mathrm{N}=7(\%)\end{array}$ & $\begin{array}{c}\text { CU SON } \\
\mathrm{N}=9(\%)\end{array}$ & $\begin{array}{c}\text { Total } \\
\mathrm{N}=16(\%)\end{array}$ \\
\hline Low salary & $6(85.7)$ & $7(77.8)$ & $13(81.2)$ \\
\hline Rural location & $3(42.9)$ & $3(33.3)$ & $6(37.5)$ \\
$\begin{array}{l}\text { Lack of faculty (research and/or } \\
\text { clinical) }\end{array}$ & $3(42.9)$ & $1(11.1)$ & $4(25)$ \\
\hline $\begin{array}{l}\text { Lack of grant writing assistance } \\
\text { Need for mentorship program }\end{array}$ & $4(57.1)$ & 0 & $4(25)$ \\
Requirement of doctorate & $3(42.9)$ & 0 & $3(18.8)$ \\
\hline $\begin{array}{l}\text { No promotion or pay raise upon } \\
\text { doctorate completion }\end{array}$ & 0 & $3(33.3)$ & $2(12.5)$ \\
\hline
\end{tabular}

All participants were questioned as to why nursing faculty left their schools of nursing. The response offered by 12 of 16 interviewees (75\%) involved low salaries for nursing faculty. 
This answer was provided by six of seven participants (85.7\%) at MU SON, but only by six of nine (66.7\%) respondents at CU SON. Another common explanation mentioned by eight of the total interviewees $(50 \%)$ focused on increased workload. Coupled with low salary for nursing educators, seven participants (43.8\%) explained that nursing faculty left to set up independent practices in which they would earn higher salaries. Additionally, six participants (37.5\%) observed that nursing faculty left their schools of nursing due to retirement. Education and tenure requirements were mentioned by both sets of participants. The pressure of tenure was noted by two MU SON faculty (28.6\%), while the requirement of a doctorate was offered by two CU SON individuals (22.2\%). Family relocation (42.9\%) was offered by MU SON interviewees as was the school's weak research infrastructure (28.6\%). CU SON participants suggested student incivility (22.2\%) as an impetus for nursing faculty's departure. Finally, one MU SON participant (14.3\%) explained that nursing faculty members' unreasonable expectations in the position was a basis for faculty leaving the school (see Table 73).

Table 73

Combined Reasons Nursing Faculty Leave Schools of Nursing

\begin{tabular}{lccc}
$\begin{array}{l}\text { Reasons nursing faculty leave } \\
\text { schools of nursing }\end{array}$ & $\begin{array}{l}\text { MU SON } \\
\mathrm{N}=7(\%)\end{array}$ & $\begin{array}{c}\text { CU SON } \\
\mathrm{N}=9(\%)\end{array}$ & $\begin{array}{c}\text { Total } \\
\mathrm{N}=16(\%)\end{array}$ \\
\hline Low salary & $6(85.7)$ & $6(66.7)$ & $12(75)$ \\
\hline Increased workload & $4(57.1)$ & $4(44.4)$ & $8(50)$ \\
\hline Independent practice & $3(42.9)$ & $4(44.4)$ & $7(43.8)$ \\
\hline Retirement & $2(28.6)$ & $4(44.4)$ & $6(37.5)$ \\
\hline Family relocation & $3(42.9)$ & 0 & $3(18.8)$ \\
\hline Weak research infrastructure & $2(28.6)$ & 0 & $2(12.5)$ \\
\hline Pressure of tenure & $2(28.6)$ & 0 & $2(12.5)$ \\
\hline Student incivility & 0 & $2(22.2)$ & $2(12.5)$ \\
\hline Doctorate requirement & 0 & $2(22.2)$ & $2(12.5)$ \\
\hline Unreasonable expectations & $1(14.3)$ & 0 & $1(6.3)$ \\
\hline
\end{tabular}




\section{Strategies to increase nursing faculty in the profession: Combined administrator and faculty perceptions.}

When all administrators and nursing faculty were queried about what strategies would be effective in recruiting nursing faculty in the profession, the overwhelming response offered by fifteen participants (93.8\%) suggested higher salaries as a tool to increase recruitment efforts. Autonomy and flexibility were noted by 12 of 16 interviewees (75\%). All CU SON participants suggested this strategy, compared to only three $(42.9 \%)$ of their peers at MU SON. Next, eight of nine (88.9\%) CU SON faculty offered increased recognition for nursing faculty as a recruitment strategy, which was not mentioned by MU SON administrators and faculty. The next combined response, set forth by three individuals at each school, recommended tuition reimbursement. Continuous education from the undergraduate to graduate program was noted by five of the 16 participants (31.3\%), with four CU SON nursing faculty (44.4\%) making this observation compared to one MU SON individual (14.3\%). CU SON interviewees also focused on decreased workload as a strategy, which was not suggested by MU SON administrators and faculty. The final two strategies, both offered solely by MU SON participants, involved continuing education and a need for mentorship (see Table 74).

Table 74

Combined Strategies to Recruit Nursing Faculty in the Profession

\begin{tabular}{lccc}
\hline $\begin{array}{l}\text { Strategies to recruit nursing faculty } \\
\text { in the profession }\end{array}$ & $\begin{array}{c}\text { MU SON } \\
\mathrm{N}=7(\%)\end{array}$ & $\begin{array}{c}\text { CU SON } \\
\mathrm{N}=9(\%)\end{array}$ & $\begin{array}{c}\text { Total } \\
\mathrm{N}=16(\%)\end{array}$ \\
\hline Higher salaries & $6(85.7)$ & $9(100)$ & $15(93.8)$ \\
\hline Autonomy and flexibility & $3(42.9)$ & $9(100)$ & $12(75)$ \\
\hline Recognition & 0 & $8(88.9)$ & $8(50)$ \\
\hline $\begin{array}{l}\text { Tuition reimbursement } \\
\text { Continuous education/progression }\end{array}$ & $3(42.9)$ & $3(33.3)$ & $6(37.5)$ \\
\hline $\begin{array}{l}\text { Decreased workload } \\
\text { Continuing education }\end{array}$ & $1(14.3)$ & $4(44.4)$ & $5(31.3)$ \\
\hline Mentorship & 0 & $5(55.6)$ & $5(31.3)$ \\
\hline
\end{tabular}


All participants were asked to suggest strategies to retain nursing faculty in the profession. Thirteen of 16 respondents $(81.3 \%)$ observed that increased salaries would be the most effective strategy. Recognition was also cited by 11 interviewees (68.8\%), with seven CU SON nursing faculty (77.8\%) and four MU SON individuals (57.1\%) making the suggestion. Eight CU SON participants (88.9\%) explained that realistic workloads and flexibility in teaching would help retain current nursing faculty, but these suggestions were not offered by MU SON interviewees. Tuition reimbursement was also a common response (43.8\%), mentioned by five CU SON individuals (55.6\%) and two MU SON nursing faculty (28.6\%). Four MU SON faculty (57.1\%) believed support for existing faculty would positively affect retention efforts. Three CU SON respondents (33.3\%) focused on changing student incivility. Two MU SON participants (28.6\%) recommended increased technical competence and equality of rewards, while one CU SON individual (11.1\%) observed that receiving a bonus for bringing in research money and sharing faculty between the health professions schools would be positive (see Table 75).

Table 75

Combined Strategies to Retain Nursing Faculty in the Profession

\begin{tabular}{lccc}
$\begin{array}{l}\text { Strategies to retain nursing faculty } \\
\text { in the profession }\end{array}$ & $\begin{array}{c}\text { MU SON } \\
\mathrm{N}=7(\%)\end{array}$ & $\begin{array}{c}\text { CU SON } \\
\mathrm{N}=9(\%)\end{array}$ & $\begin{array}{c}\text { Total } \\
\mathrm{N}=16(\%)\end{array}$ \\
\hline Increased salaries & $6(85.7)$ & $7(77.8)$ & $13(81.3)$ \\
\hline Recognition & $4(57.1)$ & $7(77.8)$ & $11(68.8)$ \\
\hline Realistic workloads & 0 & $8(88.9)$ & $8(50)$ \\
\hline Flexibility in teaching & 0 & $8(88.9)$ & $8(50)$ \\
\hline Tuition reimbursement & $2(28.6)$ & $5(55.6)$ & $7(43.8)$ \\
\hline Support & $4(57.1)$ & 0 & $4(25)$ \\
\hline Change student incivility & 0 & $3(33.3)$ & $3(18.8)$ \\
\hline Increased technical competence & $2(28.6)$ & 0 & $2(12.5)$ \\
\hline Equality of rewards & $2(28.6)$ & 0 & $2(12.5)$ \\
\hline Bonus for research money & 0 & $1(11.1)$ & $1(6.3)$ \\
\hline Shared faculty & 0 & $1(11.1)$ & $1(6.3)$ \\
\hline
\end{tabular}




\section{Summary}

The researcher studied two schools of nursing for this qualitative research analysis. Both schools are comprehensive doctoral institutions (Carnegie Foundation, 2005) and enroll a similar number of students. The location of each school within its state is comparative. The schools of nursing at each university are well-established, offer many degree programs, and are accredited by the same body. CU SON is a larger school of nursing by approximately 500 students, with a greater amount of faculty. Thus, the student-to-faculty ratio at CU SON is lower than at MU SON.

Administrators and nursing faculty from both schools answered the same demographic questionnaire and were asked an interview protocol based upon their status as administrator or nursing faculty. A cross-site analysis of responses to both the demographic questionnaire and interview protocol was made.

While the mean age of participants was similar, a comparison showed that most faculty were between 40 and 69 years of age. Most nursing faculty earned salaries of less than $\$ 60,000$ per year, while all administrators interviewed earned $\$ 90,001$ per year or greater. At MU SON, where faculty is smaller, nursing faculty members generally taught in both didactic and clinical areas, while teaching responsibility was more evenly split at CU SON. Moreover, lower ranked faculty at both schools taught in the undergraduate area, while higher ranked faculty taught in both undergraduate and graduate programs or solely in the graduate program.

MU SON nursing faculty spent more time in clinical instruction, required office hours, and hours spent at home each week than their CU SON counterparts. The amount of class-based and on-line instruction all nursing faculty provided was similar. Moreover, MU SON faculty teach an analogous amount of didactic courses as CU SON nursing faculty, but the course credits 
are higher for MU SON nursing faculty. The number of advisees and committees is comparable between both schools, and a majority of faculty at both schools are currently involved in revising or creating a course.

Both sets of interviewees generally spent more than 40 hours per week completing their duties as nursing faculty. Nursing faculty at CU SON engaged in active research and were more likely to be published than their MU SON peers. However, MU SON faculty were more likely to feel undercompensated for their credentials than their CU SON counterparts.

Both MU SON and CU SON nursing faculty explained that collaboration with other faculty, familiarity with the school's area, and the role as a recent graduate were the impetus for teaching at their respective schools. MU SON faculty were more inclined to stay at the school due to the supportive faculty and collegial environment, while CU SON nursing faculty noted satisfaction in the role as nursing faculty.

All administrators explained that lack of resources for clinical placements led to barriers to increased student enrollment, as well as various faculty issues. The type of recruitment strategies used by both schools was similar, with CU SON using the additional strategy of search committees. The challenges to recruitment were also similar between both schools. When questioned about external partnerships, both sets of administrators noted the same types of partners, with the addition of the Practice Education Program at CU SON.

Nursing faculty at both schools explained that they had a high amount of academic freedom in designing and conducting their courses, as long as they followed the curriculum and met the course's objectives. When asked to address working conditions, MU SON faculty focused on flexibility and low salaries, while CU SON faculty mentioned increased workload, low salaries, and the collegial environment of the school. 
All participants explained that low salary impacted recruitment efforts, as did the rural location of the school and a lack of qualified faculty. Low salary was also offered as a reason impacting retention, as was increased workload, the potential for an independent practice and its attendant higher salary, and retirement. CU SON faculty also noted that the requirement of a doctorate was a barrier to both recruitment and retention of nursing faculty, while MU SON noted a weak research infrastructure and the pressure for tenure as negatively impacting recruitment and retention.

Participants at both schools explained that higher salaries would positively impact both recruitment and retention. While individuals at both schools noted that recognition would increase retention rates, only CU SON faculty suggested recognition as a recruitment strategy. Likewise, flexibility was noted as improving recruitment of nursing faculty by both groups, but only CU SON faculty explained its helpfulness in retention efforts. Tuition reimbursement was suggested by both faculty for both recruitment and retention. A decreased and/or realistic workload was suggested only by CU SON participants to increase recruitment and retention, while MU SON faculty focused on mentorship and support. Finally, only CU SON interviewees noted that changing student incivility would be helpful in retention efforts. 


\section{Chapter Seven: Summary, Conclusion, and Recommendations for Future Research and Practice}

\section{Summary of Major Findings}

Two comprehensive public doctoral institutions (Carnegie Foundation, 2005) were the subjects of case studies for this qualitative research dissertation. Across these two universities, 16 nursing administrators and nursing faculty were interviewed. From these 16 individuals, five were administrators and 11 were nursing faculty. All interviewees were women and Caucasian. Salaries ranged from under $\$ 40,000$ per year to over $\$ 100,000$ per year, with administrators making the highest salaries. Seven of the 16 interviewees (43.8\%) earned salaries under $\$ 60,000$ per year.

The majority of nursing faculty at both schools spent more than 40 hours per week completing their duties. MU SON faculty spent more hours in clinicals, required office hours, and hours per week spent at home than CU SON nursing faculty. Indeed, MU SON nursing faculty spent an average of 4.2 hours per week additional at home in faculty related duties than their counterparts at CU SON nursing faculty. Additionally, MU SON individuals carried higher course credits than CU SON participants. Moreover, MU SON nursing faculty were more likely to feel undercompensated for their credentials as compared to CU SON interviewees. However, CU SON nursing faculty were on more committees and were more published than their MU SON peers.

MU SON participants chose to teach at MU SON due to collaboration with faculty, while CU SON chose their school based on its reputation. All MU SON nursing faculty decided to stay at the school because of the collegial environment and supportive faculty, which was a response only given by two CU SON interviewees. Some MU SON individuals also remained because of their passion for teaching and desire to inspire students. This response was not 
offered by CU SON participants. Moreover, CU SON nursing faculty explained that their choice to remain was based upon resources and economic incentives, which was not listed by MU SON individuals.

The biggest barrier to enrolling additional students at both schools was a lack of clinical sites. Administrators at both schools discussed different nursing faculty issues, including a lack of faculty lines, limited faculty salaries, and a lack of qualified faculty. While both schools have similar recruitment methods, there are many faculty vacancies at both schools and a lack of qualified faculty in certain specialty areas such as pediatrics, OB/GYN, and psychiatric/mental health.

The majority of nursing faculty interviewed believed they had academic freedom in designing and conducting courses. Some similarities between both schools included faculty utilization of a template for the course syllabus and flexibility in designing course activities and related assessments.

Both MU SON and CU SON utilized local hospitals, community health partners, health and community centers, and county health departments. Additionally, both schools benefited from collaborations between the School of Nursing, School of Medicine, and local health system. Nursing preceptors were used at both schools.

The majority of nursing faculty surveyed explained that their working conditions were flexible and most enjoyed the collegiality of their schools. However, all MU SON nursing faculty were dissatisfied with their low salaries, while only two interviewees were dissatisfied at CU SON. Most nursing faculty interviewed believed they were overworked and asked to do more with less. 
Low salary was noted by the majority of interviewees as impacting recruitment and retention efforts of nursing faculty. MU SON participants discussed the need for a mentorship program and the lack of grant writing assistance as barriers to recruitment and retention, while CU SON noted the requirement of a doctorate and lack of promotion or pay raise upon completion of a doctorate as negatively affecting recruitment and retention. The majority of individuals explained that low salary was the main reason individuals left schools of nursing. Other common responses included increased workload and tenure requirements.

When asked what strategies would increase nursing faculty in the profession, the overwhelming response from the participants was the need to increase salaries. Also, they suggested greater autonomy to make decisions and greater flexibility to implement those decisions. They also suggested the need for greater recognition of their achievements and a decrease or more realistic workload.

\section{Conclusion}

\section{Study participants.}

As this dissertation study has shown, the majority of participants were 50 years of age or older. An aging faculty is a common trend when one examines the nursing faculty shortage and is supported by the literature. As Joynt and Kimball (2008) have shown, nurses interested in becoming nursing faculty are traditionally older and receive doctorates between 45 to 54 years of age. Once they receive their doctorate, those nursing faculty are only able to work approximately 15 years as a faculty member. According to an American Association of Colleges of Nursing (AACN) survey (AACN, 2009a), master's prepared faculty range from 50.1 years of age for assistant professors to 58.9 years of age for professors, while doctorally prepared faculty are 51.7 years of age for assistant professors to 59.1 years of age for professors. Moreover, a 
recent report from the Institute of Medicine (IOM) (2011), explains that "the average age of nurses who work as faculty as their principal nursing position - the position in which a nurse spends the majority of his or her working hours - is 50 to 54 " (p. 182). This research is in alignment with this dissertation study's findings, where the mean age of nursing faculty at MU SON was 51.7 years of age and the mean age of nursing faculty at CU SON was 50 years of age. Aging faculty is a major concern because as those faculty are looking toward retirement, there are not a sufficient number of younger faculty to replace them. Indeed, when one looks at this dissertation study's participants, very few nursing faculty interviewed were under 40 years of age. As Hessler and Ritchie (2006) have shown, the numbers of nursing faculty are projected to steadily decrease due to a retiring faculty. Moreover, "only $43 \%$ of current nursing doctoral graduates are committed to an academic role" (Hessler \& Ritchie, 2006, p. 150). Coupled with this literature is the trend away from enrollment in research-focused doctoral programs, which only saw a $0.1 \%$ growth in the 2007-2008 academic year (AACN, 2009d). Younger individuals possibly interested in nursing faculty careers often become disinterested when they are made aware of the amount of work required not only to become nursing faculty, but what must be accomplished in the role of nursing faculty (Hessler \& Ritchie, 2006). As the IOM (2011) notes, the existing nursing faculty pipeline cannot compensate for the loss of retiring faculty or meet current and future demands for nursing educators.

\section{Research question 1.}

The first research question discussed what recent strategies schools of nursing have implemented to address recruitment and retention of nursing faculty at their own institutions. Both participating schools used advertisements in various publications and at conferences, word of mouth, and recruitment from within their own graduate programs. Unlike MU SON, CU SON 
also used search committees to address recruitment challenges. The literature supports the strategy of recruitment from within each school's graduate programs. However, the literature does not discuss the participating schools' other strategies for recruitment. This may be due to the fact that both MU SON and CU SON utilize traditional forms of recruitment, while current literature is focused on new and innovative avenues in order to increase the numbers of nursing faculty in the profession. The literature suggests some creative strategies, such as creating marketing messages about a new image for nursing education, disseminating information about salary ranges and how schools are working to improve salaries, creating and distributing faculty recruitment videos featuring testimonials from recent graduates, partnering with other schools and entities outside of education, and seeking additional funding strategies (Center to Champion Nursing, 2009; Allan \& Aldebron, 2008).

One strategy that both schools utilize is distance education because nursing faculty not located near their campuses can still teach courses on-line. The schools also hire part-time faculty in areas in which full-time faculty are unavailable. In addition, partnerships with hospitals and health systems are created in order for the schools to take advantage of their nurses and allow for partners to subsidize some nursing faculty salaries. While parts of all CU SON degree programs are available on-line, only graduate programs are offered on-line at MU SON. As the literature shows, technology is a method that increases educational capacity for schools of nursing in that nursing faculty can teach on-line courses from their homes and are not required to be on campus (Robert Wood Johnson Foundation, 2007). As Fearing and Riley (2005) illustrate, on-line programs allow students in rural locations to access programs and to attend traditional university classes. Thus, there is the possibility that students may complete a nurse educator program and impact the nursing faculty shortage in the future. 
However, for schools to interest and therefore graduate nurse educators, they must first offer a nurse educator program. Both MU SON and CU SON do not have focused nurse educator curricula. Indeed, these two schools are following a nationwide trend in schools of nursing to emphasize the role of the nurse practitioner instead of the nurse educator (Joynt \& Kimball, 2008). As Joynt and Kimball (2008) note, nurse practitioner programs have grown in size and have replaced nurse educator programs due to the high level of state and federal funding afforded nurse practitioner programs at schools of nursing. It has also been suggested in the literature that continuous or "seamless" education be offered through the master's or doctoral degree, so that a student does not go out into clinical practice and then return to education years later (AACN, 2005). As the AACN (2005) has observed, "[m]ovement from undergraduate to graduate programs must be easy and seamless for qualified students, so they can assume faculty positions more quickly" (pp. 24-25). Both schools participating in this dissertation study offer programs to positively impact this end and CU SON even offers a BSN to PhD program which is entirely on-line. Moreover, the DNP program, available at both MU SON and CU SON, is advertised as a replacement for traditional master's curricula. It is considered a terminal doctoral degree, although it is non-research based, that is accepted by schools of nursing which require doctorally-prepared faculty and is offered as a new pathway to becoming a nurse educator (AACN, 2010; RWJF, 2007).

Another strategy utilized by both participating schools is hiring part-time or adjunct faculty, especially in clinical areas. The literature notes that due to the pressures of finding qualified, full-time faculty and the high cost associated to hire full-time nursing faculty, schools of nursing have resorted to hiring an increasing number of part-time or adjunct faculty (National Advisory Council on Nurse Education and Practice, 2008). Part-time or adjunct faculty may not 
be as invested in a program as full-time faculty (NACNEP, 2008). Allan and Aldebron (2008) observe that partnering with hospitals and other healthcare institutions helps to teach students in specific clinical areas to become nurses. Both MU SON and CU SON utilize this type of partnership with their local health systems, which provide monies for clinical faculty who divide their time between the schools and the health system. In fact, CU SON's partnership with its local health system provides monies for eight full-time faculty salaries. Thus, it is clear that both participating institutions heavily rely on nurses as preceptors and part-time faculty in both undergraduate and graduate programs, which is a strategy supported by the literature.

However, one must question the impetus behind schools' insistence on hiring an increased number of part-time faculty as opposed to developing and recruiting full-time faculty. One participating administrator lamented the fact that qualified candidates for full-time positions cannot be found, which is evidenced by the numerous faculty vacancies at both schools. Indeed, this reason is one of four significant factors the AACN (2010) determined that affects the lack of hiring additional full-time faculty at schools of nursing. The primary reason reported, though, was a lack of sufficient funds to hire new faculty (AACN, 2010, p. 13). This dissertation study illustrated a trend, at least at CU SON, where clinical faculty were hired and if they desired to switch to a teaching tenure-track position, they had to obtain their doctorate. Once they completed this requirement, they were not rewarded with an increase in salary like original teaching tenure-track faculty were upon their completion of a doctorate. No reason was offered to support this decision. However, it can be suggested that the hiring of original, non-tenure track faculty is aimed to keep nursing salaries lower, which therefore does not impact each school's budget as heavily as hiring original, tenure-track faculty might, and is an increasing trend. 
Indeed, when one objectively views the decreasing budgets of schools of nursing, lack of support staff, and an overall decrease in the amount of nursing faculty with the concomitant pressure to increase the number of enrolled students, one may question whether schools of nursing actually have a budget to compensate for the number of nursing faculty vacancies. It might be that schools of nursing are not heavily focusing on recruitment efforts because of a lack of monies. Coupled with this reasoning is the possibility that nursing administrators' argument of a lack of qualified faculty is a smokescreen used to convince existing nursing faculty that more assistance is forthcoming. A recent news article suggests that a solution to hiring crises in various fields is for employers to hire individuals with basic skills and then accordingly train the individual for the position's requirements. This strategy is called a "teachable fit" and is a possibility for incorporation into schools of nursing (Wolverson, 2011, p. 36).

\section{Research question 2.}

This dissertation study's second research question asks which strategies utilized by schools of nursing to address recruitment and retention have been effective. As has been described above, MU SON and CU SON effectively use preceptors and part-time or adjunct faculty, distance education, and collaboration with local hospitals and health systems. Additionally, as this section will address, the two participating schools of nursing also allow for high amounts of academic freedom in conducting and designing courses.

The majority of interviewed participants explained that they had autonomy and flexibility in designing and conducting individual courses. While they were required to follow the curriculum, course objectives, and a template syllabus, they were given academic freedom in how information was presented and in any activities designed to foster learning. This finding is 
seemingly dissimilar from the literature, which suggests decreased faculty autonomy and control (Gappa, Austin, \& Trice, 2007).

However, while interviewed nursing faculty reported that they receive academic freedom in designing or conducting courses, the impetus behind undergraduate nursing education is passage of the National Council Licensure Examination for Registered Nurses (NCLEX-RN). While nursing faculty's method in imparting information may provide for autonomy, the goal is to have the greatest number of students pass the NCLEX-RN. Thus, the content must be uniform since the overarching purpose of undergraduate nursing programs is goal-oriented. This suggestion is supported in the literature by the IOM (2011), which reports that "the content of the NCLEX-RN directly influences the curricula used to educate nursing students” (pp. 167-68).

\section{Research question 3.}

The third research question articulated by this dissertation study focuses on what external stakeholders collaborate with nursing faculty. Both participating schools of nursing utilized local hospitals and community health partners, which consisted of clinics, health and community centers, and the county health department. Additionally, both schools collaborated with the university's School of Medicine and the local health system. Both schools used nurses as preceptors. These partnerships are consistent with trends reported in the literature (NACNEP, 2008; Allan \& Aldebron, 2008). However, these two schools of nursing are missing some current collaborative arrangements. For example, Joynt and Kimball (2008) state "the real opportunity for innovation and change may require casting a broader net to include community organizations, regional/state development or workforce bodies or companies that design and manufacture learning technology" (p. 15). Allan and Aldebron (2008) define such partnerships as "multi-sector" and assert that they are essential to expand educational capacity (p. 290). 


\section{Research question 4.}

The fourth and final research question focuses on the reasons behind the lack of recruitment and retention of nursing faculty within schools of nursing, as perceived by nursing faculty and administrators. The primary factor which affected both recruitment and retention of nursing faculty, according to an overwhelming majority of participants at both MU SON and CU SON, was low salary. Indeed, most nursing faculty interviewed earn $\$ 60,000$ per year or less, while administrators earn over $\$ 90,000$ per year. This amounts to an average disparity of $\$ 20,000$ per year when academic salaries are compared to clinical salaries (RWJF, 2007). Additionally, this disparity is increasing because clinical salaries have risen in recent years (Wood, 2011). For example, a master's prepared nurse working in academia in New Jersey earns approximately $\$ 65,000$ per year, but a similarly situated nurse in a hospital organization can earn approximately $\$ 90,000$ per year (Wood, 2011). Therefore, the literature strongly supports the proposition that low salaries for nursing faculty negatively impact recruitment and retention efforts (Yordy, 2006; Joynt \& Kimball, 2008; Allen, 2008; Benner, Sutphen, Leonard, \& Day, 2010).

Another reason offered by this dissertation study's participants which impacts lack of recruitment and retention of working faculty is stress and a feeling of being overworked. MU SON nursing faculty were more likely than their CU SON counterparts to invest greater amounts of hours per week in completing faculty-related duties and to feel undercompensated for their credentials. This finding is supported by the literature, which explains that many faculty consider themselves overworked and struggle to find an appropriate work-life balance (Oermann, 1988; Shirey, 2006; Gappa, Austin, \& Trice, 2007; Christmas, 2008; Brady, 2010). Shirey (2006) presciently explains, 
Nursing faculty, in particular, experience stressors as a result of high job expectations associated with the teaching/service/research paradigm, heavy workloads precluding personal/professional life balance, pressure to maintain clinical competence, and feelings of frustration associated with a perceived inability to satisfy the demands of multiple constituencies. Stressors on nursing faculty are compounded by lack of empowerment structures within hierarchical organizations of higher learning and by the steep expectations associated with promotion and tenure. (p. 96)

This sentiment is congruent with this dissertation study's findings, as a majority of nursing faculty interviewed worked more than 40 hours per week, felt overworked, and were "asked to do more with less."

Additionally, the pressure of tenure is a factor associated with a lack of recruitment and retention according to this dissertation study's participants. In order to obtain tenure, one must show scholarship, a commitment to teaching, extensive committee work, the ability to acquire significant grant money, and be involved in a program of research. Not only is this challenging for nursing faculty who have not left academia, but is even more daunting for returning adult nursing faculty. As a result, schools of nursing are decreasing their commitment to provide a stable, full-time, tenured faculty and are instead hiring both part- and full-time faculty off the tenure track on one-year contracts with less formal arrangements (Yordy, 2006; Joynt \& Kimball, 2008; Benner, Sutphen, Leonard, \& Day, 2010).

Both participating schools have multiple nursing faculty vacancies, which are often left unfilled for months or even, in some cases, years. Because of the number of vacancies at each school, there appears to be a lack of commitment to hiring full-time, tenure-track faculty. This is consistent with the literature, which has shown that tenured faculty lines are shrinking across all 
institutions (American Association of University Professor, 2006). Moreover, a recent publication by the American Federation of Teachers (AFT) (2011) further supports the notion of decreased hiring of full-time, tenured faculty in fields dominated by women, such as nursing. The article explains that,

a disproportionate number of female faculty members continue to be hired as contingent rather than as full-time, tenure-track faculty, which often marginalizes the contributions they can make to their institutions, and provides them with grossly inadequate pay and working conditions. (AFT, 2011, p. 6)

Another reason behind the lack of recruitment and retention of nursing faculty noted by this dissertation study's participants is a lack of qualified faculty in specialties such as pediatrics, $\mathrm{OB} / \mathrm{GYN}$, and psychiatric/mental health. This is consistent with the findings of Joynt and Kimball (2008). However, according to the interviewees, many of these needed programs are being discontinued due to limited applicants and no incentives for students to enroll. Based upon the popularity of the nurse practitioner and its focus on clinical practice, there are not as many nurses moving on to become doctorally prepared nurses in certain specialties (Joynt \& Kimball, 2008).

Lack of recognition for their achievements was also suggested by participants as negatively impacting recruitment and retention of nursing faculty. The literature often combines recognition into improving the work environment of schools of nursing (AACN, 2005; Allen, 2008), but this dissertation study's interviewees specifically suggested recognition as separate from the overall work environment in their schools. Brady (2010) has suggested that recognition comes from not only students and graduates, but from other faculty. She observes that schools of 
nursing should establish formal recognition mechanisms, which could be internal (i.e., faculty member of the year award) or external (i.e., recognition from local, state, or national agencies).

A need for mentorship and institutional support was also recommended by this dissertation study's participants. This finding is in alignment with the literature (National League for Nursing, 2006; Kapustin \& Murphy, 2008). As Kapustin and Murphy (2008) suggest, "[i]n addition to enhancing retention, effective mentoring programs can assist with socialization of new faculty, raise overall morale and job satisfaction, accelerate promotion and tenure, and improve the quality of education offered to the student population" (n.p.). Importantly, the socialization aspect of mentorship is noted as a key component to retaining novice faculty (Hessler \& Ritchie, 2006). Additionally, the NLN (2006) recommends mentorship for all nursing faculty and administrators in different forms in order to establish healthy work environments. Mentorship would be a great benefit to those nursing faculty who do not seem to be confident with their professional identity as nursing faculty. It may also assist nursing faculty in addressing student incivility, as a mentor may suggest appropriate ways to combat this problem.

A final aspect affecting recruitment and retention of nursing faculty according to this dissertation study's participants is the high cost of continued education and the expanded need for increased tuition reimbursement. The literature supports this finding and notes that the cost of obtaining a doctoral degree is often prohibitive to individuals interested in pursuing a nursing faculty career (Hinshaw, 2001; Yordy, 2006; Joynt \& Kimball, 2008). According to the American Nurses Association (2009), some federal programs for tuition reimbursement exist, but they are often limited by program. The IOM (2011) further corroborates the need for tuition reimbursement at the school, state, and national levels. It reports that while "a limited number of 
educational grants and scholarships are available, most of individuals seeking nursing education must finance their own education at any level of preparation" (p. 168). Therefore, the cost of nursing education directly impacts the lack of recruitment and retention of nursing faculty.

\section{Recommendations for Future Research}

In this section, the researcher discusses the four major recommendations for future research. The first recommendation is to study salaries of nursing faculty at a variety of different institutional types as compared to other professional faculty such as business administration and engineering. Salaries of nursing faculty have not increased at the same rate of salaries of other professional faculty. Moreover, nursing faculty teach both didactic and clinical courses, whereas other professional faculty such as engineering, law, and business administration teach only didactic or clinical courses. Thus, nursing faculty generally have an increased workload as compared to other professional faculty, but are paid much less than those faculty.

The second recommendation is to study the effects of workload on recruitment and retention of nursing faculty. The majority of participants in this study worked more than 40 hours per week and spent a significant amount of time at home completing their duties as nursing faculty. Indeed, many suggested that a key to increased recruitment and retention of nursing faculty would be a more realistic workload. Moreover, younger generations of students desire a controlled lifestyle, which is not available to current nursing faculty, especially those who teach didactic courses.

A third recommendation for future research is to study effective recruitment strategies, including what current strategies are used and their effectiveness. If recruitment strategies are ineffective, what are the reasons behind their ineffectiveness? Additionally, studies need to examine what recruitment strategies schools of nursing are not using and why they are not 
utilizing those strategies. This dissertation has shown that the participating schools examined used very limited recruitment strategies, but only a few are actually effective.

The fourth and final recommendation for research is to contact full-time nursing faculty who left schools of nursing and to interview them concerning reasons that they left their schools. This dissertation study has shown that remaining faculty believe nursing faculty leave schools for a variety of reasons, including higher salaries in clinical practice, due to pressures to obtain tenure, and due to retirement. If nursing faculty who departed schools of nursing were interviewed, it is possible that other rationales would be discovered.

\section{Recommendations for Future Practice}

In this section, the researcher presents future recommendations for practice. The first recommendation is to increase salaries to be commensurate or above those nurses in clinical practice. Nursing faculty are the key to decreasing the overall nursing shortage, for without nurse educators, there are no nurses. In order to increase the number of nursing faculty, the greatest recommendation is to raise salaries of nursing faculty. Nurses in clinical practice earn a much higher salary than nursing faculty and do not have such an extensive workload. Thus, for schools of nursing to recruit new faculty and retain existing faculty, salaries must be increased.

Second, for new nursing faculty, administrators could implement a mentorship program to help their new colleagues understand expectations for reaching tenure. This dissertation study has shown that a lack of mentorship is a reason behind decreased retention of nursing faculty within schools of nursing. Moreover, the pressures of tenure on nursing faculty are heightened, especially when little guidance is provided by school administrators. A mentorship program would assist new nursing faculty in becoming aware of the requirements of tenure, whether they are expected to obtain tenure, and when they should apply for and obtain tenure. 
A third recommendation is for schools to expand recruitment strategies for nursing faculty and develop formal recruitment plans. The current recruitment strategies used can be considered traditional strategies, but as it has been shown, are often not always effective. Nursing administrators need to use innovative thinking to develop new recruitment strategies, especially in an increasingly technological era. Additionally, formal recruitment plans for each school are needed and should include the most effective recruitment strategies in order to attract the most qualified applicants.

Fourth, schools of nursing should consider alternate paths to tenure for returning adult nursing faculty. The tenure process is often long and complicated, and not all returning faculty have the desire to invest an extraordinary amount of time and effort into obtaining tenure. Schools of nursing should develop alternate routes to tenure for those faculty who are returning to academia from practice or other areas so that these faculty have the opportunity to obtain tenure.

A fifth recommendation for future practice would be for schools of nursing to hire a sufficient number of part-time and full-time nursing faculty to adequately address the academic program's needs. Current nursing faculty not only carry a high amount of didactic and course credits, but also advise students, participate in committee work, and conduct research. This leads to an increased rate of burnout and dissatisfaction, which negatively impacts retention rates. If more part-time and full-time nursing faculty were hired to sufficiently share these duties, retention would likely not be so affected.

A sixth and final recommendation would be for administrators to publicly recognize the contributions of nursing faculty. Increased recognition was suggested by this study's participants as a key to improving retention within schools of nursing. Small forms of public 
recognition, whether a certificate of appreciation or a yearly recognition dinner, would positively impact morale at a school of nursing. Therefore, if morale is improved, it is likely that retention would also be positively impacted.

As this dissertation study has illustrated, recruitment and retention efforts of nursing faculty by schools of nursing are negatively impacted by the dual factors of low salaries for nursing faculty and by their high workloads. Often nursing administrators neglect long-range planning to address these issues. Moreover, while both participating schools of nursing currently have many full-time and part-time faculty vacancies, the administrators most often used traditional recruitment strategies, which may not always be effective, to fill these positions. It can even be questioned if schools have appropriate resources in place to fill each vacant position. Ultimately, schools of nursing must improve recruitment and retention rates if the nursing faculty shortage is to be adequately addressed. 


\section{References}

Aiken, L. H., Clarke, S. P., Cheung, R. B., Sloane, D. M., \& Silber, J. H. (2003). Educational levels of hospital nurses and surgical mortality. Journal of the American Medical Association, 290(12), 1617-1623.

Aldebron, J., \& Allan, J. D. (2010). Resisting the downward pressure on nursing faculty qualifications. Journal of Nursing Regulation, 1(1), 21-25.

Allan, J. D., \& Aldebron, J. (2008). A systematic assessment of strategies to address the nursing faculty shortage, U.S. Nursing Outlook, 56(6), 286-297.

Allen, L. (2008). The nursing shortage continues as faculty shortage grows. Nursing Economics, $26(1), 35-40$.

American Association of Colleges of Nursing. (2005, May). Faculty shortages in baccalaureate and graduate nursing programs: Scope of the problem and strategies for expanding the supply. Retrieved from http://www.aacn.nche.edu/Publications/WhitePapers/FacultyShortages.htm American Association of Colleges of Nursing. (2006). The essentials of doctoral education for advanced nursing practice. Washington, DC: American Association of Colleges of Nursing.

American Association of Colleges of Nursing. (2008a). 2007-2008 enrollment and graduations in baccalaureate and graduate programs in nursing. Washington, DC: American Association of Colleges of Nursing. 
American Association of Colleges of Nursing. (2008b, February). First group of minority nurse faculty scholars selected by the Johnson \& Johnson Campaign for Nursing's Future and $A A C N$. Retrieved from http://www.aacn.nche.edu/Media/NewsReleases/2008/J\&JScholars.htm

American Association of Colleges of Nursing. (2008c, July). Special survey of AACN membership on vacant faculty positions for academic year 2008-2009. Retrieved from http://www.aacn.nche.edu/IDS/pdf/vacancy08.pdf

American Association of Colleges of Nursing. (2008d, September). Nursing faculty shortage fact sheet. Retrieved from http://www.aacn.nche.edu/Media/FactSheets/FacultyShortage.htm

American Association of Colleges of Nursing. (2009a). 2008-2009 salaries of instructional and administrative nursing faculty in baccalaureate and graduate programs in nursing. Washington, DC: American Association of Colleges of Nursing.

American Association of Colleges of Nursing. (2009b). Funding opportunities for colleges of nursing through the American recovery and reinvestment act. Retrieved from http://www.aacn.nche.edu/government/pdf/StimFund.pdf

American Association of Colleges of Nursing. (2009c, February). Despite surge of interest in nursing careers, new AACN data confirm that too few nurses are entering the healthcare workforce. Retrieved from http://www.aacn.nche.edu/Media/NewsReleases/2009/workforcedata.html American Association of Colleges of Nursing. (2009d, April 6). Nursing shortage fact sheet. Retrieved from http://www.aacn.nche.edu/Media/FactSheets/NursingShortage.htm 
American Association of Colleges of Nursing. (2010, May 19). Special survey on vacant faculty positions for academic year 2009-2010. Retrieved from http://www.aacn.nche.edu/IDS/pdf/vacancy09.pdf

American Association of Retired Persons. (2010). Nursing provisions P.L. 111-148, the Patient Protection and Affordability Care Act (PPACA). Retrieved from http://assets.aarp.org/www.aarp.org_/cs/health/nursingandhealthreformlawtable.pdf

American Association of University Professors (2003, November). Contingent appointments and the academic profession. Retrieved from http://www.aaup.org/AAUP/pubsres/policydocs/contents/conting-stmt.htm

American Federation of Teachers Higher Education (2011). Promoting gender diversity in the faculty: What higher education unions can do. Retrieved from http://www.aft.org/pdfs/highered/genderdiversity0511.pdf

American Nurses Association. (2009). Funding for nursing workforce development. Retrieved from http://nursingworld.org/MainMenuCategories/ANAPoliticalPower/Federal/Issues/Nursin gWorkforceDevelopment.aspx

Anderson, C. (1998). Academic nursing: A desirable career? Nursing Outlook, 46(1), 5-6.

Bartels, J. E. (2007). Preparing nursing faculty for baccalaureate-level and graduate-level nursing programs: Role preparation for the academy. Journal of Nursing Education, 46(4), 15458.

Benner, P., Sutphen, M., Leonard, V., \& Day, L. (2010). Educating nurses: A call for radical transformation. San Francisco, CA: Jossey-Bass. 
Berlin, L. E., Wilsey, S. J., \& Bednash, G. D. (2005). 2004-2005 enrollment and graduations in baccalaureate and graduate programs in nursing. Washington, DC: American Association of Colleges of Nursing.

Bloomberg, L. D., \& Volpe, M. (2008). Completing your qualitative dissertation: A roadmap from beginning to end. Thousand Oaks, CA: Sage.

Boyer, E. L. (1997). Scholarship reconsidered: Priorities of the professoriate. New York: The Carnegie Foundation for the Advancement of Teaching.

Brady, M. S. (2010). Healthy nursing academic work environments. Online Journal of Issues in Nursing, 15(1), n.p. doi:10.3912/OJIN.Vol15No01Man06

Brendtro, M., \& Hegge, M. (2000). Nursing faculty: One generation away from extinction? Journal of Professional Nursing, 16(2), 97-103.

Brewer, C. (1997). Through the looking glass: The labor market for registered nurses in the $21^{\text {st }}$ century. Nursing and Health Care, 18(5), 260-269.

Buerhaus, P. (1998). Is another RN shortage looming? Nursing Outlook, 3(46), 103-108.

Buerhaus, P. I., Donelan, K., Ulrich, B. T., Norman, L., DesRoches, C., \& Dittus, R. (2007). Impact of the nurse shortage on hospital patient care: Comparative perspectives. Health Affairs, 26(3), 853-862.

Buerhaus, P. I., Donelan, K., Ulrich, B. T., Norman, L., \& Dittus, R. (2005). Is the shortage of hospital registered nurses getting better or worse? Findings from two recent national surveys of RNs. Nursing Economics, 23(2), 61-71, 96.

Buerhaus, P., Staiger, D., \& Auerbach, D. (2000). Implications of a rapidly aging registered nurse workforce. Journal of the American Medical Association, 283(22), 2948-2954. 
Carnegie Foundation for the Advancement of Teaching. (2005). The Carnegie classification of institutions of higher education. Retrieved from http://classifications.carnegiefoundation.org/

Center to Champion Nursing in America. (2009, March). White House forum on health reform. Retrieved from http://www.championnursing.org/HomeWhit-6844.html

Central University Facts. (2011).

Central University Mission. (2011).

Central University School of Nursing Self Study. (2010).

Central University School of Nursing Website. (2011).

Central University Statement of Values. (2011).

Central University Website. (2011).

Christmas, K. (2008). How work environment impacts retention. Nursing Economics, 26(5), 316-318.

Cleary, B. L., Hassmiller, S. B., Reinhard, S. C., Richardson, E. M., Veenema, T. G., \& Werner, S. (2010). Forging partnerships to expand nursing education capacity. American Journal of Nursing, 110(1), 43-50.

Creswell, J. W. (2003). Research design: Qualitative, quantitative, and mixed methods approaches (2nd ed.). Thousand Oaks, CA: Sage.

Deck, M. (n.d.). The latest and greatest ways to teach television generation learners. Retrieved from http://www.tool-trainers.com/games/0.greatest.html

Denzin, N. K. \& Lincoln, Y. S. (2004). The SAGE Handbook of Qualitative Research (3rd ed.). Thousand Oaks, CA: Sage. 
Edmunds, M. W. (2000, January 4). Nurse practitioners: Remembering the past, planning the future. Retrieved from http://www.medscape.com/viewarticle/408388

Fearing, A., \& Riley, M. (2005). Graduate students' perceptions of online teaching and relationship to preferred learning styles. MEDSURG Nursing, 14(6), 383-389.

Fink, L. D. (2002). Improving the evaluation of college teaching. In K. H. Gillespie (Ed.), A guide to faculty development: Practical advice, examples, and resources (pp. 46-58). San Francisco, CA: Jossey-Bass.

Gappa, J. M., Austin, A. E., \& Trice, A. G. (2007). Rethinking faculty work: Higher education's strategic imperative. San Francisco, CA: Jossey-Bass.

Garbee, D. D., \& Killacky, J. (2008). Factors influencing intent to stay in academia for nursing faculty in the southern United States of America. International Journal of Nursing Education Scholarship, 5(1), 1-15.

Gillespie, K. H. (Ed.). (2002). A guide to faculty development: Practical advice, examples, and resources. San Francisco, CA: Jossey-Bass.

Greene, J. (2005). What nurses want: Different generations, different expectations. Hospital Health Network, 79(3), 34-36, 38, 40.

Harper, D. C., \& Johnson, J. (1998). The new generation of nurse practitioners: Is more enough? Health Affairs, 17(5), 158-164.

Hasson, C., Cornelius, F., \& Suplee, P. D. (2008). A technology-driven nursing faculty resource center. Nurse Educator, 33(1), 22-25.

Hessler, K., \& Ritchie, H. (2006, May). Recruitment and retention of novice faculty. Journal of Nursing Education, 45(5), 150-154. 
Hinshaw, A. S. (2001). A continuing challenge: The shortage of educationally prepared nursing faculty. Online Journal of Issues in Nursing, 6(1). Retrieved from http://www.nursingworld.org/MainMenuCategories/ANAMarketplace/ANAPeriodicals/ OJIN/TableofContents/Volume62001/No1Jan01/ShortageofEducationalFaculty.aspx

Hinshaw, A. S. (2008). Navigating the perfect storm: Balancing a culture of safety with workforce challenges. Nursing Research, 57(1S), S4-S10.

Institute of Medicine. (2011). The future of nursing: Leading change, advancing health. Washington, D.C.: The National Academies Press.

Joynt, J., \& Kimball, B. (2008, May). Blowing open the bottleneck: Designing new approaches to increase nurse education capacity. Retrieved from http://www.championnursing.org/uploads/NursingEducationCapacityWhitePaper200806 18.pdf

Kapustin, J. F., \& Murphy, L. S. (2008). Faculty mentoring in nursing. Topics in Advanced Practice Nursing eJournal, 8(4), n.p. Retrieved from http://www.medscape.com/viewarticle/582904

Kaufman, K. (2007). Introducing the NLN/Carnegie national survey of nurse educators: Compensation, workload and teaching practice. Nursing Education Perspectives, 28(3), 164-67.

Lamm, N. H. (2005). Nursing faculty shortage: A crisis situation. Unpublished manuscript, West Virginia University.

Leighty, J. (2007, May 21). Four generations of nurses working side by side. Retrieved from http://www.helpatnursingspectrum.com/load_article.html?AID=946 
Lewis, L. (2010a). Adding more - and better educated - nurses in California. American Journal of Nursing, 110(5), 56-59.

Lewis, L. (2010b). Mississippi addresses the nursing shortage. American Journal of Nursing, 110(7), 58-61.

Lower, J. (2007). Brace yourself - Here comes generation Y. American Nurse Today, 2(8), 2629.

Luparell, S. (2007). The effects of student incivility on nursing faculty. Journal of Nursing Education, 46(1), 15-19.

Maryland Statewide Commission on the Crisis in Nursing. (2005). Total compensation: A call for action for retaining nurses. Retrieved from http://www.mbon.org/commission/compensation_paper2.pdf

Maslach, C., Schaufeli, W. B., \& Leiter, M. P. (2001). Job burnout. In S. T. Fiske, D. L. Schachter, \& C. Zahn-Waxler (Eds.), Annual Review of Psychiatry, Vol. 52 (pp. 397422).

Maurer, F. A., \& Smith, C. M. (2005). Community/public health nursing practice: Health for families and populations (3rd ed.). St. Louis, MO: Elsevier Saunders.

Miller, F. A., \& Alvarado, K. (2005). Incorporating documents into qualitative nursing research. Journal of Nursing Scholarship, 37(4), 348-353.

Miller, G. (1997). Contextualizing texts: Studying organizational texts. In G. Miller and R. Dingwall (Eds.), Context and method in qualitative research (pp. 77-91). Thousand Oaks, CA: Sage. 
Montgomery, K. L. (2004, November). Nursing faculty shortage: Impact on health care and the citizens of Maryland (University of Maryland, School of Nursing). Paper presented at the meeting of the Maryland Chamber of Commerce, Annapolis, MD.

Moskowitz, M. C. (2007). Academic health center CEOs say faculty shortages a major problem. Retrieved from http://www.aahdc.org/policy/reddot/AAHC_Faculty_Shortages.pdf

Mountain University Facts. (2010).

Mountain University History. (2007).

Mountain University Mission. (2010).

Mountain University School of Nursing Self Study. (2008).

Mountain University School of Nursing Website. (2011).

National Advisory Council on Nurse Education and Practice. (2008). Meeting the challenges of the new millennium: Challenges facing the nurse workforce in a changing health care environment. Rockville, MD: U.S. Department of Health and Human Services.

National Council of State Boards of Nursing. (2008, August). Nursing faculty qualifications and roles. Retrieved from https://www.ncsbn.org/Final_08_Faculty_Qual_Report.pdf

National League for Nursing. (2005). A national study of faculty role satisfaction: 2003. New York, NY: National League for Nursing.

National League for Nursing. (2006a). Nurse educators 2006: A report of the faculty census survey of RN and graduate programs. New York, NY: National League for Nursing. National League for Nursing. (2006b). Nursing data review academic year 2004-2005: Baccalaureate, associate degree, and diploma programs. New York, NY: National League for Nursing. 
National League for Nursing. (2007, September 20). Nationwide NLN-Carnegie Foundation study examines nurse faculty workload. Retrieved from http://www.nln.org/newsreleases/carnegie_092007.htm

National League for Nursing. (2008). Annual survey of schools of nursing, academic year 20062007: Executive summary. Retrieved from http://www.nln.org/research/slides/exec_summary.htm

National League for Nursing. (2009). Annual survey of schools of nursing, academic year 20072008: Executive summary. Retrieved from http://www.nln.org/research/slides/exec_summary_0708.pdf

National Organization of Nurse Practitioner Faculties. (2006, October). Statement on the Practice Doctorate in Nursing: Response to recommendations on clinical hours and degree title. Retrieved from http://www.nonpf.com/NONPF2005/PracticeDoctorateResourceCenter/PDstatement1006 .$h t m$

Nevidjon, B., \& Erickson, J. I. (2001). The nursing shortage: Solutions for the short and long term. Online Journal of Issues in Nursing, 6(1). Retrieved from http://nursingworld.org/MainMenuCategories/ANAMarketplace/ANAPeriodicals/OJIN/T ableofContents/Volume62001/No1Jan01/NursingShortageSolutions.aspx

Obama, B. H. (2009, March 5). Closing remarks by the President at White house forum on health reform, followed by Q\&A. Retrieved from http://www.whitehouse.gov/the_press_office/Closing-Remarks-by-the-President-atWhite-House-Forum-on-Health-Reform 
Oermann, M. H. (1988). Work-related stress of clinical nursing faculty. Journal of Nursing Education, 37, 302-304.

Olson, M. E. (2009). The "Millenials": First year in practice. Nursing Outlook, 57, 10-17.

Pacific Crest. (2011). Boyer's model of scholarship. Retrieved from http://www.pcrest.com/PC/FGB/test/2_5_1.htm

Pank, C. M. (2007). Online education. American Journal of Nursing, 107(5), 74-76.

Parker, M., \& Kupperschmidt, B. R. (2002, March 25). Managers: Factor X and Y in your employee equation. Retrieved from http://include.nurse.com/apps/pbcs.dll/article?AID=2002203250335

Patton, M. Q. (2002). Qualitative research and evaluation methods. (3rd ed.). Thousand Oaks, CA: Sage.

Polit, D. F., \& Beck, C. T. (2009). Essentials of nursing research: Appraising evidence for nursing practice. Baltimore, MD: Lippincott Williams \& Wilkins.

Reinecke, P. (2008, June 20). Highlights of selected federal legislation impacting the nursing shortage. Retrieved from http://www.championnursing.org/uploads/CCNAFederalLegislatiionSummaryReineke20 080620.pdf

Robert Wood Johnson Foundation. (2007, April). Charting nursing's future. Retrieved from http://www.rwjf.org/files/publications/other/nursingfuture4.pdf

Robert Wood Johnson Foundation. (2009, February). Championing nurses in health care reform. Retrieved from http://www.rwjf.org/pr/product.jsp?id=38528

Roberts, B. R. (2008, April-June). Recruitment and retention of nurse educators: An imperative intervention to decrease the nursing shortage. Kentucky Nurse, pp. 11-12. 
Robetoy, C.P. (2006). Is the burden worth the benefit of the Doctorate of Nursing (DNP) for NP's? Nephrology Nursing Journal, 33(6), 685-687.

Shirey, M. R. (2006). Stress and burnout in nursing faculty. Nurse Educator, 31(3), 95-97.

Siela, D., Twibell, R., \& Keller, V. (2009). The shortage of nurses and nursing faculty: What critical care nurses can do. AACN Career Supplement, 17-20, 22, 24.

Sullivan, L. W. (2010). Sullivan alliance. Retrieved from http://www.pemsm.com/about/alliance Tulgan, B. (2000). Managing generation x: How to bring out the best in young talent. New York: W. W. Norton, Inc.

United States Bureau of Labor Statistics. (2008, September 26). May 2006 national industryspecific occupational employment and wage estimates. Retrieved from http://www.bls.gov/oes/2006/may/naics4_621100.htm

Washington, W. (2009, April 12). USC nursing students out of luck: Shortage of instructors compounds shortage of nurses. Retrieved from http://www.thestate.com/local/vprint/story/746880.html

Webber, P. (2008). The Doctor of Nursing Practice degree and research: Are we making an epistemological mistake? Journal of Nursing Education, 47(10), 466-472.

Widger, K., Pye, C., Cranley, L., Wilson-Keates, B., Squires, M., \& Tourangeau, A. (2007). Generational differences in acute care nurses. Canadian Journal of Nursing Leadership, 20(1), 49-61.

Wolverson, R. (2011, June 13). Now what? TIME, 177(24), 34-39.

Wood, D. (2011, April 1). Salary survey shows experienced nurses gaining ground. Nursezone. Retrieved from http://www.nursezone.com/Nursing-News-Events/more-news/SalarySurvey-Shows-Experienced-Nurses-Gaining-Ground_36634.aspx 
Wulff, D. H., \& Austin, A. E. (2004). Paths to the professoriate: Strategies for enriching the preparation of future faculty. San Francisco, CA: Jossey-Bass.

Yin, R. K. (2003). Case study research design and method (3rd ed.). Thousand Oaks, CA: Sage.

Yordy, K. D. (2006, Spring). The nursing faculty shortage: A crisis for health care. Retrieved from http://www.rwjf.org/files/publications/other/NursingFacultyShortage071006.pdf 


\section{Appendix A}

\section{Faculty and Administrator Demographic Questionnaire}

\section{BACKGROUND INFORMATION:}

1. How many years have you worked in the nursing field? Years

2. What is the highest degree you have completed? (please indicate year completed) (Year:

3. What is/are your area(s) of specialty and/or certification? (please check all that apply)

Adult/Medical-Surgical

Community Health

$\square$ Pediatrics

$\square \mathrm{OB} / \mathrm{GYN}$

Psychiatric/Mental Health

․ Administration/Management

․ Informatics

$\square$ Other (please describe:

4. What is your gender?

Female

Male

5. What is your age? 
6. What is your race/ethnicity?

口 American Indian or Alaskan Native

Hawaiian or Other Pacific Islander

$\square \quad$ Asian or Asian American

Black or African American

Hispanic or Latino

White or Caucasian

$\square$ Other

\section{FACULTY/ADMINISTRATOR INFORMATION:}

7. How many years have you taught at a school of nursing? years

8. How many years have you taught at your current school of nursing? years

9. What is your current rank? (please indicate number of years)

Professor (Number of years at rank: years)

$\square$ Associate Professor (Number of years at rank: years)

․ Assistant Professor (Number of years at rank: years)

Clinical Instructor (Number of years at rank: years)

$\square$ Adjunct Instructor (Number of years at rank: years)

10. What is your employment status?

Full-time (Type of appointment: months)

ㅁ Part-time 
11. What is your current salary? (please check one response)

Under $\$ 40,000$ per year

$\$ 40,000$ to $\$ 50,000$ per year

ㅁ $\$ 50,001$ to $\$ 60,000$ per year

$\$ 60,001$ to $\$ 70,000$ per year

$\$ 70,001$ to $\$ 80,000$ per year

$\$ 80,001$ to $\$ 90,000$ per year

ㅁ $\$ 90,001$ to $\$ 100,000$ per year

ㅁ Above $\$ 100,000$ per year

12. Are you an administrator?

口 Yes Title:

No

13. What is your teaching responsibility?

口 Didactic

Clinical

ㅁ Both

14. At what program level do you teach?

口 Undergraduate

․ Graduate

․ Both 
15. Please list how many hours per week you spend in:

Class-based instruction: hours per week

Online instruction: hours per week

Clinical instruction: hours per week

Required office hours: hours per week

Hours spent at home grading/checking papers and assignments, answering emails, and communicating with students: hours per week

16. In this current semester, how many courses do you teach and for how many credits? courses credits

17. In this current semester, how many clinicals do you teach and for how many credits? clinicals credits

18. In this current semester, what is the student-faculty ratio for clinicals? ratio

19. In this current semester, how many advisees do you have? advisees

20. Are you currently revising a course or creating a course?
口 Yes
Course Area:

口 No

21. In this current semester, on how many committees do you participate? committees

22. To what extent are you involved in research?

$\square \quad$ To a great extent

To some extent

口 Very little

口 Not involved 
23. How many hours do you spend per week completing your duties as nursing faculty? (please check one)

40 hours/week

$\quad 41-50$ hours/week

$\quad 51-60$ hours/week

$\quad 61-70$ hours/week

$70+$ hours/week

24. Have you published articles, books, or book chapters in the past three (3) years?

口 Yes Number: publications

口 No

25. Are you tenured?

Yes

口 No

26. Projecting three years in the future, do you anticipate remaining in your role as nurse faculty?
口 Yes
No

Reason(s) for leaving role:

27. Do you believe you are fully compensated for your credentials and time spent as nursing faculty?
口 Yes
口 No

Reason(s): 
28. Are you satisfied in your current role?

$\square \quad$ Yes

$\square \quad$ No

Reason(s):

Thank you for taking your time to complete this faculty and administrator demographic questionnaire. 


\section{Appendix B-1}

\section{Interview Protocol for Nursing Administrator Participants}

Script:Good Morning/Afternoon/Evening. I first want to thank you for volunteering to participate in this interview. I really appreciate the time you are taking out of your schedule to help. My name is Naomi "Bea" Lamm and I will be asking you a few questions today about your experience as a nursing faculty/administrator. This interview will be part of the research collected to complete my doctoral dissertation at West Virginia University. The purpose of this study is to examine the types of strategies that nursing academic programs are utilizing to address the recruitment and retention of nursing faculty at various universities. This interview should take no longer than 50 minutes. This session will be audio recorded in order for me to capture as much of our discussion today for later analysis and keep the flow of questions and conversation going throughout the interview. All responses and tapes will be kept in the strictest confidence. Once the study is completed, the tapes will be destroyed. If you do not feel comfortable with any of the questions, please let me know and we will move on to the next one. Do you have any questions for me at this point?

\section{FOR FACE-TO-FACE INTERVIEWS}

I am providing you with the demographic questionnaire now. Once you are done with the form, please hand it in to me and we will then get started on our discussion. Do you have any questions about the form?

\section{FOR PHONE INTERVIEWS}

I first will read the demographic questions (see demographic questionnaire) and ask for your responses to each question. Then I will ask you the remaining questions.

Thank you. We will now begin.

\section{Interview Questions}

1. Do you have an enrollment management plan at [said institution]? If you do, what are the components of the plan? Do you have a fluctuating enrollment of students for the BSN?

2. What percentage, if any, of qualified students do you turn away from admission? How do you make a final decision to accept a student?

3. What are the limitations at [said institution] to increasing student admission? \{Probe: Increase in faculty? Lack of resources?\}

4. Is distance education implemented at [said institution]? If distance education is present, how has it been implemented? \{Probe: As a result, have you been able to increase student admissions?\} 
5. Does [said institution] have a simulation lab? \{Probe: As a result, have you been able to increase student admissions? Lack of clinical sites?\}

6. Does [said institution] partner with outside agencies or groups? Who are those partners? What do those partners contribute? \{Probe: Clinical sites, money, educational opportunities $\}$

7. Could you describe how [said institution] recruits nursing faculty members? What strategies does [said institution] use to recruit new nursing faculty? Have there been any challenges in recruiting new faculty? If so, what are the challenges?

8. Are there vacant nursing faculty positions at [said institution]? If so, how many vacancies and in what area(s)?

9. For what reasons do you remain as a nursing administrator at this university? For what reasons do you think other faculty remain here at this university?

10. For what reasons do nursing faculty leave their positions at [said institution]? \{Probe: Adequate support staff? Increased workload? Low salary? Incivility - faculty and/or students?\}

11. Please describe the requirements to obtain tenure at [said institution]. If you have tenure, could you discuss how difficult or challenging it was for you to obtain tenure?

12. What criteria are used to determine tenure for faculty members? \{Probe: Teaching? Research? Publishing? Service to the community?\}

13. What strategies to help recruit and retain the nursing of nursing faculty at [said institution] have been effective?

14. In the future, what strategies do you believe would help to recruit and increase the number of nursing faculty in the profession across the United States?

15. What should be done to retain nursing faculty in education? \{Probe: Flexibility of schedule? Tuition reimbursement? Recognition? Increased salary?\}

That's all the questions I have for you today. Thank you so much for taking time out of your schedule to assist me in my research. If you have any questions or concerns I will answer any questions to the best of my ability. If you don't have any questions, the interview is concluded. Thank you again. 


\section{Appendix B-2}

\section{Interview Protocol for Nursing Faculty Participants}

Script:Good Morning/Afternoon/Evening. I first want to thank you for volunteering to participate in this interview. I really appreciate the time you are taking out of your schedule to help. My name is Naomi "Bea" Lamm and I will be asking you a few questions today about your experience as a nursing faculty/administrator. This interview will be part of the research collected to complete my doctoral dissertation at West Virginia University. The purpose of this study is to examine the types of strategies that nursing academic programs are utilizing to address the recruitment and retention of nursing faculty at various universities. This interview should take no longer than 50 minutes. This session will be audio recorded in order for me to capture as much of our discussion today for later analysis and keep the flow of questions and conversation going throughout the interview. All responses and tapes will be kept in the strictest confidence. Once the study is completed, the tapes will be destroyed. If you do not feel comfortable with any of the questions, please let me know and we will move on to the next one. Do you have any questions for me at this point?

\section{FOR FACE-TO-FACE INTERVIEWS}

I am providing you with the demographic questionnaire now. Once you are done with the form, please hand it in to me and we will then get started on our discussion. Do you have any questions about the form?

\section{FOR PHONE INTERVIEWS}

I first will read the demographic questions (see demographic questionnaire) and ask for your responses to each question. Then I will ask you the remaining questions.

Thank you. We will now begin.

\section{Interview Questions}

1. Why did you decide to teach nursing at this particular college or university?

2. Is distance education implemented at [said institution]? If distance education is present, how has it been implemented? \{Probe: As a result, have you been able to increase student admissions?\}

3. Does [said institution] have a simulation lab? \{Probe: As a result, have you been able to increase student admissions? Lack of clinical sites?\}

4. Do you have freedom in designing and conducting your own courses? Please explain. \{Probe: Designing your own course syllabus and selecting your own texts for your course\}

5. Please describe the requirements to obtain tenure at [said institution]. If you have tenure, could you discuss how difficult or challenging it was for you to obtain tenure? 
6. What criteria are used to determine tenure for faculty members? \{Probe: Teaching? Research? Publishing? Service to the community?\}

7. How do you feel about the working conditions at [said institution]?

8. For what reasons do you remain as a nursing professor at this university? For what reasons do you think that other faculty remain here at this university?

9. For what reasons do nursing faculty leave their positions at [said institution]? \{Probe: Adequate support staff? Increased workload? Low salary? Incivility - faculty and/or students?\}

10. What strategies to help recruit and retain the nursing of nursing faculty at [said institution] have been effective?

11. In the future, what strategies do you believe would help to recruit and increase the number of nursing faculty in the profession across the United States?

12. What should be done to retain nursing faculty in education? \{Probe: Flexibility of schedule? Tuition reimbursement? Recognition? Increased salary?\}

That's all the questions I have for you today. Thank you so much for taking time out of your schedule to assist me in my research. If you have any questions or concerns I will answer any questions to the best of my ability. If you don't have any questions, the interview is concluded. Thank you again. 


\section{Appendix C}

\section{Letter to Request Institutional Approval for Pilot Study}

(On WVU letterhead)

Date

Address

Dear Dr.

My name is Naomi "Bea” Lamm, MS, RN and I am a doctoral candidate in Educational Leadership Studies at West Virginia University. My doctoral chair is Dr. Elizabeth A. Jones. I am writing to obtain your permission to conduct a pilot study for research at your institution as part of my dissertation study, Examining Nursing Schools' Strategies for Recruitment and Retention of Nursing Faculty: An Exploratory Study. The purpose of the study is to examine the types of strategies that academic leaders at various universities are utilizing to recruit and retain nursing faculty.

Specifically, I am writing to secure permission to conduct a pilot study with an administrator and two (2) additional nursing faculty who have various ranks (Professor, Associate Professor, Assistant Professor, and Clinical Instructor). The study is qualitative and I will ask questions to each participant in one-on-one interviews lasting approximately 50 minutes. I would ask openended questions to glean information about strategies being used by the faculty, the school and any other approaches administrators/faculty suggest that may be helpful to recruit and retain nursing faculty. A demographic questionnaire will be sent to participants via e-mail to complete prior to the interview. Should the participant not complete the demographic questionnaire, one will be provided at the beginning of the interview and time will be allowed for the document's completion. Also, I request that the participant review the open-ended questions and the questionnaire and give constructive feedback that I will use to improve my interview protocol and demographic questionnaire. I also would like to examine documents such as self-study reports for accreditation, the annual report of the nursing program, dean's report, strategic plan, brochures, committee reports for recruitment and retention of faculty, and salary ranges for each rank of faculty/administrators of nursing as permitted. By collecting and analyzing multiple types of data the study will be strengthened and credibility given to the findings. Additionally, I am seeking permission to use the name of your program and institution with my dissertation document.

In completing requirements from West Virginia University's Institutional Review Board for the Protection of Human Subjects (WVU IRB), I am required to obtain a written letter of consent from the selected institutions granting me permission to conduct my study. I have attached a template for you to use and alter as you see needed. I ask that this letter of permission be placed on your institutional letterhead for official submission to WVU IRB for approval. If you approve of this visit, please identify with whom I may contact at your institution to schedule interviews and gather documents. Once I receive your letter of approval to conduct my pilot study for my 
dissertation, I will than submit all of my materials for formal review to WVU IRB. Once WVU IRB approval is granted, I will immediately contact you or your representative to schedule interviews to complete the pilot study.

The data collection in this study will be strictly for completion of my dissertation requirements. I assure you that all data will be preserved with the utmost level of confidentiality and participants' anonymity will be protected at all times as well. I am open and willing to share my findings with you in a summary upon your request. Results of this pilot study will be important to assure the quality of my data collection of my questions and questionnaire.

I am attaching a template letter of approval, which you may alter as you see fit, and then copy to your institution's letterhead. If you decide to allow your school of nursing to participate, I would appreciate if you would forward me a letter of approval by December 17, 2010 due to the holiday season. For your convenience, I have enclosed a postage-paid envelope.

In closing, I want to reassure you that the results of this study will be used specifically for my dissertation and I will follow all WVU IRB policies. All responses will remain entirely anonymous and confidentiality will be maintained throughout the collection and reporting process.

Should you have any questions or concerns, please contact me via telephone at 301-268-3446 or email at nlamm@mix.wvu.edu. Thank you so much in your assistance in obtaining permission to conduct research at your institution as part of my dissertation study.

Sincerely,

Naomi "Bea" Lamm, MS, RN

Doctoral Candidate

West Virginia University
Chair, W
Elizabeth A. Jones, Ph.D.

Dissertation Committee est Virginia University 


\section{Appendix D}

\section{Letter Template from Institution Granting Permission for Pilot Study}

(On letterhead from pilot study institution)

Date

Ms. Naomi “Bea” Lamm

5 Virginia Avenue

Cumberland, MD 21502

Dear Ms. Lamm,

I am writing to convey my support for your doctoral dissertation research at $<<$ institution $>>$. I understand that you will interview two (2) nursing faculty and one (1) administrator of our nursing administration and faculty to discuss strategies to recruit and retain nursing faculty. In addition, I realize that you will be provided with various documents related to both processes that will contribute to your analysis.

It is my understanding that you will schedule individual appointments in advance with administrators and faculty sometime during January 2011. You have agreed to emphasize to these individuals that their participation is entirely voluntary. I understand that interviews will last approximately 50 minutes and will be scheduled at our institution upon official approval from West Virginia University's Institutional Board for the Protection of Human Subjects. I also understand that you will protect the confidentiality of these discussions and the participants will not be identified in your dissertation study.

Thank you for soliciting my input and approval. We look forward to seeing you on campus soon and helping you move forward with your dissertation study.

Sincerely,

Dr.

Title 


\section{Appendix E}

\section{Pilot Participant Invitation Letter}

(On WVU letterhead)

Date:

\section{Dear Participant:}

My name is Naomi "Bea” Lamm, MS, RN, and I am a West Virginia University doctoral candidate in the College of Human Resources and Education. I am studying nursing schools' strategies currently used to recruit and retain nursing faculty. The research will investigate how schools of nursing are implementing these strategies for practical use within each school and any other approaches that administrators/faculty suggest that may be helpful in understanding this phenomenon.

My intent is to pilot my dissertation study at your institution and I would like to invite you to participate in this study. This research is being conducted to fulfill the requirements for a doctoral dissertation in Educational Leadership Studies in the Department of Advanced Educational Studies at West Virginia University, under the supervision of Dr. Elizabeth A. Jones.

I would like to schedule a 50 minute interview with you in January 2011. In addition, I would ask that you complete a demographic questionnaire prior to the interview that will be sent to you via e-mail. The interview will be audio-taped. The tapes will be identified by a number and destroyed after the conclusion of the study. Upon completion of the interview, I will be soliciting your feedback on the clarity of questions and ask you to critique the interview protocol. I will use your feedback to improve the interview protocol.

It is important to emphasize that your responses to the interview and questionnaire will be anonymous. Your name or any other identifying information will not be released in the reported results and all responses will remain confidential. Moreover, your participation is entirely voluntary and you need not respond to every item. Additionally, please note that there are no known or expected risks from participating in this study. The knowledge gained from this study may eventually benefit others in their future research efforts.

If you agree to participate in this study, please contact me as soon as possible to make arrangements for the interview. Should you have any questions or concerns, please feel free to contact me via telephone at 301-268-3446 or email at nlamm@mix.wvu.edu.

Sincerely,

Naomi "Bea" Lamm, MS, RN

Doctoral Candidate

West Virginia University 


\section{Appendix F}

\section{Letter to Request Institutional Approval}

(On WVU letterhead)

Date

Address

Dear Dr.

My name is Naomi "Bea” Lamm, MS, RN and I am a doctoral candidate in Educational Leadership Studies at West Virginia University. I am writing to obtain your permission to conduct research at your institution as part of my dissertation study, Examining Nursing Schools' Strategies for Recruitment and Retention of Nursing Faculty: An Exploratory Study. The purpose of the study is to examine the types of strategies that nursing faculty and administrators at various universities are utilizing to address recruitment and retention of nursing faculty. The research will investigate how schools of nursing are implementing these strategies for practical use within each school. The study is highly significant as it will present a current portrait of the ways in which schools of nursing are addressing this issue.

Specifically, I am writing to secure permission to conduct a research study with three administrators (Dean, Associate Dean, Assistant Dean, Department Chair) and five nursing faculty of differing rank (Professor, Associate Professor, Assistant Professor, Clinical Instructor). The study is qualitative and the researcher will ask questions posed to the participant in one-onone interviews lasting approximately 50 minutes. The interviews will be audio-taped with permission of the participant. Open-ended questions will be posed to glean information about strategies currently used by the faculty, the school and any other approaches administrators/faculty suggest that may be helpful to this phenomenon. A demographic questionnaire will be given to the participants prior to the interview to complete. I also would like to examine documents such as self-study reports for accreditation, the annual report of the nursing program, dean's report, strategic plan, brochures, committee reports for recruitment and retention of faculty, and salary ranges for each rank of nursing faculty/administrators as permitted. By collecting and analyzing multiple types of data the study will be strengthened and credibility given to the findings. Additionally, I am seeking permission to use the name of the program and institution with my dissertation document.

In completing requirements for West Virginia University's Institutional Review Board for the Protection of Human Subjects (WVU IRB), I am required to obtain a written letter of consent from the institution granting me permission to conduct my study. I have attached a template for you to use and alter as you see needed. I ask that this letter of permission be placed on your institutional letterhead for official submission to WVU IRB for approval. If you approve of this visit, please identify with whom I may contact at your institution to schedule interviews and gather documents. Once I receive your letter of approval to conduct for my dissertation study, I 
will than submit all of my materials for formal review to WVU IRB. Once WVU IRB approval is granted, I will immediately contact you or your representative to schedule interviews.

The data collection in this study will strictly be for completion of my dissertation requirements. I want to assure you that all data will be preserved with the utmost level of confidentiality and participants' anonymity will be protected at all times as well. I am open and willing to share my findings with you in a summary upon your request

I am attaching a template letter of approval, which you may alter as you see needed, and then copy to your institution's letterhead. If you decide to allow your school of nursing to participate, I ask that you forward me a letter of approval by $<<$ Date $>>$ or sooner. For your convenience, I have enclosed a postage-paid envelope.

In closing, I want to reassure you that the results of this study will be used specifically for my dissertation and I will follow all IRB policies. All responses will remain entirely anonymous and confidentiality will be maintained throughout the collection and reporting process. Participants do not need to answer all questions.

Should you have any questions or concerns, please contact me via telephone at 301-268-3446 or email at nlamm@mix.wvu.edu. Thank you so much in your assistance in obtaining permission to conduct research at your institution as part of my dissertation study.

Sincerely,

Naomi “Bea” Lamm, MS, RN

Doctoral Candidate

West Virginia University 


\section{Appendix G}

\section{Letter Template from Institution Granting Permission for Case Study}

(On letterhead from case study institution)

Date

Ms. Naomi “Bea” Lamm

5 Virginia Avenue

Cumberland, MD 21502

Dear Ms. Lamm,

I am writing to convey my support for your doctoral dissertation research at $<<$ name of institution $>>$. I understand that you will need to interview various members of our nursing administration and faculty to discuss recruitment and retention of nursing faculty. In addition, I realize that you will be provided with various documents related to both processes that will contribute to your analysis.

It is my understanding that you will schedule individual appointments in advance with administrators and faculty sometime during January 2011. You have agreed to emphasize to these individuals that their participation is entirely voluntary and that all questions need not be answered. I understand that interviews will last approximately 50 minutes and will be scheduled at our institution upon official approval by West Virginia University's Institutional Review Board for the Protection of Human Subjects. I also understand that you will protect the confidentiality of these discussions and the participants will not be identified in your dissertation study.

Thank you for soliciting my input and approval. We look forward to seeing you on campus soon and helping you move forward with your dissertation study.

Sincerely,

Dr.

Title 


\title{
Appendix H
}

\author{
Case Study Participant Invitation Letter
}

(On WVU letterhead)

Date

Dear Participant:

My name is Naomi "Bea" Lamm, MS, RN, and I am a West Virginia University doctoral candidate. I am studying nursing schools' strategies for recruiting and retaining nursing faculty. The research will investigate how schools of nursing are implementing these strategies for practical use within each school and any other approaches that administrators and nursing faculty suggest that may be helpful in examining this phenomenon.

My intent is to pilot my dissertation study at your institution and I would like to invite you to participate in this study. This research is being conducted to fulfill the requirements for a doctoral dissertation in Educational Leadership Studies in the Department of Educational Leadership Studies at West Virginia University, under the supervision of Dr. Elizabeth A. Jones.

At your institution, I am seeking to interview five nursing faculty of various ranks (Professor, Associate Professor, Assistant Professor, Clinical Instructor) and three administrators (Dean, Associate Dean, Assistant Dean, Department Chair). I am inviting you to participate and ask that you be interviewed for approximately 50 minutes with open-ended questions, a demographic questionnaire, and to give suggestions about my interview protocol and questionnaire. The interview will be audio-taped. The tapes will be identified by a number and destroyed after the conclusion of the study.

It is important to emphasize your responses to the interview and questionnaire will be anonymous. Your name or any other information that may identify you will not be released in the reported results and all responses will remain confidential. Moreover, your participation is entirely voluntary and you need not answer all questions. Additionally, please note that there is no known or expected risks from participating in this study. The knowledge gained from this study may eventually benefit others in their future research efforts.

If you agree to participate in this study, please contact me as soon as possible to make arrangements for the interview. Should you have any questions or concerns, please feel free to contact me via telephone at 301-268-3446 or email at nlamm@mix.wvu.edu.

Sincerely,

Naomi "Bea" Lamm, MS, RN

Doctoral Candidate

West Virginia University

John H. 